Universidade de São PAUlo

Faculdade de Economia, Administração e Contabilidade de Ribeirão Preto DePARTAMENTO DE ECONOMIA

Programa de Pós-Graduação em EConomia - Área: Economia Aplicada

LUCAS GEREZ FORATTO

O brilho das cidades: efeitos da urbanização sobre a pobreza rural no Brasil

Orientador: Prof. Dr. Alexandre Chibebe Nicolella

Ribeirão Preto 
Prof. Dr. Vahan Agopyan

Reitor da Universidade de São Paulo

Prof. Dr. André Lucirton Costa

Diretor da Faculdade de Economia, Administração e Contabilidade de Ribeirão Preto

Prof. Dr. Sérgio Kannebley Júnior

Chefe do Departamento de Economia

Prof. Dr. Sérgio Naruhiko Sakurai

Coordenador do Programa de Pós-Graduação em Economia 


\title{
O brilho das cidades: efeitos da urbanização sobre a pobreza rural no Brasil
}

\author{
Dissertação de mestrado apresentada ao Pro- \\ grama de Pós-Graduação em Economia - Área: \\ Economia Aplicada da Faculdade de Econo- \\ mia, Administração e Contabilidade de Ribei- \\ rão Preto da Universidade de São Paulo para \\ obtenção do título de Mestre em Ciências. \\ Orientador: Prof. Dr. Alexandre Chibebe Nico- \\ lella
}

\section{Versão Corrigida}

(versão original disponível na Faculdade de Economia, Administração e Contabilidade de Ribeirão Preto)

Ribeirão Preto 
Autorizo a reprodução e divulgação total ou parcial deste trabalho, por qualquer meio convencional ou eletrônico, para fins de estudo e pesquisa, desde que citada a fonte.

FORATTO, Lucas Gerez.

O Brilho das Cidades: Efeitos da Urbanização sobre a Pobreza Rural no Brasil / Lucas Gerez Foratto - Ribeirão Preto, SP, 2020.

87 p.: il.; $30 \mathrm{~cm}$

Dissertação de mestrado apresentada ao Programa de PósGraduação em Economia - Área: Economia Aplicada da Faculdade de Economia, Administração e Contabilidade de Ribeirão Preto da Universidade de São Paulo, para obtenção do título de Mestre em Ciências. - Universidade de São Paulo

Orientador: Nicolella, Alexandre Chibebe

1. Pobreza Rural. 2. Imagens de Satélite. 3. Luz para Todos. 4. Variáveis Instrumentais com Erros Espaciais 
Aos meus pais. 



\section{AGRADECIMENTOS}

A vida é marcada por conexões, grande parte de minhas conquistas se devem as pessoas maravilhosas nas quais eu tive o prazer de conviver. Primeiramente, gostaria de expressar minha incomensurável gratidão aos meus pais, Silvana e Sérgio. Se tem uma pessoa que me inspira desde que nasci, esse alguém é minha mãe, muito obrigado por me apresentar o mundo dos livros e o poder da educação. Ao meu pai, meu exemplo de pessoa, quando crescer quero ter essa empatia com as pessoas em volta igual a sua. Essa conquista é tão de vocês quanto minha. Aos meus demais familiares, meu maninho Dé, meus avós, José, Maria, Hélio e Denise, tios, tias, primos (vocês são demais!).

Ao meu caro orientador, Alexandre Chibebe Nicolella, por ser não apenas um mentor, mas um verdadeiro amigo, durante o mestrado, toda sua paciência e preocupação com a saúde mental dos mestrandos me inspiram para continuar no âmbito acadêmico com pesquisas que contribuam para o debate científico.

Aos membros da banca de defesa, André Chagas, Márcio Laurini e Paulo Picchetti, pelos ótimos apontamentos e contribuições.

Aos professores que tive a honra de ser aluno na graduação, Paula Pereda, Pedro Duarte e Laura Valladão, o conhecimento e o comprometimento com a pesquisa de vocês me impulsionaram para adentrar nessa jornada. Durante as aulas do mestrado, meu agradecimento aos professores Daniel dos Santos, Elaine Pazello, e ao Márcio Laurini pelas disciplinas essenciais para o presente estudo e certamente para trabalhos futuros, e pelas valiosas contribuições nos exames de qualificação, pré-defesa e defesa.

Aos professores e pesquisadores do NEREUS-USP, Tainá, Keyi, Ana Barufi, Rodger e todos os demais, que além de amigos, me apresentaram trabalhos acadêmicos de excelência e sempre se mostraram à disposição nos entraves de base de dados, nas ideias de analisar os problemas com diferentes pontos de vista.

À minha companheira de todas as ocasiões, Dii, que sorte a minha ter encontrado você por ai.

Aos amigos dos momentos difíceis de estudo e também fiéis parceiros de bandejão, Igor, Lívia, André, Gabrié, Dudu, Rafa, Plens, Poke, Paolo, Patrícia. O caminho seria muito mais longo e complicado sem todo o suporte dos senhores.

Aos veteranos, que me mostraram o verdadeiro significado de subir em ombros de gigantes, Felipe, Laura, Poke, Ricardo, Wander.

À equipe de Atletismo FEA-USP, que me apoiou desde meu primeiro ano de graduação, amigos da pista para a vida. Um abraço especial ao Pedrão, Pivo, Paulinha, Tom Tom, Jhonny, 
Flora, Lukita, Diogo, Paulinho, Amanda, Godinho, Iqueda, Rodriguinho, Rômulo, Nathiely, Hary, Vander, Fari, Guizão, Fernando, Catarina, e meus Técnicos Vitão, Mikinha e Ru. Vocês estiveram em grande parte dos momentos mais feliz da minha vida. O Atletismo é insano.

À equipe de Atletismo da FEARP, a empolgação de vocês tornou os meus dias muito melhores. Sabão, André, Sheik, Taxi, Verinha, Gabriela e claro, e também aos que não eram da equipe, mas possuem um lugar no meu coração, Hemo, Pedro, Zileide e meu Técnico André.

À tuma do C-Micro da FGV, André Portela, Dani, Fernando, Simões, Ronan, Bruno, Giovana, Giovanna, Leandrão, Pati, Rocio, Amandinha, Ana, Bernardo, Rafa e todos os demais. A experiência de trabalhar com pesquisa com tanta seriedade e com um excelente ambiente de trabalho me motiva todos os dias a continuar nessa área.

À todas as pessoas que moraram comigo nesses anos, Quelq, Ricardin, Luca, Waginão, Paixão, Rickers, Deia, Paulão. Com certeza o meu amadurecimento como pessoa se deve a vocês.

Aos amigos de infância para toda a vida, Rickers, Igor, Vitão, Rick, Julis, Pedro, João. É muito bom acompanhar o crescimento de todos vocês (de tamanho e como pessoa).

Aos amigos da graduação, Mizael, Vitinho, Rafa, Thalisson, Renan, Rubão, Sayuri, Radha. Por mais caipirados com vocês!

Aos companheiros que estudaram comigo em Zagreb, Kate, Luís, Tó, Erik, Léo, Mariusz, Yutaro, Ryoda (que semestre, meus caros!).

Pelo suporte acadêmico meus agradecimentos à PPEGE.

A todos os técnicos e funcionários da FEARP/USP, especialmente do Serviço de Pós-Graduação.

À CAPES pelo apoio financeiro concedido ao longo do mestrado. O presente trabalho foi realizado com o apoio da Coordenação de Aperfeiçoamento de Pessoal de Nível Superior Brasil (CAPES) - Código de Financiamento 001. 


\section{RESUMO}

FORATTO, L. G. O Brilho das Cidades: Efeitos da Urbanização sobre a Pobreza Rural no

Brasil. Dissertação (Mestrado) - Faculdade de Economia, Administração e Contabilidade de Ribeirão Preto, Universidade de São Paulo, Ribeirão Preto, 2019.

As zonas rurais brasileiras permanecem com expressiva proporção de famílias em situação de pobreza extrema, 25\% segundo o Censo Demográfico de 2010 (IBGE). Dentre os diversos fatores que podem afetar a pobreza rural, pesquisas recentes apontam que o crescimento urbano pode contribuir para esse processo a partir do fomento de novas oportunidades de trabalho e do aumento da demanda por produtos agrícolas. A urbanização está muito atrelada com o crescimento da economia local, de todo modo, o crescimento de centros altamente urbanizados pode interagir com o meio rural de maneira distinta quando comparado com a urbanização incipiente presente nas regiões mais periféricas dos grandes centros e nas cidades menores. Nesse contexto, estimou-se os efeitos da urbanização dos centros e das regiões incipientes no total de habitantes do campo com renda domiciliar per capita abaixo das linhas de pobreza. Utilizou-se como proxy da urbanização imagens de sensoriamento remoto de luminosidade noturna, que somados com dados de uso da terra e informações dos Censos Demográficos de 2000 e 2010 compuseram a base de dados do estudo. No tocante a metodologia, utilizou-se um modelo de Variáveis Instrumentais com Erros Espaciais para endereçar a questão da endogeneidade entre pobreza e luminosidade, e a persistência dos resíduos espacialmente correlacionados. Os instrumentos foram construídos a partir do Programa Luz Para Todos e as questões topográficas do país, os resultados apontam que o avanço da urbanização incipiente acompanha a diminuição da pobreza rural, permanecendo negativo e significante em todas as especificações com instrumentos, enquanto que o avanço dos centros altamente urbanizados apresenta o efeito contrário, no sentido de aumentar o total de habitantes em situação de pobreza rural na região.

Palavras-chave: Pobreza Rural. Imagens de Satélite. Luz Para Todos. Variáveis Instrumentais com Erros Espaciais. 



\begin{abstract}
FORATTO, L. G. The Bright of the Cities: Effects of Urbanization in Rural Poverty in Brazil. Dissertation (Master Degree) - School of Economics, Business and Accounting at Ribeirão Preto, University of São Paulo, Ribeirão Preto, 2019.
\end{abstract}

Rural poverty in Brazil remains a relevant issue inside policies to reduce poverty in the country, according to household Census in 2010, one-quarter of the rural population lives under the extremely poverty lines. Urbanization seemly to reduce rural poverty with two main channels: providing new opportunities in non-rural jobs, and increasing the demand for agriculture products when new connections with city and rural are made. Urbanization and growth are very interrelated, nevertheless, the interaction between the central core and rural can be different in comparison with the growth of early-stage urbanization which can be seen on the edge of big cities and in small towns throughout the countryside. Based on this context, this paper aims to analyze the impacts of urbanization, comparing the central and the urban fringe, on the number of people living under the extreme poverty line. Our proxy of urban growth was built on nightlights data, and so does land use covariates, both of them were combined with household Census from 2000 and 2010 to compose our data. The methodology addressed two issues: the endogeneity relation of urbanization and rural poverty, and spatial correlation between minimum comparable area variables. Our first issue tackled with Instrumental Variable estimation based on Lights for All (Luz para Todos) federal program. Furthermore, the second issue was overcome with the Spatial Panel Econometrics, based on Spatial Error Model estimated on the second stage. The results show that urban growth of the small towns and the edge of the big cities is in line with the rural poverty reduction, otherwise, the central core growth responds in the opposite direction, increasing the rural poverty.

Keywords: Rural Poverty. Night-time lights. Lights for All. Spatial Panel Econometrics with Instrumental Variable 



\section{LISTA DE ILUSTRAÇÕES}

Figura 2.1 - Distribuição da luminosidade na Região Metropolitana de Ribeirão Preto 27

Figura 2.2 - Variação da Luminosidade entre 2000 e 2010 nos tipos de cidades . . . . . . 30

Figura 2.3 - Distribuição espacial da Pobreza Rural Extrema no Brasil entre 2000 e 201034

Figura 2.4 - Distribuição espacial da elegibilidade ao LPT . . . . . . . . . . . . . . . . 44

Figura 3.1 - Distribuição espacial dos indicadores de pobreza rural no Brasil . . . . . 48

Figura A.1 - Áreas Mínimas Comparáveis (AMCs) no Brasil . . . . . . . . . . . . . . . 72

Figura B.1 - Linhas de Transmissão no Brasil . . . . . . . . . . . . . . . . . . . . . . 73

Figura C.1 - Distribuição espacial da Pobreza e de Vulneráveis à Pobreza Rural no Brasil 75

Figura F.1 - Tipos de matrizes de vizinhança por contiguidade. Fonte: Arbia (2014) . . . 82

Figura A.1 - Classificação dos níveis de Urbanização a partir de imagens de satélite.

Fonte: Álvarez-Berríos, Parés-Ramos e Aide (2013) . . . . . . . . . . . . . . . 87 


\section{LISTA DE TABELAS}

Tabela 2.1 - Número de AMCs com dados de luminosidade não nulos . . . . . . . . . 28

Tabela 2.2 - Comparação Pobreza Rural e Urbana . . . . . . . . . . . . . . . . . . . . 33

Tabela 2.3 - Estatísticas Descritivas . . . . . . . . . . . . . . . . . 37

Tabela 3.1 - Teste de Wald para dados em painel . . . . . . . . . . . . . . . 51

Tabela 3.3 - Teste LM de Baltagi e Liu (2008) nas três variáveis de pobreza . . . . . . . . 51

Tabela 3.2 - Modelos para o total de habitantes em situação de pobreza extrema no Brasil 52

Tabela 3.4 - Modelos para o total de habitantes em situação de pobreza no Brasil . . . . 56

Tabela 3.5 - Modelos para o total de habitantes em situação de vulneráveis à pobreza no Brasil . . . . . . . . . . . . . . . . . . . . . . 57

Tabela 3.6 - Análise de sensibilidade na delimitação da luminosidade para urbanização incipiente nas AMCs $\ldots \ldots \ldots \ldots \ldots$

Tabela 3.7 - Modelos de Erros Espaciais com Variáveis Instrumentas ～. . . . . . . . 60

Tabela D.1 - Modelo OLS para a Aclividade média do terreno em 2000 . . . . . . . . . . 77

Tabela E.1 - Resultado do primeiro estágio das regressões com Variáveis Instrumentais 79 


\section{SUMÁRIO}

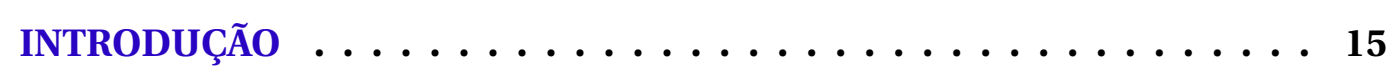

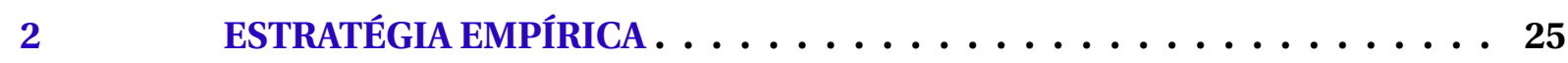

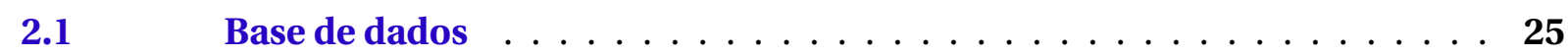

2.1.1 Imagens de Sensoriamento Remoto $\ldots \ldots \ldots \ldots$

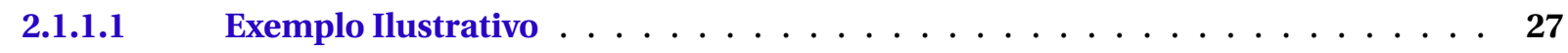

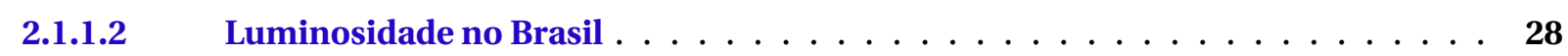

2.1.2 A pobreza rural no Brasil $\ldots \ldots \ldots \ldots \ldots \ldots$

2.1.3 Variáveis de controle dos Censos Demográficos . . . . . . . . . . . . 35

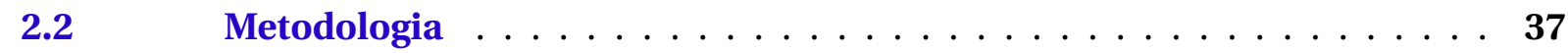

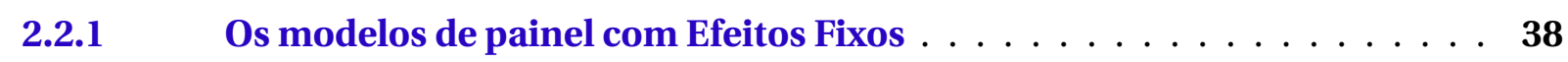

2.2.2 Os modelos de painel com Erros Espaciais $\ldots \ldots \ldots \ldots \ldots$

2.2.3 O Programa Luz para Todos e a Topografia . . . . . . . . . . . . 40

2.2.4 A estratégia de Variáveis Instrumentais $\ldots \ldots \ldots \ldots$

$3 \quad$ RESULTADOS $\ldots \ldots \ldots \ldots \ldots \ldots \ldots \ldots \ldots \ldots \ldots \ldots$

$3.1 \quad$ Investigação da dependência espacial $\ldots \ldots \ldots \ldots \ldots$

Besultados das regressões à pobreza extrema rural $\ldots \ldots \ldots \ldots$

3.3 Resultados dos modelos para as demais linhas de pobreza $\ldots \ldots \ldots$

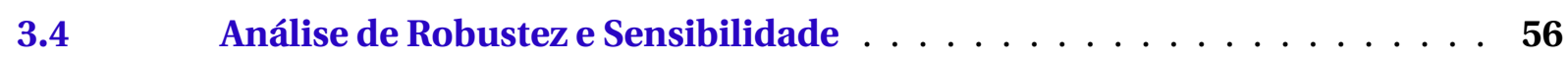

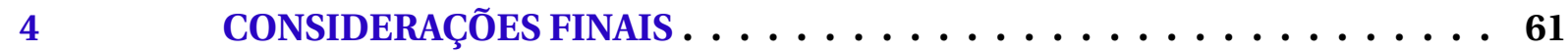


APÊNDICE A - ÁREAS MÍNIMAS COMPARÁVEIS UTILIZADAS NO ESTUDO 71 APÊNDICE B - LINHAS DE TRANSMISSÃO NO BRASIL . . . . . . . 73 APÊNDICE C - MAPAS COM AS DEMAIS LINHAS DE POBREZA RURAL • 75 APÊNDICE D - INVESTIGAÇÃO DOS INSTRUMENTOS UTILIZADOS . . . 77 APÊNDICE E - RESULTADOS DO PRIMEIRO ESTÁGIO DOS MODELOS COM VARIÁVEIS INSTRUMENTAIS $\ldots \ldots \ldots \ldots 79$

APÊNDICE F - MATRIZES DE VIZINHANÇA EM ECONOMETRIA ESPACIAL $\ldots \ldots \ldots \ldots \ldots \ldots \ldots$. ANEXO A - CLASSIFICAÇÃO DAS CIDADES A PARTIR DA LUMINOSIDADE 87 


\section{INTRODUÇÃO}

A pobreza ainda é uma realidade à maioria dos países em desenvolvimento. Estimase que um quinto da população mundial vivia com menos de US\$ 1,25 por dia em 2015 (BANERJEE et al., 2015), o que corresponde a 1,46 bilhões de indivíduos nessa situação crítica (NATIONS, 2015). Em virtude disso, pesquisadores e formuladores de políticas públicas buscam entender quais são seus determinantes e quais fatores tem maior impacto na sua redução. Um fator comumente observado é o padrão de aglomeração dos indivíduos que vivem em situação de pobreza extrema, como elucida Ravallion (2017).

Nas comparações entre nações, observa-se que países com elevada porcentagem da população em situação de pobreza extrema localizam-se próximos a outros que vivenciam o mesmo problema. Além disso, uma característica marcante nos países em desenvolvimento é a concentração da pobreza extrema nas zonas rurais. Em 2015, 80\% da pobreza extrema no mundo residia no campo (WORLD BANK, 2016). O caso brasileiro não é diferente, como mostra Mattos e Waquil (2006) e Paula, Dalberto e Bohn (2013).

Do ponto de vista da teoria marginalista, o bem estar dos indivíduos depende do consumo de bens e serviços a depender de suas respectivas preferências. Dessa forma, o monitoramento do consumo dos agentes seria o mais indicado para uma avaliação do bem estar, entretanto, pesquisas direcionadas a esse tópico são escassas nos países, sobretudo nos em desenvolvimento. Uma alternativa proposta pelo Banco Mundial é aproximar as variações do consumo a partir da renda dos indivíduos, assim surgem as delimitações das linhas internacionais de pobreza (GLEWWE; GAAG, 1990; SQUIRE, 1993).

Nessa perspectiva, a predominância de indivíduos que vivem abaixo da linha internacional da pobreza é marcante nas zonas rurais da América Latina. A título de exemplo, Bolívia, Guatemala, Honduras, Nicarágua, Paraguai e Peru possuíam pelo menos $70 \%$ da população rural vivendo abaixo desse limiar (FERRANTI et al., 2005). A partir dos dados do Censo Demográfico de 2010 (IBGE, 2010), constatou-se que 12,4 milhões de indivíduos da população rural do Brasil viviam em situação de pobreza, o que corresponde a $42 \%$ dos habitantes do campo.

A questão da pobreza rural se difere da enfrentada no ambiente urbano por alguns motivos: no que tange ao acesso a alimentos, a presença da economia de subsistência em determinadas regiões torna os agentes menos dependentes de renda para o acesso a esse tipo de bem, em contrapartida, as zonas rurais são marcadas pela escassez de diversos outros bens, como saneamento básico, educação e saúde hospitalar, entre outros. Esse fenômeno é conhecido como as múltiplas dimensões da pobreza (ALKIRE et al., 2015).

Além disso, o combate da pobreza rural responde a diferentes incentivos quando comparada com o caso urbano. No estudo voltado para a região Nordeste do Brasil, Araújo, 
Tabosa e Khan (2012) encontraram evidências de que a pobreza rural é mais sensível as alterações do crescimento econômico, enquanto que a pobreza urbana está mais suscetível as questões relacionadas as desigualdades. Ashley e Maxwell (2001) argumentam que a pobreza rural está atrelada a fatores como: o crescimento agrícola, a viabilidade da agricultura familiar e de pequenas fazendas, a governança em políticas públicas e, o potencial da economia não agrícola no meio rural.

Um possível canal de atuação no combate a pobreza rural está relacionado ao crescimento urbano das cidades próximas, o processo de urbanização, que corresponde a ampliação das áreas urbanas, pode aumentar a conectividade entre as áreas rurais e urbanas, o que fomenta a demanda por produtos agrícolas locais e amplia a possibilidade de novos empregos não agrícolas, tanto no campo quanto em localidades próximas as zonas rurais, reduzindo então o número de indivíduos em situação de pobreza. Evidências para países como Etiópia, Tanzânia e Índia apontam que essa conexão é mais intensa nas cidades menores, conhecidas também como cidades secundárias ${ }^{1}$, e as zonas rurais (VANDERCASTEELEN et al., 2018; GIBSON et al., 2017; LANJOUW; MURGAI, 2010; CHRISTIAENSEN; KANBUR, 2018).

Na literatura de urbanização e concentração urbana, a relação da redução da pobreza rural a partir do desenvolvimento das cidades é explorada por Ravallion, Chen e Sangraula (2007). Segundo os autores, urbanização e crescimento são processos altamente interligados, de modo que a proximidade das indústrias com a mão de obra possibilita importantes economias externas de escala ${ }^{2}$.

Sob o aspecto teórico, Henderson (2003), mostra que o crescimento da produtividade nacional não é afetado pela urbanização per se, mas sim pelo nível de concentração urbana, condicionado ao nível de desenvolvimento dos países e o seu tamanho. O processo de urbanização tem um importante impacto na composição da sociedade, sendo o primeiro passo para transformar relações sociais, sobretudo no rural.

Além disso, outro processo importante nesse contexto é o chamado transbordamento ${ }^{3}$ sob o qual a urbanização e o crescimento urbano impactam não somente o local, mas também suas regiões adjacentes (SOUZA et al., 2018). Deste modo, a população rural pode ser beneficiada pelas externalidades positivas que promovem o aumento da renda no campo e uma absorção de mão de obra excedente do âmbito rural para os centros urbanos.

No que tange a absorção de mão de obra dos habitantes do campo para atividades até então inexistentes nas zonas rurais, pode-se observar um efeito de composição, sob o qual os habitantes do campo migram para os centros urbanos, também conhecido como êxodo rural, e uma mudanças nas atividades realizadas pelo indivíduos que permanecem no campo, mas

\footnotetext{
${ }^{1}$ Secondary Towns, do termo em inglês

${ }^{2}$ Entende-se por economias de escala o conceito desenvolvido por Marshall (1890) no qual o custo médio de produção se reduz com o aumento da produção

${ }^{3}$ Spillover no jargão econômico.
} 
agora exercendo outros tipos de trabalho, além dos agrícolas.

O efeito dos fluxos migratórios é amplamente discutido na literatura de sociologia rural, demografia, e economia agrícola. O impacto da diminuição da pobreza a partir do mercado de trabalho é recorrentemente tratado nesta literatura (LEWIS, 1954; HARRIS; TODARO, 1970; LIPTON, 1980; LANJOUW; MURGAI, 2010). No caso brasileiro, Martine (1976) discute as condições dos migrantes e não migrantes da região de destino na década de 1980 e aponta que, em alguns casos, há uma aparente mobilidade social da população migrante, colocando-os em uma situação melhor no novo local de moradia quando comparado com a residência no campo.

A análise dos fluxos migratórios é complexa e exige um entendimento das etapas de migração, uma vez que entre o ponto inicial e final podem existir diversos pontos intermediários, sendo esses determinantes para explicar a situação atual dos migrantes. Sem contar a dificuldade do monitoramento dos fluxos migratórios a partir dos Censos Demográficos, uma vez que "os migrantes enumerados em qualquer corte transversal constituem apenas o resíduo momentâneo, os sobreviventes de um processo contínuo" (MARTINE, 1976).

De todo modo, os possíveis efeitos do crescimento urbano nos habitantes que permanecem nas zonas rurais é muitas vezes deixado de lado. Até meados de 1980, a literatura de urbanização e pobreza rural se voltava à dicotomia entre as grandes cidades e o campo, com o avanço de cidades médias no Brasil entre as décadas de 1980 e 2000, novas abordagens vieram à tona (ANDRADE; SERRA, 1998). Nessa perspectiva, com as cidades menores crescendo acentuadamente, assim como as conexões com as zonas rurais, que também avançaram no período, surgiu o projeto Rurbano ${ }^{4}$, que discute as mudanças que vem ocorrendo nas zonas rurais brasileiras, tais como a questão da pluriatividade, que consiste em combinar o trabalho no campo com as atividades não agrícolas, aumentando assim os rendimentos dos cidadãos do campo. Como aponta Silva (2001), entre os principais fatores para essas mudanças se destacam o crescimento das cidades em direção ao campo e a ampliação dos meios de transportes.

Esse fenômeno não se restringe ao Brasil, estudos sobre a redução recente da pobreza rural na Índia, por exemplo, apontam que o principal canal para a redução da pobreza rural no país foi a partir da criação de empregos não agrícolas nas zonas rurais, que por sua vez são decorrentes de processos regionais de urbanização e expansão dos diferentes tipos de cidades (LANJOUW; MURGAI, 2010; GIBSON et al., 2017) .

\footnotetext{
${ }^{4}$ Para mais informações do Projeto Rurbano, acesse:

- <https://revistapesquisa.fapesp.br/2000/04/01/o-novo-rural-brasileiro/>

- <https://bv.fapesp.br/pt/auxilios/958/caracterizacao-do-novo-rural-brasileiro-199298-fase-iii/>

- <http://www.iapar.br/arquivos/File/zip_pdf/novo_rural_br.pdf>

- <https://bv.fapesp.br/pt/auxilios/906/caracterizacao-do-novo-rural-brasileiro-198195/>
} 
Desta forma, para aprofundar o entendimento sobre o combate a pobreza rural é necessário identificar o crescimento dos diferentes tipos de cidades brasileiras. Para Ravallion, Chen e Sangraula (2007), urbanização e crescimento são processos altamente interligados, de modo que a proximidade das indústrias com a mão de obra possibilita importantes economias externas de escala.

Para analisar os diferentes ambientes urbanos e como se dá a interação com a pobreza extrema local, Ferré, Ferreira e Lanjouw (2012) estimaram o efeito do tamanho da cidade na porcentagem dos habitantes em situação de pobreza extrema ${ }^{5}$ para oito países, incluindo o Brasil. Os resultados empíricos suportam a hipótese do "viés metropolitano“, de maneira que a concentração da população em cidades é inversamente relacionada com a proporção de habitantes em pobreza extrema. Entretanto, as relações espaciais da pobreza não foram exploradas, assim como a classificação entre rural e urbano. Deste modo, possíveis efeitos de transbordamento, tais como os apontados por Souza et al. (2018) foram deixados de lado.

Sem o devido tratamento da correlação espacial na disposição dos indivíduos em situação de pobreza, perde-se as relações de vizinhança, comumente tratadas na literatura de econometria espacial (TORRES et al., 2011; ARBIA, 2014; ANSELIN; GALLO; JAYET, 2008). Para lidar com a disposição espacial da pobreza, o presente trabalho propõem a elaboração de um estudo com enfoque nos impactos do crescimento urbano das cidades na pobreza rural, por isso, o tratamento da correlação espacial é importante.

Uma contribuição importante que buscou corrigir o problema das variáveis espacialmente correlacionadas dos modelos para pobreza rural foi proposta por Gibson et al. (2017). Os autores reforçam a importância da absorção da mão de obra, já presente nos estudos clássicos, e inovam na diferenciação dos efeitos das cidades secundárias e das grandes cidades. $\mathrm{O}$ termo "cidades secundárias" marca justamente as áreas de transição entre o extremo rural e o totalmente urbanizado. Trata-se de uma especificação alternativa a da dicotomia clássica rural-urbana, a qual não contempla as informações dos diferentes tipos de cidade, assim como as escalas de ruralidade no país.

No tratamento teórico, os autores propõem uma economia com três setores: o campo, as cidades secundárias e as cidades grandes. Os resultados apontam para uma ambiguidade no quanto as cidades secundárias podem diminuir a pobreza rural vis-à-vis o efeito dos grandes centros urbanos, uma vez que esses dependem das elasticidades da demanda por mão de obra em cada setor.

No que tange aos resultados empíricos, por sua vez, Gibson et al. (2017) constataram que as cidades secundárias promoveram uma redução maior na pobreza rural quando comparadas com o impacto do crescimento das cidades grandes ${ }^{6}$. Os autores utilizaram os dados

\footnotetext{
${ }^{5}$ A definição de pobreza extrema dos autores seguiu os critérios internacionais, considerando todos os indivíduos com rendimento diário inferior a um dólar americano em 2000.

${ }^{6}$ No estudo foi considerado uma cidade grande na Índia municípios com mais de 1 milhão de habitantes.
} 
das mesorregiões da Índia, e estimaram, a partir das técnicas de econometria espacial para dados em painel, um modelo de Durbin Espacial para captar os efeitos diretos e indiretos do desenvolvimento das cidades na pobreza rural do país.

É importante destacar que diversos fatores podem explicar os indicadores de pobreza rural nas regiões brasileiras: componentes históricos, como rotas de comércio, proximidade ao mar, arranjos institucionais locais, indicadores de capital humano, entre muitos outros. Quando se avalia a influência da urbanização da região, deve-se analisar com precaução, uma vez que um polo industrial pungente, ou um centro comercial importante apresenta, na maioria das vezes, um elevado nível de urbanização, da mesma forma que atrai mão de obra qualificada em busca de remunerações mais altas, e pode repelir, em alguns casos, as pessoas menos qualificadas, devido aos altos custos de vida (LUCAS JR, 2004).

A partir dessas questões, o intuito do presente trabalho é avaliar o impacto do crescimento de diferentes níveis de urbanização das cidades brasileiras na redução da pobreza rural. Nesse contexto, estimou-se os efeitos da urbanização dos grandes centros metropolitanos e das regiões incipientes, com menor nível de complexidade urbana, nos indicadores de pobreza rural, como, por exemplo, o total de habitantes do campo com renda domiciliar per capita abaixo da linha de pobreza extrema a preços de 2010. Utilizou-se imagens de sensoriamento noturno como proxy do avanço urbano para as regiões no Brasil. Foram captados dois tipos de urbanização: a referente aos centros altamente urbanizados com alta luminosidade, e uma urbanização secundária, de regiões ainda incipientes.

A base de dados utilizada contou com outras variáveis obtidas por imagem de satélites, tais como a área do município destinada a agricultura e a área de vegetação nativa, ambas obtidas pelo projeto MAPBIOMAS (SOUZA; AZEVEDO, 2017), e os dados de relevo e altimetria dos municípios brasileiros disponibilizados pelo Embrapa (SILVA et al., 2013). Somou-se a isso o controle por variáveis dos Censos Demográficos de 2000 e 2010. A unidade de análise territorial se deu no nível de Áreas Mínimas Comparáveis (AMCs) nos anos referência, as quais agregam municípios criados entre 2000 e 2010 no mesmo polígono, com base em 2000. Desta forma, tem-se um painel balanceado de AMCs para dois períodos.

A escolha metodológica teve como enfoque tratar de duas questões presentes nos estudos de urbanização e pobreza rural: a presença de simultaneidade nas relações entre os indicadores de crescimento urbano e pobreza rural, e a correlação espacial das variáveis utilizadas. A solução proposta para a primeira questão se deu a partir da estimação de modelos com Variáveis Instrumentais, com base nos investimentos públicos realizados durante o programa Luz Para Todos (LPT) entre 2003 e 2010.

Concomitantemente, para controlar a presença de correlação espacial nas variáveis de interesse, recorreu-se as técnicas de Econometria Espacial, no caso aos modelos de Erros Espaciais com dados em painel que foram utilizados no segundo estágio das estimações com 
Variáveis Instrumentais. Tendo isso em vista, estimou-se os efeitos a partir de modelos de Métodos dos Momentos Generalizados (GMM) com Variáveis Instrumentais e Erros Espacias.

O presente documento está organizado em quatro capítulos, sem contar a Introdução: no capítulo 1 de Revisão de Literatura apresenta-se a discussão sobre os possíveis canais de atuação sob os quais o crescimento urbano pode diminuir a pobreza rural; o capítulo 2 se refere a estratégia empírica utilizada, com a apresentação da base de dados sistematizada e dos aspectos metodológicos para a estimação dos parâmetros de interesse; o capítulo 3 contém os principais resultados do trabalho, seguido por uma discussão sobre os efeitos encontrados; por fim, o capítulo 4 apresenta as considerações finais sobre o estudo. 


\section{REVISÃO DE LITERATURA}

A revisão bibliográfica presente neste capítulo tem como intuito apresentar os três principais blocos discutidos ao longo do estudo, são eles: os possíveis canais de atuação do crescimento urbano na diminuição da pobreza rural; os avanços das pesquisas de urbanização a partir de imagens de sensoriamento remoto; e trabalhos que inspiraram a estratégia de Variáveis Instrumentais a partir de programas de investimento em linhas de transmissão e a topografia local.

O padrão espacial da pobreza rural no Brasil foi tratado por Paula, Dalberto e Bohn (2013). Com os dados do Censo Agropecuário de 2006 do IBGE, eles mostraram que regiões rurais com elevada porcentagem de habitantes em situação de pobreza rural estavam próximas as outras regiões com indicadores parecidos e vice-versa, essa análise permanecia válida às regiões com baixa proporção de pobres próximas, as quais situavam-se próximas as outras em condições semelhantes. Assim, a partir das análises exploratórias espaciais, os autores introduziram um modelo de econometria espacial na avaliação, o que indicou um ganho considerável no poder explicativo da disposição no país.

No que tange aos estudos com enfoque na relação entre as cidades e a pobreza rural, a especificação do problema geralmente é baseada na dicotomia rural-urbano. Essa divisão reducionista para apenas dois cenários, ser urbano ou não, deixa de lado as possíveis diferenças nos efeitos do desenvolvimento urbano no caso das metrópoles via-à-vis as demais cidades cuja classificação de urbano permanece, mas sua complexidade como cidade, aglomeração e dinâmica são distintas da visão clássica do que é um ambiente urbano definido por Santos (2005).

Para Bezerra et al. (2013) a tipologia proposta pelo Banco Mundial como classificação de áreas rurais e urbanas possibilita o ganho de informação, pois partem do entendimento que a ruralidade não pode ser definida a partir de uma metodologia única e inflexível. A transição entre zonas estritamente rurais a áreas muito urbanizadas não é abrupta, a classificação deve se basear em um gradiente, indo das áreas puramente urbanas, semiurbanas, rurais e áreas remotas que, por sua vez, estão normalmente interligadas por complexos laços econômicos e sociais.

A subestimação da composição rural no país não se restringe ao Brasil, segundo outras especificações do que seria um ambiente rural, como a proposta por Ferranti et al. (2005) para países da América Latina e Caribe ${ }^{7}$, que leva em consideração a densidade demográfica e a distância dos principais centros urbanos o tamanho do meio rural corresponderia a uma média de $42 \%$ do total nacional, muito acima dos $24 \%$ com os dados oficiais.

\footnotetext{
${ }^{7}$ Foram considerados Áreas rurais locais com menos de 150 pessoas por $\mathrm{km}^{2}$ e distantes mais de uma hora de carro dos centros urbanos
} 
As questões sobre a vastidão das zonas rurais no país, cujas dimensões eram muitas vezes reduzidas ao âmbito agrícola tiveram um salto na qualidade da discussão a partir do fim da década de 1980, com importantes projetos focados no tema, foi o caso do "Projeto Rurbano", uma coleção de quatro volumes lançada por José Graziano da Silva, professor do Instituto de Economia (IE) da Unicamp e Diretor Geral da Organização das Nações Unidas para a Agricultura e a Alimentação (FAO), de 2012 a 2019, e Clayton Campanhola, pesquisador da Embrapa Meio Ambiente.

Em um dos volumes, Silva (1997) levanta o ponto de que o Brasil rural não é só agrícola, o desenvolvimento das cidades e suas integrações cada vez mais intensas com as zonas do campo vem corroborando à redução do abismo tradicional entre os meios altamente urbanos e os rurais. $\mathrm{O}$ avanço das pesquisas teve como enfoque investigar a evolução das interações entre cidades e zonas rurais no Brasil entre os anos 1992 e 1998, nesse contexto, foram obtidos resultados relevantes ${ }^{8}$ sobre os modos de vida dos habitantes do campo no Brasil e como se dá a relação entre o crescimento das cidades e a pobreza rural. Por exemplo, um canal essencial de mudança passa pelas modificações nos mercados de trabalhos locais conforme as relações com as cidades se tornam mais intensas.

A chamada pluriatividade, que consiste em exercer tarefas totalmente diferentes na rotina de trabalho, marca a população rural há muito tempo, o fator que mais se diferencia quando há um aumento das relações com as cidades consiste na ampliação de atividades não agrícolas exercidas pelos habitantes do campo as quais ganham cada vez mais espaço na renda rural. Evidências nesse caminho foram encontradas em pesquisas de outros países, como é o cas o do trabalho de Lanjouw e Murgai (2010) sobre a Índia. Nesse caso, constatou-se a diminuição da pobreza no campo e um dos canais se deu via oferta de trabalho não agrícola proporcionado pela rede urbana.

Segundo Silva (1996), as rendas não-agrícolas de cidadãos do campo são, em média, substancialmente maiores do que as rendas obtidas com trabalhos relacionados as atividades agrícolas. Estudos de casos indicaram que essa diferença poderia chegar a até cinco vezes o rendimento obtido na agropecuária quando comparados em valores por horas trabalhadas (SILVA, 2001).

A partir de dados da Pesquisa Nacional por Amostra de Domicílio (PNAD) entre 1992 e 1998, Silva (1997) constatou que 35\% das famílias ligadas as atividades agropecuárias no Brasil tinham a pluriatividade com trabalhos não-agrícolas em suas rotinas de trabalho. A critério de ilustração, trabalhadores de festas de rodeio, funcionários de estabelecimentos do tipo pesque-pague ${ }^{9}$, produtores envolvidos no comércio de floricultura, são exemplos simples de pessoas as quais obtêm renda a partir de trabalhos não-agrícolas, e podem muito

\footnotetext{
${ }^{8}$ Veja (SILVA, 1996; SILVA, 1997; SILVA, 1999)

${ }^{9}$ Estabelecimentos destinados a cultura de peixes em cativeiro utilizados como produtos de pescadores os quais pagam pelo peixe que pescam.
} 
bem trabalhar no campo a depender das questões de sazonalidade, estrutura familiar, e afins.

Os estudos de urbanização tiveram um salto tecnológico com as imagens de sensoriamento remoto no fim da década de 1990, após a disponibilização das imagens orbitais dos satélites da Administração Nacional de Oceanos e Atmosfera (NOAA, da sigla em inglês), com dados anuais de 1992 a 2012, e disponibilizadas em grides de 30 arc-segundos, ou aproximadamente 1 quilômetro na resolução de um pixel na linha do Equador. Dessa forma, viabilizou-se estudos demográficos e socioeconômicos (LEVIN; DUKE, 2012), análises da concentração espacial da pobreza, combinando metodologias de aprendizagem de máquina (machine learning, do termo em inglês) e os dados de imagens orbitais (JEAN et al., 2016), construção do Índice de Desenvolvimento de Luminosidade Noturna (NLDI, da sigla em inglês) para todos os países (ELVIDGE et al., 2012), e sobre a dinâmica de urbanização em países até então com pouca disponibilidade de dados sobre o tema, como era o caso da China (MA et al., 2012; HUANG et al., 2015).

Especificamente nos estudos de urbanização, Henderson et al. (2003) utilizou os dados de iluminação das cidades para avaliar o nível da variável calculada e assim propor uma métrica de categorização do que poderia ser considerada uma cidade em diferentes locais do globo. Ainda nessa linha de pesquisa Zhou et al. (2014) avançaram nessa categorização, indicando, por exemplo, que nos Estados Unidos, 2\% da área do país é urbanizada. Sob essa perspectiva, Huang et al. (2015) analisou a dinâmica de crescimento das cidades durante duas décadas na China.

Dentre estudos que analisam programas de eletrificação rural em países da África, Bernard (2010) analisa os efeitos de três décadas de ampliação do acesso à energia elétrica nos países da África subsaariana e encontra efeitos nas dimensões relacionadas à pobreza rural, saúde, educação e empoderamento feminino, resultados esses que variam de país para país. Um dos estudos mais notáveis sobre esse tema foi elaborado por Dinkelman (2011) para a África do Sul.

Com enfoque nos efeitos da eletrificação das zonas rurais no mercado de trabalho, Dinkelman (2011) utilizou técnicas de Variáveis Instrumentais para avaliar os impactos do acesso a energia elétrica no mercado de trabalho e encontraram efeitos positivos e significantes na empregabilidade das mulheres habitantes do campo no país, de modo que o aumento da eletrificação das residências rurais ampliou a possibilidade de trabalho para as habitantes locais. Nesse trabalho, Dinkelman (2011) aponta que efeitos de migração também foram detectados.

Tendo em vista a relação de endogeneidade entre o processo de ampliação do acesso a eletricidade e o crescimento econômico, os autores utilizaram os dados de topografia da região para construírem a função de custo de construção da infraestrutura de transmissão que, por sua vez, é exógena a empregabilidade dos habitantes no campo (variável de interesse 
desse estudo).

A estratégia de utilizar as características topográficas na construção de instrumentos para avaliação de impacto não se restringe a estudos de eletrificação, Duflo e Pande (2007), por exemplo, construíram os instrumentos a partir dos dados de relevo nas regiões da Índia para captarem os efeitos das construção de barragens nos indicadores de bem estar social local. Nesse caso, a construção de uma barragem se mostra mais favorável em termos econômicos quando os rios possuem um mínimo de queda, o que facilita na construção de usinas hidroelétricas. 


\section{ESTRATÉGIA EMPÍRICA}

\subsection{Base de dados}

Os dados utilizados estão em estrutura de painel com dois períodos, 2000 e 2010, sendo a unidade de análise as Áreas Mínimas Comparáveis (AMCs) do Brasil ${ }^{10}$, propostas pelo IBGE para o período de referência. Assim, utilizou-se as informações dos Censos Demográficos de 2000 (IBGE, 2000) e 2010 (IBGE, 2010), agregando as informações nas AMCs, com os dados de imagens de sensoriamento remoto, apresentados na subseção 2.1.1, também a nível de AMCs, o que resulta em um painel balanceado.

Como o intervalo temporal entre as observações é de dez anos (entre 2000 e 2010), espera-se captar os efeitos do crescimento urbano na pobreza rural, uma vez que os canais de atuação, tais como as mudanças nos mercados de trabalho, o aumento da conexão entre o campo e as cidades, e a expansão da infraestrutura urbana, demandam tempo para se estabelecerem. Uma ressalva importante nesse caso é que as relações de curto prazo entre esses fatores não será captada nos modelos.

Assim, essa seção está organizada em quatro subseções, sendo elas: a de Imagens de Sensoriamento Remoto, que constitui as variáveis proxies de urbanização, assim como os dados de uso da terra - agropecuária e a de vegetação natural - e de aclividade; a subseção sobre os indicadores de pobreza rural no Brasil, que apresenta como se realizou a contagem das pessoas em situação de pobreza no campo de acordo com três linhas de pobreza; e a subseção com as demais covariadas dos modelos, coletadas a partir dos Censos Demográficos nos períodos de referência.

\subsubsection{Imagens de Sensoriamento Remoto}

O avanço das pesquisas empíricas dependem da formulação teórica dos modelos estatísticos e econométricos, da disponibilização de informações, tais como novas bases de dados, e também da capacidade computacional às estimações. As imagens de sensoriamento remoto, portanto, podem ser consideradas como um choque tecnológico nas pesquisas aplicadas, por possibilitar novas abordagens de avaliação das questões espaciais, tais como o crescimento das cidades, a mensuração do avanço econômico em locais desprovidos de contas nacionais, análise de uso de solo em grande escala, entre muitos outros.

Segundo Amaral et al. (2015), os primeiros sensores ópticos de imageamento noturno

\footnotetext{
${ }^{10}$ Forma de agregação dos novos municípios criados entre os períodos. Para mais informações sobre a delimitação das AMCs, assim como a compatibilização dos dados do Censo Demográfico para essa unidade territorial, veja o apêndice A
} 
surgiram na década de 1960. Com a utilização das regiões do infravermelho e do microondas do espectro eletromagnético foi possível observar fenômenos imperceptíveis durante o dia tais como as auroras nos polos, focos de incêndios florestais, chamas provenientes da queima de gases e luzes emitidas das cidades.

A ideia de utilizar o sensoriamento remoto para o acompanhamento do processo de urbanização surgiu no fim da década de 1970, todavia, o grande salto se deu em meados da década de 1990, após a disponibilização das imagens orbitais dos satélites da Administração Nacional de Oceanos e Atmosfera (NOAA, da sigla em inglês), com dados anuais de 1992 a 2012, e disponibilizadas em grides de 30 arc-segundos, ou aproximadamente 1 quilômetro na resolução de um pixel na linha do Equador. Especificamente sobre os dados de iluminação noturna das cidades, muitas pesquisas utilizam o DMSP/OLS ${ }^{11}$ calibrado, em virtude de sua compatibilidade entre os períodos anuais, o que permite acompanhar a evolução da luminosidade em uma dada região ao longo do tempo.

A obtenção e sistematização desses dados é altamente complexa. A fim de fomentar pesquisas em diversas áreas do conhecimento, pesquisadores da NOAA e do Google Engine disponibilizaram os grides da base de dados completa, que cobre grande parte da área terrestre do planeta em formato de mapas de bits (Bitmap, do termo em inglês), onde cada pixel contém as informações de luminosidade noturna do polígono referido, o que possibilita a utilização das informações já calibradas pelo próprio departamento.

É importante situar que a definição de áreas urbanizadas pode variar entre os países, dado que a luminosidade também depende de escolhas dos agentes locais, por exemplo, iluminação pública pode ser prioridade em um determinado local, por questões de segurança pública, mas não estão presente em outras regiões, as quais pode ser urbanizadas, mas não possuem iluminação pública nos bairros mais afastados, como é o caso dos subúrbios nos Estados Unidos. Por isso, é necessário utilizar classificações mais regionais das áreas urbanas para se avaliar o crescimento das cidades.

No contexto da América do Sul, Álvarez-Berríos, Parés-Ramos e Aide (2013) propuseram um mapeamento da área urbanizada a partir da luminosidade noturna e identificaram padrões em comum, como: o valor mínimo para se classificar um local como suburbano, o que podemos chamar de luminosidade secundária, está entre 21 e $53 \mathrm{DN}$, enquanto que regiões altamente compactas, por sua vez, com uma urbanização elevada emitem luminosidade superior a $53 \mathrm{DN}$, o Anexo A apresenta a ilustração dos autores para tal classificação. O presente estudo utiliza essa classificação para avaliar o crescimento das cidades brasileiras.

É importante ressaltar que no trabalho de Álvarez-Berríos, Parés-Ramos e Aide (2013) não foram utilizadas cidades brasileiras para a análise de classificação dos tipos de urbanização, o que pode ser uma limitação para o presente estudo, em virtude disso, no capítulo 3

\footnotetext{
${ }^{11}$ O Programa de Defesa Meteorológica e Satelite (DMSP, da sigla em inglês) disponibiliza uma base de dados de 1992 a 2012 dos grides com medida de intensidade entre 0-63 unidades digitais ${ }^{12}$
} 
de resultados será apresentado flexibilizações nas classificações da urbanização para fins de análise de sensibilidade.

Entre os trabalhos com base em imagens orbitais para o Brasil, Laurini (2016) partiu dos dados de iluminação noturna para estimar a renda per capita do país de maneira bem segmentada, com delimitações menores que os municípios, para os anos em que não há dados do Censo Demográfico. Além de propor um modelo contínuo de efeitos aleatórios para o território brasileiro, Laurini (2016) realizou simulações para tratar o possível erro de medida da variáveis de iluminação.

Uma contribuição na classificação de uso do solo com base em imagens de sensoriamento remoto foi proposta por SILVA et al. (2013), que utilizou as fotografias de imagens de satélite TM/Landsat, disponibilizadas no catálogo "Earth Explorer" do Serviço Geológico do Estado Unidos (USGS), e criaram polígonos de delimitação das áreas urbanas com área mínima de 10 ha referentes a 2013. O presente estudo contribui para essa literatura estabelecendo critérios para classificação de áreas urbanas desde de 2000 no Brasil.

\subsubsection{Exemplo Ilustrativo}

Com o intuito de corroborar na visualização de como foram montados os dados de área com luminosidade noturna elaborou-se as imagens 2.1 a e 2.1 b a seguir para a região metropolitana de Ribeirão Preto/SP. Os dados de luminosidade noturna correspondem ao DMSP/OLS citados na subseção 2.1.1 que variam de 0 a 63 DN. Como se pode observar, as regiões centrais de cada cidade contém as áreas de luminosidade alta, acima de $53 \mathrm{DN}$, enquanto que o espraiamento urbano, marcando as áreas de franja nas grandes cidades, indica luminosidade secundária, entre 21 e 53 DN.

Figura 2.1 - Distribuição da luminosidade na Região Metropolitana de Ribeirão Preto

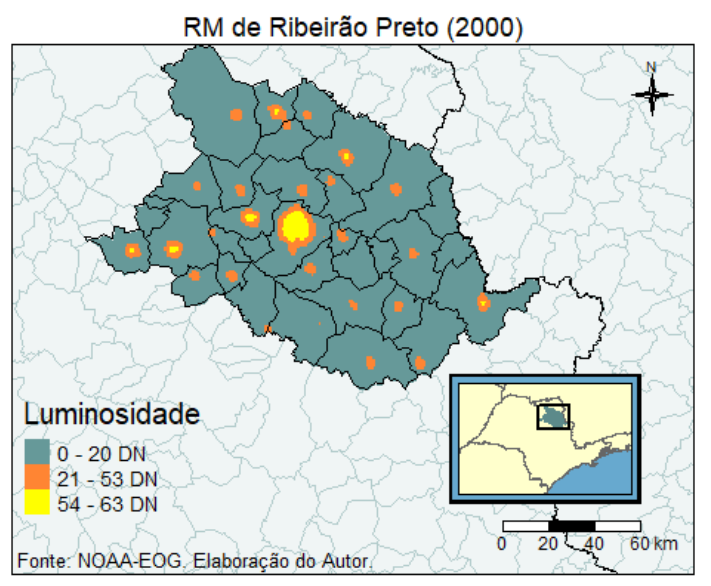

(a) Luminosidade em 2000

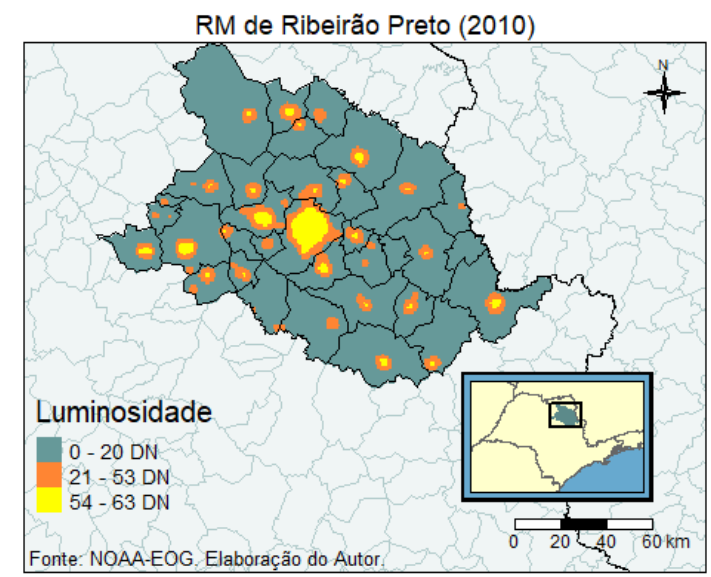

(b) Luminosidade em 2010

Um fato já esperado, mas interessante de ser ressaltado é que a luminosidade se- 
cundária das faixas entre 21 e 53 marcam a transição da luminosidade alta e as zonas sem urbanização, muitas vezes rurais. Dessa forma, como o avanço da urbanização se dá em etapas, é provável que a luminosidade secundária se localize em regiões mais acessíveis para os habitantes de zonas rurais, por isso seu canal de atuação na pobreza rural pode ser mais relevante.

No presente estudo a variável de crescimento urbano das cidades é representada justamente por essa luminosidade secundária. Esse procedimento é semelhante ao utilizado por Gibson et al. (2017) para o caso da Índia, os autores denominaram como cidades secundárias as regiões com luminosidade nessa faixa. Note que nas imagens 2.1a e 2.1b a área preenchida pela luminosidade alta é muito concentrada em alguns municípios, tais como Ribeirão Preto, mais iluminado em ambos os mapas, porém muitos outros municípios estão com baixa luminosidade.

As regiões com vegetação nativa, com pastagens, lavouras (temporárias e/ou permanentes), e áreas de pecuária se encontram nos locais com luminosidade inferior ou igual a 20 DN. Entretanto, é importante situar que outros arranjos habitacionais podem se encontrar nessas regiões, desde vilarejos, a zonas rurais pouco povoada até centros municipais com uma urbanização aquém do que se considerou como incipiente. Em vista disso, a subseção 2.1.1.2 apresenta estatísticas descritivas e uma discussão sobre a distribuição de luminosidade noturna no Brasil.

\subsubsection{Luminosidade no Brasil}

O procedimento de sistematização dos dados de luminosidade foi realizado para as 5.450 Áreas Mínimas Comparáveis da base de dados, para os 2000 e 2010. O apêndice A contém mais informações sobre a delimitação das AMCs utilizadas. A partir de uma análise da evolução nacional da luminosidade a tabela 2.1 apresenta o número de AMCs que possuem ao menos um quilômetro quadrado com variável de luminosidade não nula.

\begin{tabular}{cccc}
\hline \hline Tipos de Luminosidade & 2000 & 2010 & Crescimento \% \\
\hline Lum. acima de 5 DN & 5.114 & 5.441 & $6,4 \%$ \\
Lum. acima de 10 DN & 3.395 & 5.088 & $49,9 \%$ \\
Lum. acima de 15 DN & 2.469 & 4.286 & $73,6 \%$ \\
Lum. acima de 20 DN & 1.921 & 3.558 & $85,2 \%$ \\
Lum. acima de 25 DN & 1.575 & 2.961 & $88,0 \%$ \\
Lum. acima de 53 DN & 482 & 1.027 & $113,1 \%$ \\
\hline \hline
\end{tabular}

Tabela 2.1 - Número de AMCs com dados de luminosidade não nulos

Em cada linha da tabela realizou-se a contagem de AMCs com informações de áreas preenchidas de acordo com o mínimo necessário para se contabilizar, por exemplo, a primeira linha corresponde ao número de AMCs com luminosidade acima de 5 DN para o ano 2000 
e para o 2010, e na última coluna o crescimento percentual do número de AMCs com informações não nulas. Nota-se que as demais linhas contém subconjuntos das AMCs, uma vez que as AMCs com luminosidade acima de 10 DN estão contidas nas AMCs com luminosidade acima de $5 \mathrm{DN}$ e assim por diante.

Uma questão importante de ser pontuada é a elevada concentração de luminosidade em áreas específicas do país. Como a sistematização da área com luz foi realizada a partir de um mínimo de luminosidade para ser contabilizado, o número de AMCs com zero pode ser muito alto, como é o caso da luminosidade alta, acima de 53 DN: em 2000, apenas 482 AMCs possuíam áreas com essa luz, a saber, 8,9\% das observações, aproximadamente. No caso da luminosidade acima de $20 \mathrm{DN}$, constatou-se que 1.921 AMCs possuíam esse nível de luz noturna, o que aumentou em 85,2\%, situando-se em 3.558 AMCs, de todo modo, é possível notar que, sob a classificação de urbanização incipiente, para o ano 2000 tem-se 3.529 AMCs sem informações, a saber, com área equivalente a zero nessa variável, e 1.892 AMCs que permanecem com zero em 2010.

Uma abordagem adicional sobre os dados de luminosidade na escala nacional corresponde a evolução das variáveis de luz, no caso a luminosidade secundária, entre 21 e $53 \mathrm{DN}$, e a luminosidade central, acima de $53 \mathrm{DN}$ com diferentes recortes populacionais. A figura 2.2 apresenta a evolução dos tipos de luminosidade, central e secundária, nas cidades brasileiras, com diferentes recortes populacionais. A esquerda observa-se a evolução da Luminosidade Alta (acima de $53 \mathrm{DN}$ ), enquanto que no gráfico da direita, estão as informações da Luminosidade Secundária (entre 21 e 53 DN). Em ambos os gráficos, os tons mais claros das cores correspondem a área com luminosidade em 2000, os tons mais escuros se referem a luminosidade de 2010.

O recorte populacional se deu com base nas informações de 2000, por exemplo, cidades que foram classificadas no recorte entre 500 mil e 1 milhão de habitantes em 2000, permaneceram no mesmo grupo em 2010, mesmo que elas tenham mais de 1 milhão de habitantes em 2010. Esse procedimento foi realizado para todas as classificações populacionais.

Como se pode notar, em todos os recortes populacionais, tanto na luminosidade alta quanto na secundária, houve uma expansão da área iluminada entre 2000 e 2010. A grande diferença está na taxa de crescimento dessa luminosidade para cada recorte.

Em 2000, a área total preenchida pela luminosidade Central nas cidades acima de 1 milhão de habitantes era de 11 mil quilômetros quadrados ${ }^{13}$ aproximadamente, e aumentou em 36\% em 2010, situando-se em 15 mil quilômetros quadrados. Nota-se que os crescimentos mais expressivos da luminosidade alta se deram nas cidades menores, como é o caso, por exemplo, das cidades entre 100 mil e 250 mil habitantes, as quais saltaram de 12 mil quilômetros quadrados, para 26 mil, e também nas cidades entre 50 mil e 100 mil, que foram de 6 mil

\footnotetext{
${ }^{13} \mathrm{Em} 2000,8$ cidades brasileiras possuíam mais de 1 milhão de habitantes
} 
para 19 mil quilômetros quadrados.

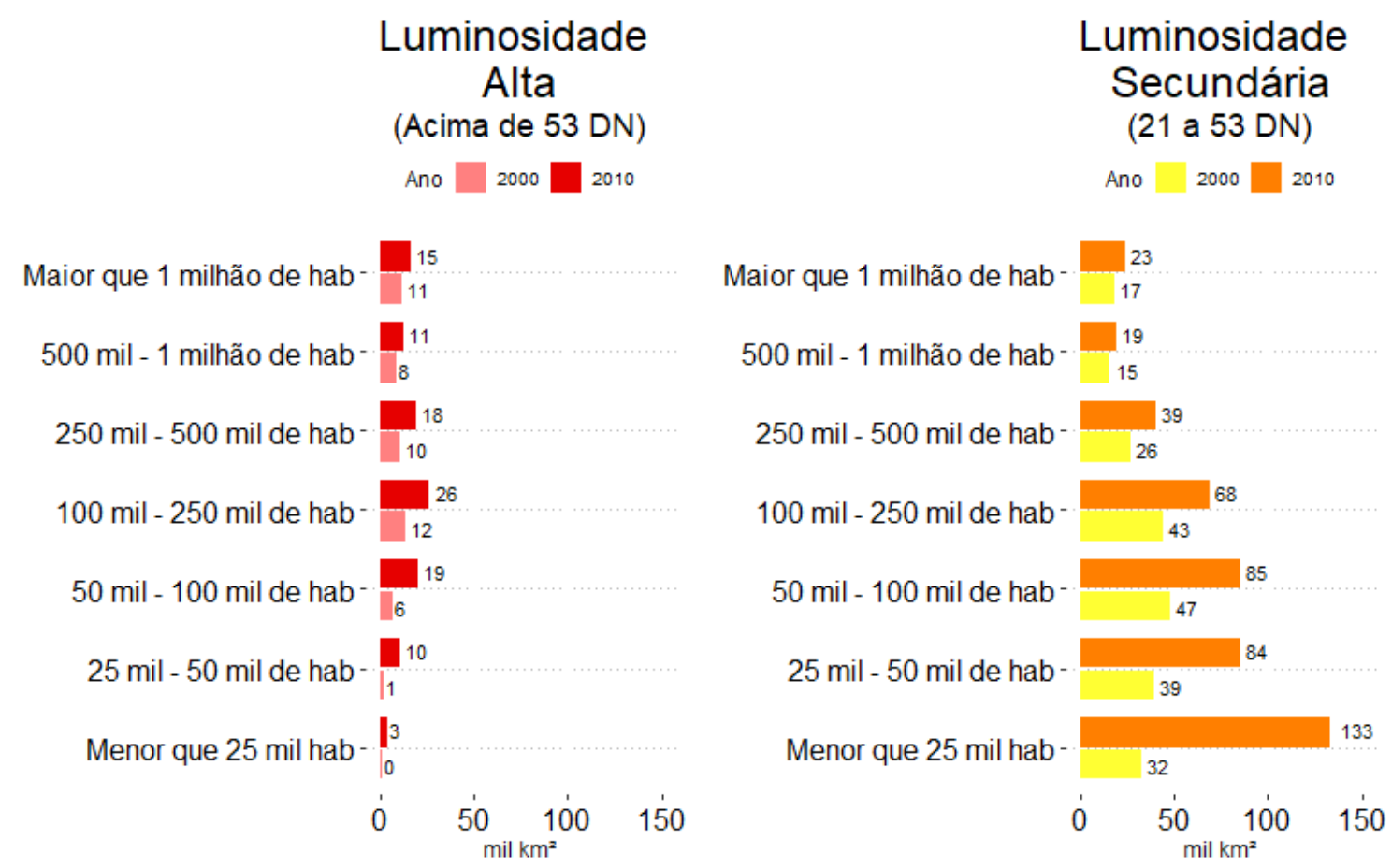

Figura 2.2 - Variação da Luminosidade entre 2000 e 2010 nos tipos de cidades

De todo modo, as evoluções da luminosidade secundária se mostram um crescimento ainda maior. O crescimento deste tipo de luminosidade nas cidades com mais de 1 milhão de habitantes foi de $35 \%$ (3,1\% a.a) de 17 mil para 23 mil quilômetros quadrados, todavia, nas cidades com menos de 25 mil habitantes esse aumento foi de $315 \%$ (15,3\% a.a) de 32 mil para 133 mil quilômetros quadrados.

Essa análise se mostra importante, pois zonas rurais tendem a se localizar mais próximo de cidades menores, como é o caso dos municípios com menos de 25 mil habitantes. Assim, é de se esperar que esse aumento da urbanização nas cidades menores tenha maior efeito na pobreza rural no período, como será apresentado na seção 3 de resultados.

Muitos fatores podem explicar o crescimento da luminosidade secundária entre 2000 e 2010: o crescimento econômico do país, os investimentos em infraestrutura, construção civil, novos distritos industriais, entre outros. Todavia, no caso das AMCs com menos de 50 mil habitantes, é importante destacar uma política pública a nível nacional com enfoque em disponibilizar o acesso a energia elétrica em locais até então desprovidos deste bem: o Programa Luz para Todos. Haja vista que esse programa é utilizado na metodologia de variáveis Instrumentais, a explicação em detalhes da sua execução, assim como suas consequências, está na subseção 2.2.3. 


\subsubsection{A pobreza rural no Brasil}

Na teoria marginalista clássica de bem estar, a proposição teórica de desejo dos indivíduos se baseia na maximização da utilidade satisfeito um conjunto de restrições. Sob essa perspectiva, o consumo de bens e serviços está contido no conjunto de preferências dos indivíduos, portanto, o aumento de acesso a esses bens promove um incremento de seu bem estar no quesito econômico.

Dentre os possíveis efeitos da urbanização no bem estar da população rural seria ideal analisar as mudanças nos padrões de consumo dos habitantes do campo, dado um aumento exógeno da urbanização, tudo mais constante nos demais fatores. Algumas pesquisas mais direcionadas utilizam as despesas familiares como proxy do consumo, como por exemplo, a base de dados da Pesquisa de Orçamento Familiar (POF).

Entretanto, algumas limitações dessa base de dados inviabilizam uma análise mais profunda a nível municipal, pelo fato da amostra da POF ser representativa por Unidade Federativa. Como o presente estudo tem enfoque nos indivíduos em situação de pobreza extrema, pobreza e vulneráveis à pobreza, a renda pode ser uma proxy no nível de consumo, uma vez que a taxa de poupança destes grupos de indivíduos é muito próxima de zero.

Para dados de renda, assim como outras características demográficas a nível municipal, optou-se por utilizar as informações de rendimento dos indivíduos informados nos Censos Demográficos do IBGE de 2000 (IBGE, 2000), e 2010 (IBGE, 2010). Nessa perspectiva, o presente estudo se baseou nos critérios propostos pelo Banco Mundial para as Linhas de pobreza. Essas definições foram propostas em meados dos anos 1990 por pesquisadores das áreas de desenvolvimento econômico e combate à pobreza tais como Glewwe e Gaag (1990) e Squire (1993). A proposta de estabelecer linhas monetárias para níveis de pobreza tem como objetivo mensurar o limiar das chamadas linhas de pobreza e, a partir dessas definições, propor políticas públicas para reduzir o número de pessoas que vivem nessas situações de alta privação a bens de consumo e serviços essenciais.

No caso brasileiro, Falcão e Costa (2014) propuseram o estabelecimento de linhas monetárias de pobreza com o intuito de realizar uma abordagem unidimensional da pobreza que propicia uma boa aproximação das múltiplas dimensões das situações de pobreza do público-alvo, a depender da linha. Desta forma, os autores utilizaram os dados da POF, para obter as informações de consumo, e da PNAD, com informações de rendimentos, para a construção de três linhas de pobreza: a linha de pobreza extrema, a de pobreza e a de vulneráveis à pobreza.

A aplicação dessas linhas para os dados dos Censos Demográficos resultou nas seguintes linhas monetárias para as zonas rurais: definiu-se como situação de pobreza extrema o conjunto de indivíduos com renda domiciliar per capita igual ou inferior a $\mathrm{R} \$ 70,00$ mensais 
em reais de agosto de 2010 segundo o IBGE ${ }^{14}$; a situação de pobreza corresponde ao conjunto de habitantes do campo renda domiciliar per capita igual ou inferior a R \$ 140,00 mensais em reais de agosto de 2010; e a situação de vulneráveis a pobreza corresponde aos indivíduos renda domiciliar per capita igual ou inferior a $\mathrm{R} \$ 255,00$ mensais, ou meio salário mínimo, no mesmo período de referência.

Tendo por base as três linhas de pobreza supracitadas, utilizou-se os microdados dos Censos Demográficos para a criação das seguintes variáveis:

1. Número de pessoas em situação de pobreza rural: que corresponde ao número de pessoas da AMC que residem no campo e possuem renda domiciliar per capita igual ou inferior a renda mínima para cada uma das três linhas de pobreza;

2. Taxa de pobreza rural: apresentada com mais detalhes na equação 2.1 a seguir:

Taxa pobreza rural $_{i}=\frac{\text { Núm. pessoas em sit. de pobreza rural na AMC i }}{\text { Total de habitantes nas zonas rurais na AMC i }}$

A variável Taxa pobreza rural $_{i}$ corresponde a proporção dos indivíduos com renda domiciliar per capita igual ou inferior a determinada linha de pobreza, esse procedimento foi realizado às três linhas citadas, por questão de simplicidade, neste capítulo apresenta-se as estatísticas para a linha de pobreza rural extrema. No apêndice C estão as estatísticas para as demais linhas. Deste modo, essa variável resulta do comportamento do número de pessoas em situação de pobreza na AMC $i$, numerador da fração, e o total de habitantes nas zonas rurais na AMC $i$, denominador da fração.

Portanto, observa-se que um aumento da renda dos indivíduos que estavam em situação de pobreza rural extrema na AMC $i$, tudo mais constante, diminui o número de pessoas nessa situação de pobreza extrema, o que diminuiria a taxa de pobreza rural em $i$. Um possível canal para isso ocorrer poderia ser atribuído ao aumento da renda das pessoas do campo em virtude do crescimento urbano na AMC $i$ em questão.

Entretanto, nota-se que a variável Taxa pobreza rural $_{i}$ depende também da dinâmica do denominador, o que pode estar relacionado a outros fatores e deve ser analisada com cautela, é o caso das migrações. Desta maneira, há uma mudança na composição da população, dado que as migrações podem afetar tanto a população em geral do campo, denominador,

\footnotetext{
${ }^{14}$ Uma ressalva importante é que, para o presente exercício, utilizou-se a mesma linha de pobreza extrema, com correção dos valores declarados a partir do índice de preços IPCA entre os Censos de 2010 e 2000. Assim, a linha de pobreza, em termos de poder de compra, foi mantida constante entre os períodos. Esse procedimento também foi realizado para as outras duas linhas, a de pobreza e a de vulneráveis à pobreza
} 
como também o subconjunto dessa população em situação de extrema pobreza, afetando diretamente o numerador.

Suponha que modelo teórico de Lucas Jr (2004) tenha implicações empíricas na dinâmica de êxodo rural no Brasil. A partir dessa perspectiva, a migração para os centros urbanos acontece, majoritariamente, pela população rural menos pobre, a qual possui mais capital humano e espera obter mais renda se mudando para o centro urbano em busca de melhores postos de trabalho, fenômeno que já foi constatado em trabalhos para o Brasil (SILVA, 2001).

Tudo mais constante, o movimento de emigração do campo promove uma queda no denominador e do numerador. Se seguissem variação percentual, numerador e denominador, a taxa de pobreza rural permaneceria constante entre os períodos de análise. Mas se ocorrer o efeito de Lucas Jr (2004), a emigração será dos menos pobres, de modo que o denominador diminui mais acentuadamente que o numerador.

Assim, a taxa de pobreza aumenta na AMC $i$ em virtude da mudança na composição dos habitantes. Note que, sob o ponto de vista da proporção de pessoas em situação de pobreza rural com relação ao total de habitantes do campo, houve um aumento da taxa, porém, isso não significa um aumento da pobreza no campo per se. Ademais, como os dados do censo não correspondem a um painel de indivíduos identificados, não é possível saber se quem migrou para as cidades efetivamente melhorou em termos de renda.

Para ilustrar a composição total do Brasil em termos de número de pessoas em situação de pobreza extrema, a tabela 2.2 apresenta, na primeira coluna, o total de habitantes em zonas Rurais e no Urbano, entre 2000 e 2010. A segunda coluna indica a quantidade de habitantes com renda per capita inferior a $\mathrm{R} \$ 70,00$ mensais a preços de agosto de 2010.

\begin{tabular}{lccc}
\hline \hline & Total (milhões) & Pob. Extrema (milhões) & \% do total \\
\hline Zonas Rurais & & & \\
2000 & 31.70 & 11.47 & 36.20 \\
2010 & 29.70 & 7.35 & 24.80 \\
Urbano & & & \\
2000 & 137.74 & 15.65 & 11.40 \\
2010 & 160.62 & 12.76 & 7.90 \\
\hline \hline
\end{tabular}

A situação de pobreza extrema é caracterizada por indivíduos com renda domiciliar per capita igual ou inferior a $\mathrm{R} \$ 70,00$ mensais, em reais de agosto de 2010. Os dados de rendimento dos indivíduos em 2000 foram corrigidos para o mês de referência de 2010 a partir do IPCA acumulado entre os períodos.

Tabela 2.2 - Comparação Pobreza Rural e Urbana

Nota-se que a diminuição do total de indivíduos em situação de pobreza extrema é verificada tanto no âmbito rural quanto no urbano. Nas Zonas Rurais, houve uma redução de 
11,47 milhões de indivíduos para 7,35 milhões, enquanto que no campo a redução foi de 15,65 milhões para 12,76 milhões. De todo modo, é importante situar que o total de habitantes do campo diminuiu entre os períodos, de 31,7 mihões para 29,7 mihões, e no urbano, o aumento foi expressivo, de 137,74 milhões para 160,62 milhões.

Para analisar a disposição espacial pobreza extrema rural entre os anos 2000 e 2010, pode-se observar as figuras 3.1 a e 3.1b, apresentadas a seguir. Em termos gerais, nota-se uma diminuição acentuada da pobreza rural no período de análise, porém, a melhora ocorreu de maneira muito desigual entre os municípios. Alguns clusteres de pobreza permaneceram acentuados, sobretudo na região da caatinga, interior do Nordeste, na Zona dos Cocais (Maranhão) e na região Norte.

Figura 2.3 - Distribuição espacial da Pobreza Rural Extrema no Brasil entre 2000 e 2010

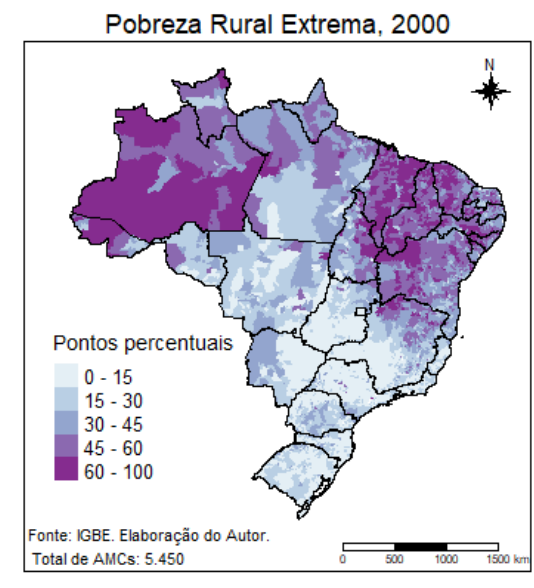

(a) Pobreza Extrema 2000

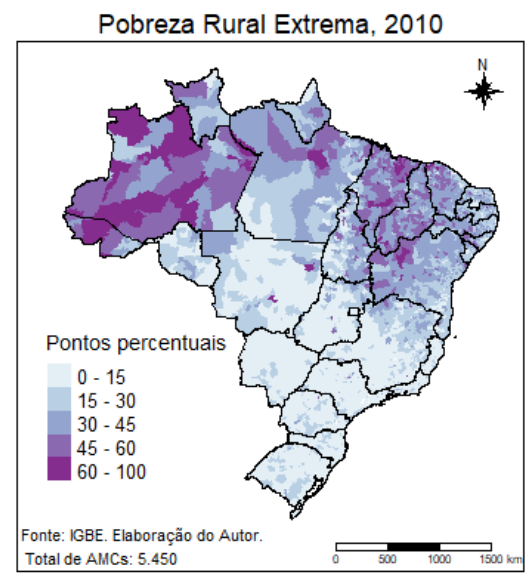

(b) Pobreza Extrema 2010

Em ambas as figuras é possível verificar uma relação entre os indicadores de pobreza das AMCs com suas respectivas vizinhanças. Bolsões de pobreza são facilmente identificados, de modo que, a aglomeração de regiões com perfis semelhantes é realidade no país, AMCs com elevados níveis de pobreza se situam ao lado de outras com a mesma dinâmica, o resultado é análogo para os casos de AMCs com baixa proporção de indivíduos que vivem em situação de pobreza. Essa característica dá indícios da presença de correlação espacial que será tratada na seção 3 de Resultados.

No apêndice C pode-se observar a distribuição espacial de outras duas taxas de pobreza calculadas a partir dos Censos, a proporção de pessoas em situação de pobreza que habitam áreas rurais, cujo o limiar é o de R\$140,00 por mês, em reais de agosto de 2010 segundo o IBGE e a proporção de pessoas em situação de vulnerabilidade à pobreza rural, com renda domiciliar per capita inferior a $\mathrm{R} \$ 255,00$, que correspondia a meio salário mínimo em 2010.

No presente estudo utilizou-se como variável dependente dos modelos o total de 
habitantes em situação de pobreza rural, a depender da linha de pobreza em cada caso. Além disso, controlou-se, em todos os casos, pelo total de habitantes das zonas rurais das respectivas AMCs. Na subseção seguinte, apresenta-se as demais variáveis dos Censos Demográficos utilizadas como covariadas nos modelos do capítulo 3 de resultados.

\subsubsection{Variáveis de controle dos Censos Demográficos}

Além das variáveis de indicadores de pobreza, construiu-se variáveis de controle a partir dos Censos Demográficos ${ }^{15}$ para as AMCs utilizadas. Como o presente estudo está voltado para a dinâmica da pobreza rural nos municípios brasileiros, as variáveis mais relevantes são as relacionadas aos dados de capital humano, como nível de escolaridade, composição da família, fecundidade e características demográficas, que podem ser observadas na tabela 2.3.

Nessa tabela, todas as variáveis com a indicação '(Rural)' foram calculadas apenas com os microdados dos setores censitários rurais do questionário amostral do Censo. As variáveis de pobreza, Pobreza Extrema (Rural), Pobreza (Rural), e Vulneráveis à Pobreza (Rural) correspondem as taxas de pobreza apresentadas na subseção anterior. Segundo os dados apresentados, pode-se observar que $24 \%$ da população rural vivia em situação de pobreza extrema, juntando os dois períodos analisados. No caso da linha da pobreza, Pobreza (Rural), a renda domiciliar per capita mínima é o dobro da extrema, portanto, contém todos os indivíduos em situação de pobreza extrema e outras pessoas com renda domiciliar per capita inferior a linha definida, assim, $42 \%$ da população rural se encontrava nessa situação. Analogamente, no caso da população vulnerável à pobreza, $61 \%$ se encontravam nessa situação.

No que tange as variáveis de capital humano, nota-se que a proporção da população rural que é analfabeta é de $36 \%$, e vai diminuindo nos demais níveis de educação, como Fundamental Completo, Ensino Médio Completo, e assim por diante.

A variável Prop. com Carteira Assinada (Rural) indica a proporção dos habitantes que trabalhavam com carteira assinada na semana de referência dos Censos é de $9 \%$ do total da população rural. A variável Mãe Chefe de Família, por sua vez, corresponde a proporção de mulheres chefes de família, que não possuem ensino fundamental completo e têm pelo menos 1 filho de idade inferior a 15 anos morando no domicílio com relação ao total de mulheres chefes de família.

Algumas variáveis foram introduzidas com o intuito de captar a dinâmica de migração local, assim, a Prop. que sempre morou (Rural) indica a proporção dos habitantes do campo

\footnotetext{
${ }^{15}$ Agradecemos ao Data Zoom, desenvolvido pelo Departamento de Economia da Pontifícia Universidade Católica do Rio de Janeiro (PUC-Rio), que disponibiliza ferramentas para a leitura dos microdados do Censo Demográfico do IBGE já agregado em AMCs, utilizadas nesse trabalho
} 
que sempre moraram no município de referência. $\mathrm{O}$ mesmo vale para a variável de proporção que nasceu na UF em que mora atualmente, Prop. Nasceu na UF (Rural).

Imputou-se nesta tabela as variáveis nos modelos com Variáveis Instrumentais, tais como a Prop. Domicílios com Acesso a Sanitário indica que 88\% dos domicílios tinham acesso a sanitário, por outro lado, apenas $26 \%$ se inseriam em um sistema de Rede Geral de Esgoto, Prop. Domicilios com Instalação Sanitária.

Soma-se a isso, as variáveis que compuseram os instrumentos, explicados com mais detalhes na subseção 2.2.3, como a variável Dummy Elegíveis ao LPT, que corresponde a um se a AMC é considerada elegível ao programa Luz para Todos, no sentido de possuir menos de $85 \%$ dos domicílios com acesso a energia elétrica em 2000, e zero caso contrário. Como se pode observar, $30 \%$ das AMCs são elegíveis ao programa, no apêndice A pode-se observar essas AMCs no território brasileiro.

Ademais, computou-se também variáveis relacionadas às AMCs, tais como a variável de Bolsa Família (milhões R\$), que indica o volume total, em milhões de reais, transferido pelo Governo Federal para o programa de Bolsa Família, e o total da população urbana que reside nas respectivas AMCs. Os dados referentes as imagens de satélites serão apresentados nas duas subseções seguintes. 


\begin{tabular}{lccccc}
\hline \hline Estatísticas & N & Média & Desv. Pad & Min & Max \\
\hline Microdados Censo & & & & & \\
Pobreza Extrema (Rural) & 10,900 & 0.24 & 0.19 & 0.00 & 0.91 \\
Pobreza (Rural) & 10,900 & 0.42 & 0.24 & 0.00 & 1.00 \\
Vulneráveis à Pobreza (Rural) & 10,900 & 0.61 & 0.24 & 0.00 & 1.00 \\
Prop. de Analfabetos (Rural) & 10,900 & 0.36 & 0.13 & 0.00 & 0.88 \\
Prop. de Fundamental Completo (Rural) & 10,900 & 0.36 & 0.10 & 0.00 & 1.00 \\
Prop. de Ensino Médio Completo (Rural) & 10,900 & 0.16 & 0.07 & 0.00 & 1.00 \\
Prop. de Ensino Superior Incompleto (Rural) & 10,900 & 0.10 & 0.07 & 0.00 & 1.00 \\
Prop. de Ensino Superior Completo (Rural) & 10,900 & 0.01 & 0.02 & 0.00 & 0.21 \\
Prop. com Carteira Assinada (Rural) & 10,900 & 0.09 & 0.08 & 0.00 & 1.00 \\
Prop. de Pretos e Pardos (Rural) & 10,900 & 0.50 & 0.27 & 0.00 & 1.00 \\
Mãe Chefe de Família & 10,900 & 0.17 & 0.09 & 0.00 & 0.78 \\
Prop. que Sempre Morou (Rural) & 10,900 & 0.65 & 0.19 & 0.00 & 1.00 \\
Prop. que Nasceu na UF (Rural) & 10,900 & 0.89 & 0.13 & 0.00 & 1.00 \\
Fecundidade (Rural) & 10,900 & 3.11 & 0.68 & 0.00 & 7.44 \\
Prop. Domicílios com Energia Elétrica & 10,900 & 0.92 & 0.14 & 0.00 & 1.00 \\
Dummy Elegíveis ao LPT & 10,900 & 0.31 & 0.46 & 0.00 & 1.00 \\
Prop. Domicílios com Acesso a Sanitário & 10,900 & 0.88 & 0.18 & 0.00 & 1.00 \\
Prop. Domicílios Instalação Sanitária & 10,900 & 0.26 & 0.30 & 0.00 & 1.00 \\
Bolsa Família (milhões de Reais) & 10,900 & 1.20 & 4.16 & 0.00 & 182 \\
População Urbana (mil habitantes) & 10,900 & 23.02 & 164.10 & 0.00 & $11,152.34$ \\
\hline
\end{tabular}

Nota: dados de um painel balanceado a partir das AMCs de compatibilização entre 2000 e 20105.450 polígonos em cada período. As variáveis de pobreza estão em proporção a sua respectiva população, por exemplo: Pobreza Extrema (Rural) representa a porcentagem de habitantes do campo em situação de pobreza extrema nas AMCs com relação a população rural do respectivo local. Os dados de rendimento dos indivíduos em 2000 foram corrigidos para o mês de referência de 2010 a partir do IPCA acumulados entre os períodos

Tabela 2.3 - Estatísticas Descritivas

\subsection{Metodologia}

No âmbito metodológico, optou-se por utilizar técnicas econométricas com dados em painel para estimar os possíveis efeitos da urbanização, captada pelas variáveis de luminosidade noturna, nos indicadores de pobreza rural nas Áreas Mínimas Comparáveis do Brasil. Esta seção apresenta as etapas de estimação utilizadas para compor os resultados da seção 3, seguindo a ordem de apresentação, tem-se: a especificação dos modelos de Efeitos Fixos, com base na literatura clássica de dados em painel; os modelos de Erros Espaciais, a partir das técnicas de econometria espacial, e a estratégia de estimação via Variáveis Instrumentais com Erros Espaciais, com a discussão sobre os Instrumentos utilizados, e a correção para os erros espacialmente correlacionados. 


\subsubsection{Os modelos de painel com Efeitos Fixos}

Haja vista o painel balanceado apresentado na seção 2.1 de base de dados, uma primeira análise das relações entre as variáveis de luminosidade e os indicadores de pobreza poderia ser a partir de modelos com Efeitos Fixos das AMCs. A estrutura de dados em painel permite captar os efeitos das variáveis ao longo do tempo, o que até então era inviável nos modelos com dados transversais, em Cross Section. Nesse caso, possíveis heterogeneidades não observadas das unidades de análise são controladas na estimação de modelos com Efeitos Fixos, desde que elas sejam constantes para cada AMC ao longo do tempo (CAMERON; TRIVEDI, 2005).

A especificação do modelo de Efeitos Fixos para a variável de interesse $y_{m t}$, como por exemplo o número de habitantes em situação de pobreza extrema rural, pode ser observada na equação 2.2 a seguir:

$$
y_{m t}=\Phi_{0}+\Theta_{m}+\Phi_{1} L u m . \_21 \_e \_53_{m t}+\sum_{j=1}^{J} \gamma_{j} x_{j m t}+u_{m t}
$$

Ainda no exemplo acima, $y_{m t}$ corresponde ao número de habitantes em situação de pobreza extrema rural na AMC $m$ no período $t$. $\Phi_{0}$ indica o intercepto da regressão, $\Theta_{m}$ capta os Efeitos Fixos da AMC $m$ em questão, Lum._21_e_53 ${ }_{m t}$, indica a área da AMC $m$ no período $t$ que possuía uma luminosidade entre 21 e $53 \mathrm{DN}$ - as explicações dessa classificação da luminosidade estão na seção 2.1 de base de Dados. Essa variável é utilizada como proxy do crescimento urbano incipiente das AMCs, a saber, das cidades menores e/ou das regiões mais periféricas das grandes cidades.

Outras variáveis são utilizadas como controle nas regressões e estão no conjunto $x_{j}$ para $j=1,2, \ldots, J$, é o caso, por exemplo, da área com Luminosidade acima de $53 \mathrm{DN}$, apresentada como luminosidade central na seção 2.1. Além disso, controlou-se pelas variáveis de capital humano, tais como níveis de escolaridade médias da AMC $m$ no período $t$, características demográficas da população, programas de transferência de renda para os indivíduos em situação de pobreza, tais como o Programa Bolsa Família, e as variáveis de uso da terra, para agricultura e para vegetação nativa.

Essas covariadas se mantiveram presentes em todos os modelos com indicadores de pobreza rural apresentados no capítulo 3 de resultados. Sob a hipótese de distribuição normal dos erros, $u_{m t} \sim \mathscr{N}\left(0, \sigma^{2}\right)$, estimou-se os parâmetros de interesse pelo método de Máxima Verossimilhança, usualmente utilizado nesses casos. Entretanto, essa especificação de estimação impõe, implicitamente, duas hipóteses que talvez sejam fortes demais para o presente estudo: a inexistência da correlação espacial e a exogeneidade das covariadas utilizadas, incluindo a Lum._21_e_5 3 t . 
A subseção 2.3 a seguir apresenta a discussão e a especificação da incorporação da correlação espacial a partir de um modelo de Erros Espaciais com dados em painel e a seção 2.2.4 apresenta a estratégia da estimação via variáveis Instrumentais a partir do Programa Luz para Todos e a topografia.

\subsubsection{Os modelos de painel com Erros Espaciais}

A utilização de dados espaciais, tais como variáveis atreladas aos municípios, Estados, países, entre outros, pode apresentar características espaciais peculiares, como já dizia Tobler (1970): "Tudo está relacionado com tudo o resto, mas coisas próximas estão mais relacionadas do que coisas distantes". No jargão de econometria e estatística espacial, esses casos são marcados pela violação da hipótese de independência espacial das unidades de análise e o resultado disso pode acarretar em estimadores viesados e/ou inconsistentes (LESAGE, 2014).

Existem algumas maneiras de analisar a necessidade da inclusão de defasagens espaciais nos modelos de painel, uma delas foi proposta por Baltagi e Liu (2008), que testa a persistência de correlação espacial dos resíduos, a partir de uma matriz de vizinhança especificada. Sob a hipótese nula de que não há correlação espacial nos resíduos dos modelos de efeitos fixos estimados, o teste aponta um possível problema de especificação no modelo em caso da hipótese nula ser rejeitada.

No que tange as defasagens espaciais citadas, existe uma vasta gama de modelos com diferentes propósitos, como por exemplo: a defasagem na variável dependente, nas covariadas, e/ou no termo de erro. Os modelos espaciais permitem todas as combinações possíveis formando assim um conjunto extenso de modelos espaciais com interpretações e finalidades distintas. Note que cada uma das especificações implicará em canais diferentes de atuação das relações entre as unidades de análise e seus respectivos vizinhos.

Na literatura de econometria espacial exite nomenclaturas distintas para os modelos, no presente estudo utilizou-se a taxonomia proposta por LeSage e Pace (2009) e Vega e Elhorst (2013). Desta forma, o modelo de Erros Espaciais é conhecido como SEM, da sigla em inglês, sob o mesmo conjunto de variáveis apresentados no modelo de Efeitos Fixos, tem-se:

$$
\begin{aligned}
& y_{m t}=\Phi_{0}+\Theta_{m}+\Phi_{1} L u m . \_21 \_e \_53_{m t}+\sum_{j=1}^{J} \gamma_{j} x_{j m t}+u_{m t} \\
& u_{m t}=\rho W^{*} u_{m t}+\epsilon_{m t} \quad \text { sendo } \quad|\rho|<1
\end{aligned}
$$

Como se pode notar, essa especificação corresponde a um modelo de Erros Espaciais com dados em painel, como proposto por Elhorst (2014). O conjunto de covariadas utilizadas nesse caso é o mesmo da apresentada na equação 2.2 de Efeitos Fixos. Pelas condições de estacionaridade do modelo, assume-se que $|\rho|<1$, o que pode ser interpretado como um 
decaimento dos distúrbios no espaço, o choque será menor nos vizinhos em comparação com a região, e ainda menor nos vizinhos dos vizinhos, e assim por diante.

O componente novo na estimação do modelo SEM é a matriz de vizinhança $W^{*}$ que está no termo de erro $u_{m t}$. Como a escolha da matriz precede o modelo e pode influenciar no resultado, o apêndice F contém os critérios utilizados para utilização da matriz de contiguidade do tipo Rainha, utilizada no presente estudo. Ademais, no capítulo 3 de resultados estão os parâmetros estimados com outras especificações de matrizes de vizinhança para fins de robustez.

A questão das variáveis espacialmente correlacionadas pode ser corrigida a partir do modelo SEM apresentado, entretanto, uma possível relação de simultaneidade entre a variável de luminosidade e o indicador de pobreza pode resultar em estimadores viesados e inconsistentes, caso não sejam estimados com choques exógenos da covariada. Nesse contexto, e especificação via Variáveis Instrumentais pode ser uma saída para se realizar inferências causais a partir de estimadores consistentes ${ }^{16}$. Tendo em vista isso, na subseção seguinte discute-se propostas de utilizar instrumentos advindos da Topografia e do Programa Nacional de Universalização do Acesso e uso da Energia Elétrica - Luz Para Todos (LPT) para captar choques exógenos da variável de luminosidade $L u m . \_21 \_e \_53_{m t}$.

\subsubsection{O Programa Luz para Todos e a Topografia}

Múltiplos fatores podem aumentar a luminosidade de uma região, como: o aumento da mancha urbana, a construção de polos industriais, o loteamento de casas em regiões até então sem energia elétrica, e as construções de infraestruturas (escolas, hospitais, etc), é possível que exista um viés de simultaneidade entre os indicadores de pobreza e o nível de luminosidade local. Ainda no exemplo da variável do indicador de pobreza rural extrema, $y_{m t}$, uma relação de simultaneidade entre a variável de luminosidade $L u m$. $21 \_e \_53_{m t} \mathrm{e}$ esse indicador de pobreza pode resultar em estimadores inconsistentes, tanto no modelo de Efeitos Fixos quanto no de Erros Espaciais.

Imagine que nos dados sistematizados entre os períodos de 2000 e 2010 registrou-se um aumento da luminosidade e, concomitantemente, um decréscimo do número de pessoas em situação de pobreza extrema nas zonas rurais. Uma pergunta possível seria se a diminuição da pobreza não proporcionou o aumento da luminosidade, ou se o aumento da luminosidade colaborou à redução da pobreza local. Pode ser que ambos os efeitos ocorram em diferentes regiões do país, portanto, para analisar o efeito do crescimento da luminosidade na pobreza rural é necessário obter choques exógenos de luz. Essa é a motivação para a utilização das estimações de modelos com variáveis instrumentais. Essa subseção apresenta a construção

\footnotetext{
${ }^{16}$ Essas propriedades das estimações via Variáveis Instrumentais acontecem caso os Instrumentos sejam fortes e com alto poder de explicação
} 
dos instrumentos a partir do Programa Luz para Todos (LPT) e a Topografia do país que, conjuntamente, forneceram choques exógenos de luminosidade nas AMCs potencialmente elegíveis ao programa.

O programa Luz para Todos (LPT) se consolidou como o maior programa de eletrificação em áreas rurais do país, fornecendo luz elétrica, muitas vezes de maneira gratuita, para comunidades até então excluídas do acesso a esse bem. Entre as diretrizes, priorizou-se beneficiários do Programa Brasil sem Miséria ${ }^{17}$, escolas rurais, quilombolas, indígenas, assentamentos, ribeirinhos, pequenos agricultores, famílias em reservas extrativistas, afetadas por empreendimentos do setor elétrico e poços de água comunitários.

Segundo o levantamento do Censo Demográfico do IBGE de 2000 (IBGE, 2000), dois milhões de famílias viviam no meio rural sem acesso a energia elétrica, desse total, $90 \%$ viviam com até três salários mínimos, sendo $33 \%$ com menos de um salário mínimo ${ }^{18}$ (FREITAS; SILVEIRA, 2015).

Em vista disso, o Programa Luz para Todos foi aprovado no fim de 2003 e tinha como meta universalizar o acesso a energia elétrica no meio rural até 2008. Apesar de não ter atingido completamente o esperado, houve uma ampliação significativa no acesso a esse bem, com $80 \%$ das novas conexões realizadas, 2,6 milhões em número totais, entre 2004 e 2010. Outra questão importante se deu na focalização do programa, com aproximadamente $50 \%$ do total de conexões concentradas nas regiões Norte e Nordeste (BRANCHER, 2019). Entre 2004 e 2008 foram investidos R $\$ 20$ bilhões de reais no programa.

Do ponto de vista da estruturação do programa, o LPT se constituiu como uma política pública federal coordenada pelo Ministério de Minas e Energia e operacionalizada com a participação das Companhias Elétricas Brasileiras, como é o caso da Eletrobras e de suas empresas. Dentre os objetivos específicos do programa, elucidados por Freitas e Silveira (2015), destacam-se:

- Melhorar a prestação de serviços à população beneficiada;

- Intensificar o ritmo de atendimento;

- Mitigar o potencial impacto tarifário, por meio da alocação de recursos subvencionados e pelo complemento de recursos financiados;

- Incremento da produção agrícola;

- Inclusão social da população beneficiada;

\footnotetext{
${ }^{17}$ Para mais informações sobre o programa, consulte: (CAMPELLO; FALCÃO; COSTA, 2014; PAIVA; FALCÃO; BARTHOLO, 2013; FALCÃO; COSTA, 2014)

${ }^{18}$ Em 2000, o salário mínimo nacional era de R\$151,00
} 
Com o suporte da metodologia de modelo lógico, Freitas e Silveira (2015) avaliaram a primeira etapa do programa LPT, entre 2003 a 2011 e apresentaram alguns impactos de curto prazo mensurados pelo programa, como: a melhoria nas atividades escolares, dada a expansão de aulas no período noturno, aumento no consumo de bens elétricos nas regiões que até então não tinham acesso a energia elétrica. De todo modo, os autores destacam que um efeito não esperado na concepção teórico do programa e que foi verificada foi o retorno do homem ao campo.

Os resultados da Pesquisa Quantitativa Domiciliar de Avaliação da Satisfação e de Impacto do Programa Luz para Todos (MME, 2009) mostraram que 96.000 famílias retornaram para as suas respectivas áreas rurais, o que equivale a 480.000 pessoas. Esse resultado deve ser visto com cuidado, pois não ponderou o saldo líquido das migrações, o qual contabiliza o fluxo das emigrações e imigrações para o campo. Tendo em vista os investimentos federais para o programa LPT entre os períodos de análise do presente estudo e os resultados verificados em pesquisas de avaliação de impacto, a forma como o programa atendeu os municípios brasileiros possibilita a obtenção de choque exógenos de luminosidade.

O primeiro ponto a se destacar é que os dados disponíveis referentes aos investimentos do programa LPT contemplam apenas a nível estadual, o que impossibilita a construção de um painel municipal sobre os recursos alocados. Haja vista que o programa seguiu diretrizes desde novembro de 2003, data de início da execução do projeto, o intuito do presente estudo é inferir a luminosidade secundária advinda do LPT, a partir dos critérios de elegibilidade do programa e da topografia a qual influencia o custo de provenção da energia elétrica. Com base nos objetivos gerais e específicos apresentados por Freitas e Silveira (2015), os critérios de elegibilidade, tornando um município elegível a receber aportes de investimento em construção de linhas de transmissão, cabeamento e outros procedimentos necessários para prover o acesso a energia elétrica nos domicílios, utilizados na concepção do programa seguiram as seguintes características:

- Municípios com menos de 85\% dos domicílios com acesso a energia elétrica com base no Censo Demográfico de 2000 (IBGE, 2000);

- Municípios com Índice de Desenvolvimento Humano (IDH) inferior a média do Estado;

- Comunidade afetadas pela construção de hidroelétricas ou por sistemas de transmissão de energia os quais não contemplavam atendê-las;

- Projetos de eletrificação rural com metas na utilização de eletricidade na promoção de desenvolvimento integrado;

- Escolas públicas, hospitais e centros de saúde;

- Vilarejos rurais; 
- Desenvolvimento da agricultura de subsistência ou produção de artesanato;

- Estabelecimentos rurais de pequeno e médio porte;

- Projetos de eletrificação rural para populações que habitam próximas as Unidades de Conservação ${ }^{19}$ (UCs) de uso sustentável;

- Projetos de eletrificação para populações em áreas específicas utilizadas por comunidades tradicionais, tais como minorias raciais, se referindo a comunidades extrativas e/ou quilombolas.

A amplitude de critérios de elegibilidade é consistente com o objetivo principal de universalização do acesso a energia elétrica, entretanto, os resultados apontam que a alocação dos recursos seguiu, majoritariamente, o primeiro critério citado. outrossim, as análises de custo foram levadas em consideração.

Um dos principais fatores que influenciam o acesso a energia elétrica está ligado a presença das linhas de transmissão, e o custo de construção das mesmas depende essencialmente do relevo (LIMA, 2012). No caso do Programa Luz para Todos a priorização se deu de maneira a afetar o maior número de pessoas, dado um custo de promoção.

Em outras palavras, suponha dois municípios, ambos com mil habitantes sem energia elétrica, a ordem de prioridade do investimento seguiu o projeto menos custoso, do ponto de vista de construção da malha de transmissão até o local. Portanto, a função custo de prover a energia, se bem especificada, é um choque exógeno de luminosidade, dado que independe dos municípios do subconjunto dos elegíveis. A estratégia de construção dos instrumentos a partir da topografia da região como choque exógeno na função custo foi inspirada no trabalho de Dinkelman (2011) para a África do Sul, que também vivenciou por uma política pública de eletrificação.

Os critérios de elegibilidade tiveram como base Brancher (2019), que utilizou a probabilidade do município receber os investimentos do Programa Luz para Todos com base nas informações da porcentagem de domicílios com energia elétrica em 2000, as condições geográficas como aclividade e altimetria, entre outros. Deste modo, se o modelo estiver bem especificado, a variação exógena de luminosidade será captada pela combinação dos elegíveis ao LPT e a topografia.

Como se pode notar, há uma forte concentração das AMCs elegíveis ao programa Luz para Todos nas regiões Norte e Nordeste, além de localidades no norte de Minas Gerais e locais mais pontuais nos demais Estados do Centro-Sul. Desta forma, os choques exógenos

\footnotetext{
${ }^{19}$ As unidades de conservação (UCs) são legalmente instituídas pelo poder público, nas suas três esferas (municipal, estadual e federal). Elas são reguladas pela Lei no. 9.985, de 2000, que institui o Sistema Nacional de Unidades de Conservação (SNUC). Estão divididas em dois grupos: as de proteção integral e as de uso sustentável (WWF, 2019)
} 


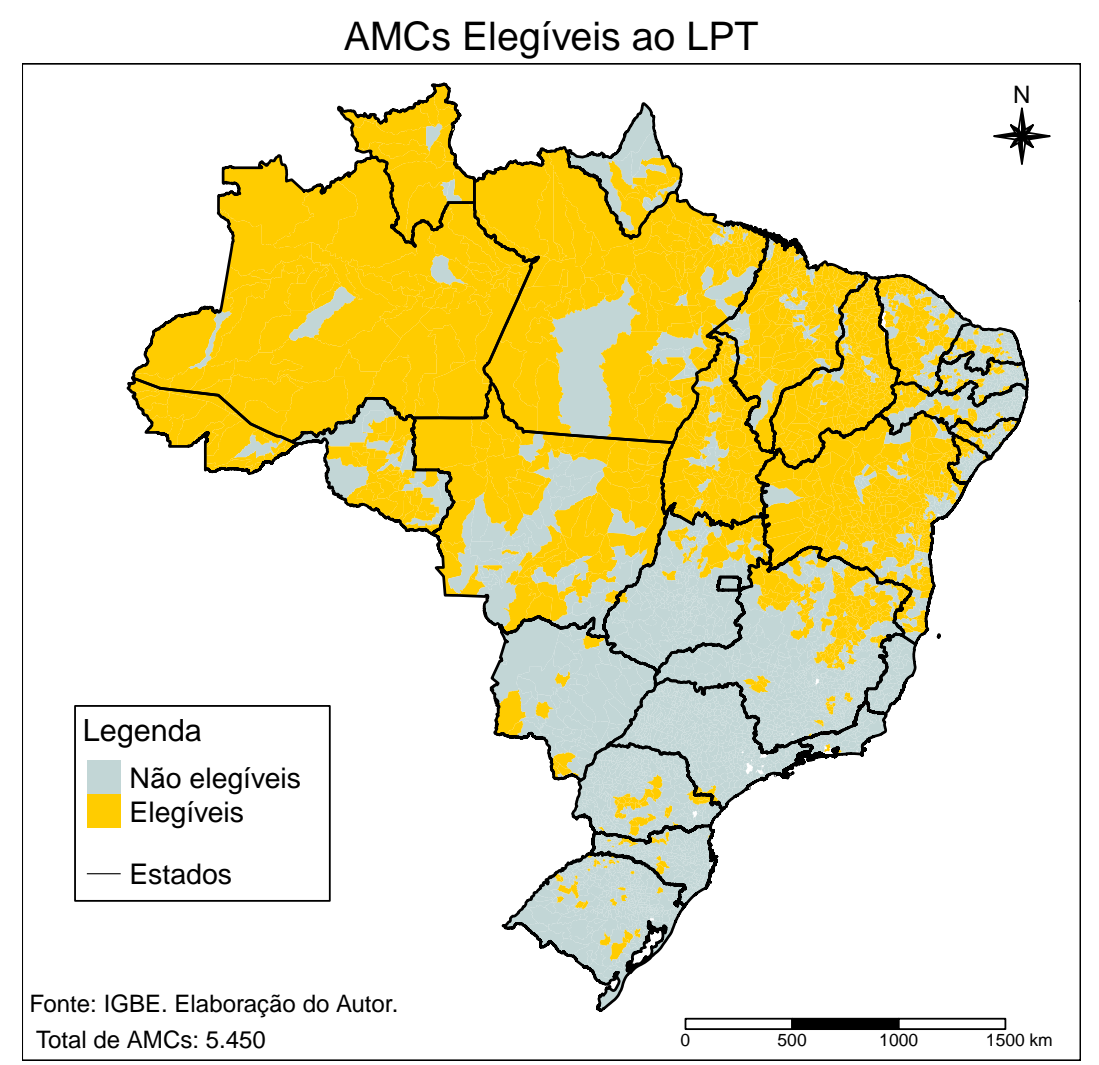

Figura 2.4 - Distribuição espacial da elegibilidade ao LPT

de luminosidade. Uma questão que surge dessa visualização espacial é que os resultados dos modelos terão como base os choques de luminosidade, majoritariamente das regiões supracitadas.

A questão dos instrumentos para os dados de Luminosidade secundária parecem ser relevantes, entretanto, no caso da Luminosidade Central, isso parece não ser aplicável. Como se pode notar na tabela 2.1 apresentada na subseção 2.1.1.2, em 2000 a base de AMCs utilizada apresentou apenas 482 com dados de luminosidade acima de $53 \mathrm{DN}$, dentre as 5.450 AMCs da base, desses, apenas 6 possuíam menos de 85\% dos domicílios com luz elétrica, sendo 3 acima de $80 \%$.

Deste modo, o critério de elegibilidade do programa Luz para Todos indica que esse conjunto de municípios com luminosidade acima de 53 DN não receberam investimento do programa. Ademais, das 545 novas AMCs, que não possuíam luminosidade de 53 DN em 2000 e registraram 2010, 79 possuíam menos de $85 \%$ dos domicílios, sendo que 33 possuíam mais que $80 \%$ em 2000.

Portanto, AMCs que possuíam luminosidade acima de 53 DN em 2000 não eram elegíveis ao programa, assim como as AMCs que não tinham essa luminosidade em 2000, mas adquiriram em 2010. Uma hipótese que parece razoável é de que essa faixa de luminosidade não parece estar atrelada ao programa Luz para Todos. Por isso, os instrumentos serão 
aplicados na variável de luminosidade secundária.

\subsubsection{A estratégia de Variáveis Instrumentais}

Tendo em vista o Programa Luz para Todos e as questões de aclividade do Terreno, esta seção apresenta a estratégia de Variáveis Instrumentais com Erros Espaciais utilizada para captar choques exógenos de luminosidade e assim, estimar os efeitos do crescimento da luminosidade nos indicadores de pobreza rural. No que tange a correção dos resíduos, espacialmente correlacionados, utilizou-se a especificação do modelo de Erros Espaciais no segundo estágio do modelo.

Esta subseção apresenta as etapas de estimação utilizadas para compor os principais resultados da seção 3 de resultados. A estimação desses modelos se deu via Método dos Momentos Generalizados (GMM, da sigla em inglês), mais especificamente, estimou-se um GMM factível com a matriz de vizinhança no termo de erro do segundo estágio. A equação 2.4 a seguir apresenta a regressão do primeiro estágio, enquanto que a 2.5 indica o passo subsequente da estimação:

$$
\begin{aligned}
& \text { Lum._21_e_53 } 3_{m t}=\beta_{0}+\theta_{m}+\beta_{1} D_{2010}+\beta_{2}\left(D_{2010} * D_{\text {Elegibilidade }} * \text { Inclinacao }\right)+ \\
& \beta_{3}\left(D_{2010} * D_{\text {Elegibilidade }}\right)+\beta_{3} D_{2010} * \text { Inclinacao }+ \\
& \beta_{4} \text { Sanitario }+\beta_{5} \text { Saneamento }+\sum_{j=1}^{J} \delta_{j} x_{j m t}+\eta_{m t} \\
& y_{m t}=\Phi_{0}+\Theta_{m}+\Phi_{1} L u m \cdot \overline{2_{2}{ }_{-} e_{-}} 53_{m t}+\sum_{j=1}^{J} \gamma_{j} x_{j m t}+u_{m t} \\
& u_{m t}=\rho W^{*} u_{m t}+\epsilon_{m t} \quad \text { sendo } \quad|\rho|<1
\end{aligned}
$$

Apesar de ambos os estágios serem estimados simultaneamente no GMM, a apresentação dos mecanismos de estimação será dividida em dois estágios. A equação 2.4 supracitada corresponde ao primeiro estágio, no qual a variável dependente, $L u m$._21_e_53 $m t$, indica a área do município $m$ no período $t$ que possuía uma luminosidade entre 21 e $53 \mathrm{DN}$ citada nas subseções anteriores. O intuito dessa regressão é captar variações exógenas da luminosidade que serão utilizadas no segundo estágio, representado pela equação 2.5.

Alguns comentários sobre os parâmetros da equação: o $\beta_{0}$ corresponde ao intercepto; $\theta_{m}$ é o efeito fixo da AMC $m ; \beta_{1}$ capta o efeito do tempo a partir da dummy para o ano 2010, $D_{2010} ; \beta_{2}$ indica o efeito marginal da combinação de três variáveis, sendo elas: a dummy de ano, a dummy para as AMCs elegíveis ao programa LPT, que possuíam menos de $85 \%$ dos domicílios com acesso a energia elétrica no Censo Demográfico de 2000, DElegibilidade, e a de inclinação, Inclinacao, que indica o nível de aclividade do terreno. 
Os parâmetros $\beta_{3}$ e $\beta_{4}$ indicam as combinações dois-a-dois da dummy de ano com as variáveis $D_{\text {Elegibilidade }}$ e Inclinacao, respectivamente. Deste modo, capta-se o efeito de ambas as variáveis no tempo, tudo mais constante. O parâmetro $\beta_{4}$ controla o efeito da proporção dos domicílios com acesso a esgoto, Sani tário, enquanto que o $\beta_{5}$ controla o efeito da proporção dos domicílios com saneamento básico, Saneamento. Por fim, os parâmetros $\delta_{j}$, para $j=1,2, \ldots J$, controlam o efeito das covariadas que serão utilizadas no segundo estágio do modelo, representado pela equação 2.5 .

Deste modo, se o primeiro estágio do modelo estiver bem especificado, o valor predito da variável de luminosidade $L u m . \widehat{21 \_} e_{-} 53_{m t}$ corresponde aos choques exógenos nas covariadas de interesse. É importante ressaltar que o valor predito da Lum._21_e_53 $m t$ capta os efeitos da luminosidade na AMC advindas de investimentos do programa LPT.

Sob as hipóteses de inexistência de correlação espacial e da distribuição normal dos erros, $u_{m t} \sim \mathscr{N}\left(0, \sigma^{2}\right)$, esse modelo poderia ser estimado a partir da metodologia clássica de Variáveis Instrumentais, como será apresentado na seção 3 de resultados. Entretanto, como será notado no capítulo 3 de resultados sobre investigação espacial, a hipótese de que não há correlação espacial dos resíduos parece ser forte demais, o que pode resultar em estimadores viesados e inconsistentes (ARBIA, 2014; ELHORST, 2003; LESAGE, 2014). Uma tentativa de corrigir os possíveis erros de estimação dos modelos sem o controle espacial pode recorrer aos modelos de Erros Espaciais com Variáveis Instrumentais, que correspondem a equação 2.5 .

As características 2.5 são análogas ao modelo de Erros Espaciais apresentados na subseção 2.3, a diferença se dá na variável de luminosidade secundária, entre 21 e 53 DN, que agora é substituída pelo predito do primeiro estágio, isso implica em correções nos desvios padrões, como proposto por Kelejian, Prucha e Yuzefovich (2004). Os modelos foram estimados com base nas contribuições de Millo, Piras et al. (2012) com o pacote SPLM software estatístico do R (R CORE AND OTHERS, 2013). 


\section{RESULTADOS}

Haja vista a estratégia empírica apresentada no capítulo 2, composta pela base de dados, seção 2.1, e metodologia, seção 2.2, o presente capítulo contém os principais resultados do trabalho. A primeira análise apresentada, na seção 3.1, investiga a dependência espacial das três variáveis de pobreza rural, sendo elas a proporção da pobreza extrema rural, a proporção da pobreza rural, e dos vulneráveis à pobreza nas Áreas Mínimas Comparáveis do Brasil.

A seção 3.2, por sua vez, foca nos resultados dos modelos para a variável de pobreza extrema rural e, em sequência, encontra-se na seção 3.3 os resultados para as demais linhas de pobreza supracitadas. Por fim, a seção 3.4 apresenta os resultados dos modelos com novas especificações, com mudanças nas escolhas da delimitação do crescimento das cidades a partir da luminosidade, e com novas especificações das matrizes de vizinhança para fins de robustez.

\subsection{Investigação da dependência espacial}

Os modelos espaciais surgem como uma tentativa de corrigir possíveis vieses advindos da correlação espacial das variáveis e que podem incorrer em problemas nas estimações de modelos clássicos de painel. O primeiro passo para verificar a necessidade de tal especificação parte da análise do padrão espacial das variáveis tratadas, no caso, os indicadores de proporção de indivíduos em situação de pobreza extrema em 2000 e 2010, tanto para o subconjunto da população que vive nas áreas rurais, quanto para os habitantes urbanos.

Nos modelos em Cross Section, a literatura utiliza estatísticas descritivas, tais como o I de Moran, que verifica a disposição espacial de uma dada variável. A figura 3.1 apresenta a distribuição espacial dos três indicadores de pobreza para os anos 2000 e 2010. Nesse caso, se não houvesse correlação espacial nas variáveis em questão era de se esperar uma reta com inclinação zero, paralela à abcissa.

Entretanto, como se pode verificar, em todos os casos há uma inclinação positiva, o que sugere uma correlação espacial positiva. Tendo como exemplo as figuras 3.1a e 3.1b referentes a linha de pobreza extrema rural, pode-se observar que AMCs com baixos níveis dessa variável se encontram próximo de outras AMCs com indicadores semelhantes, a interpretação é análoga para regiões com elevados indicadores de pobreza rural extrema. Uma ressalva importante é que, além da correlação espacial, há também uma correlação temporal entre as observações, a forma de tratar isso é por meio dos modelos de efeitos fixos em painel.

Outra questão que pode ser observada é a diminuição em termos gerais, da proporção da pobreza. Quando comparado entre os anos 2000 e 2010, nota-se que há um desloca- 
Figura 3.1 - Distribuição espacial dos indicadores de pobreza rural no Brasil

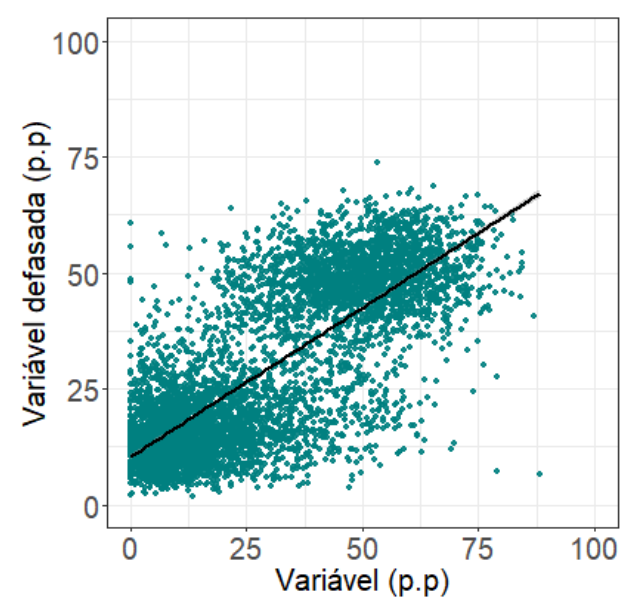

(a) Pobreza rural extrema 2000

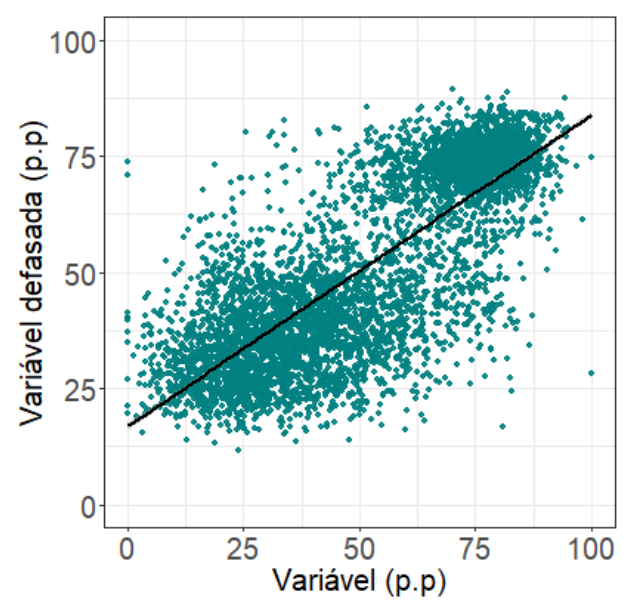

(c) Pobreza rural 2000

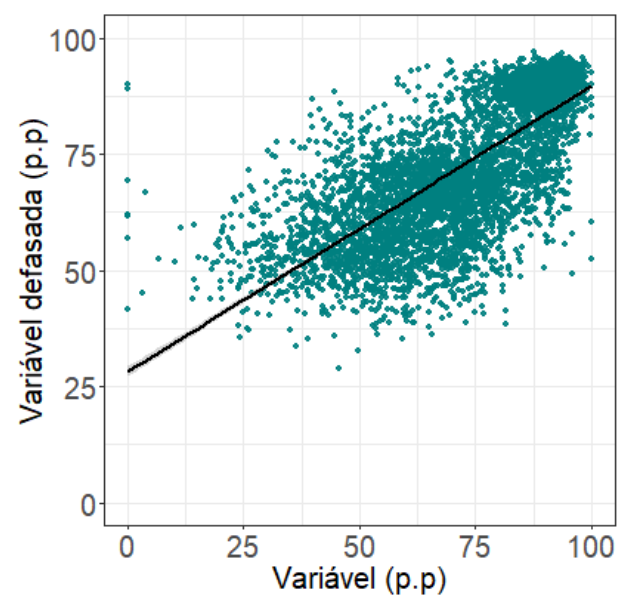

(e) Vulneráveis à pobreza 2000

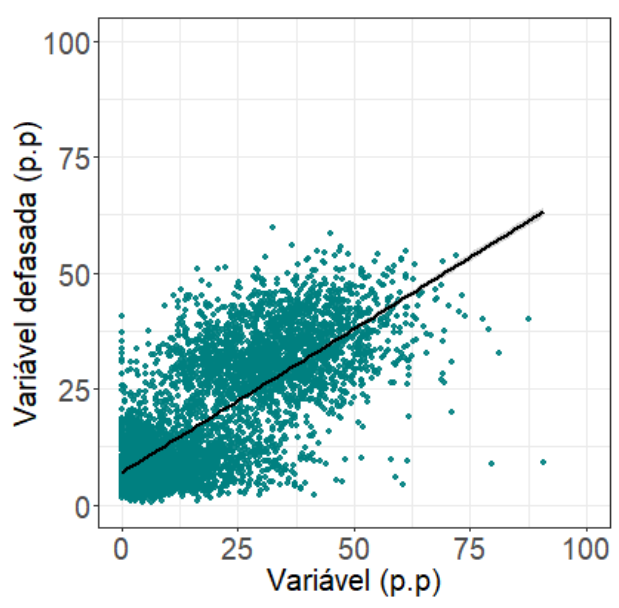

(b) Pobreza rural extrema 2010

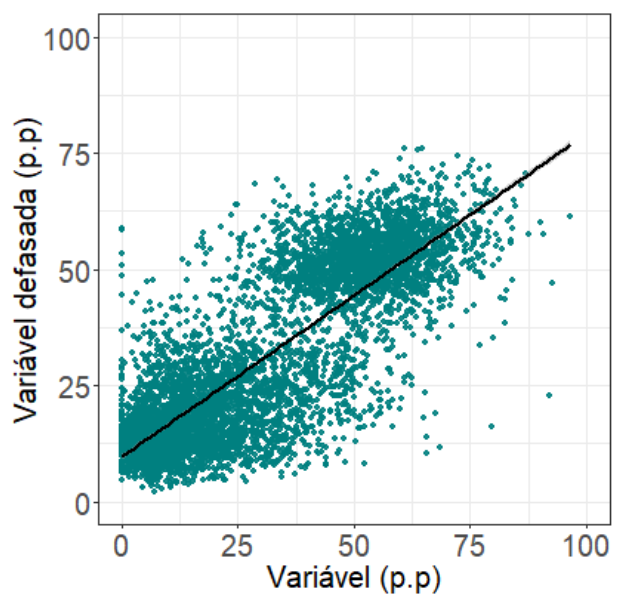

(d) Pobreza rural 2010

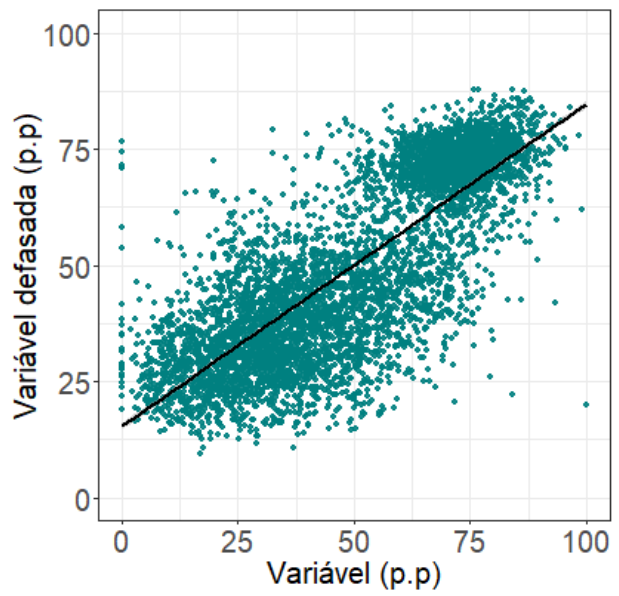

(f) Vulneráveis à pobreza 2010

mento dos pontos do canto superior direito de cada gráfico, para o canto inferior esquerdo, sinalizando um decrescimento da taxa de pobreza para todos os indicadores. Parte dessas informações já tinham se mostrado presentes na apresentação dos mapas de pobreza na seção 2.1 sobre a base de dados, mas nas figuras a seguir o padrão se mostra com maior 
clareza.

Essa apresentação gráfica apenas aponta para uma possível correlação espacial das variáveis, um teste para identificar a presença da correlação espacial foi proposto por Baltagi e Liu (2008) e consiste em verificar a correlação espacial dos resíduos a partir de um modelo de efeitos fixos com dados em painel, e uma matriz de vizinhança previamente especificada.

Portanto, na seção a seguir, apresenta-se os resultados dos modelos em painel com efeitos fixos (EF) e, em sequência, pode-se verificar que a hipótese nula de que não há correlação espacial nos resíduos no teste proposto por Baltagi e Liu (2008) é rejeitada, o que motiva a utilização dos modelos de erros espaciais.

\subsection{Resultados das regressões à pobreza extrema rural}

Em linhas gerais, apresenta-se na tabela 3.2 três modelos estimados com a mesma variável dependente: o total de habitantes em situação de pobreza rural nas AMCs. O modelo (1) apresenta os resultados com a estimação com Efeitos Fixos, o (2) contém os parâmetros estimados com Variáveis Instrumentais apresentadas na seção 2.2, e o (3) o modelo de Erros Espaciais com Variáveis Instrumentais.

Em todos os casos aplicou-se a transformação do arcosseno hiperbólico ${ }^{20}$ para as variáveis explicadas e covariadas. Deste modo, a interpretação dos parâmetros é análoga a e de modelos log-log, a saber, a variação de $1 \%$ em uma dada covariada acarreta em uma alteração de $\beta \%$ na variável dependente. Outra característica comum a todos os modelos é o painel balanceado com a base de dados, foram consideradas 5.450 AMCs em dois períodos, 2000 e 2010.

Além disso, todos os modelos apresentados foram estimados sob a especificação de Efeitos Fixos das Áreas Mínimas Comparáveis ${ }^{21}$, portanto, fatores determinantes para a pobreza rural extrema, como componentes históricos locais, que são constantes ao longo dos períodos de análise são controlados nas especificações apresentadas.

No que tange aos modelos com Variáveis Instrumentais, utilizou-se como primeiro estágio a equação 2.4, para captar choques exógenos da variável de Área com luminosidade entre 21 e 53 DN e utilizar o predito do primeiro estágio em cada uma das especificações. Outra ressalva importante é que em todos os modelos de Erros Espaciais foram estimadas sob a mesma especificação da matriz de vizinhança de contiguidade do tipo Rainha no termo de erro, $\left(W^{*} u_{m t}\right)$, como explicado no apêndice F. Para análise de sensibilidade, a subseção 3.4 contém os resultados do modelo (3) de SEM com IV sob diferentes especificações de matrizes de vizinhança.

\footnotetext{
${ }^{20}$ Para uma dada variável $z_{i}$, a função Arco seno hiperbólico é dada como $\operatorname{arcsen}\left(z_{i}\right)=\ln \left(z_{i}+\left(z_{i}{ }^{2}+1\right)^{1 / 2}\right)$

${ }^{21}$ Para mais informações sobre as AMCs, veja o Apêndice A
} 
Um pouco mais sobre os resultados da tabela 3.2, o modelo (1) apresenta os parâmetros sobre a hipótese de exogeneidade de todas as covariadas do modelo. Dessa forma, as variáveis proxies do crescimento da cidade, sendo a Área com Luminosidade entre 21 e 53 DN a expansão de regiões menos urbanizadas das AMCs e a Área com Luminosidade acima de 53 DN os locais com maior concentração urbana, lembrando que apenas 482 AMCs, ou 8,8\%, possuíam essa luminosidade maior que zero em 2000, e 1027, ou 18,8\%, em 2010.

Assim, ambas as variáveis de luminosidade não apresentam efeitos estatisticamente diferentes de zero no total de habitantes em situação de pobreza extrema rural, controlado pelas demais variáveis. No que tange as variáveis de capital humano, colocou-se como variável omitida a proporção da população acima de 18 anos analfabeta e/ou com ensino fundamental incompleto, de modo que a interpretação das demais variáveis de educação seja feita com base nessa linha do intercepto.

Deste modo, pode-se afirmar que o aumento de $1 \%$ na proporção de habitantes com Ensino Médio Completo com mais de 18 anos, diminui em 1,09\% no número de pessoas em situação de pobreza rural extrema na AMC. As interpretações são análogas para as demais variáveis de educação, com uma ressalva para o a variável de proporção de Ensino Fundamental Completo para esse modelo (1) não se mostrou estatisticamente diferente de zero, sob um nível de $5 \%$ de significância.

A grande questão do modelo (1) apresentado está no fato de assumir duas hipóteses pouco plausíveis: a de exogeneidade de todas as covariadas e a inexistência de correlação espacial das variáveis. Para investigar as implicações dessas premissas no modelo, elaborou-se dois testes, um para cada uma dessas hipóteses.

O primeiro consiste em avaliar a possível endogeneidade da variável de Área com Luminosidade entre 21 e 53 DN e a população em situação de pobreza rural extrema na AMC. O teste proposto por Arellano (1993), indica se os instrumentos utilizados possuem poder explicativo da variável endógena de interesse. Com base na especificação apresentada na seção 2.2 de metodologia, pode-se definir como modelo irrestrito e restrito da seguinte forma:

\section{Modelo Irrestrito:}

Lum._21_e_53 $3_{m t}=\beta_{0}+\theta_{m}+\beta_{1} D_{2010}+\beta_{2}\left(D_{2010} * D_{\text {Elegibilidade }} *\right.$ Inclinacao $)+$

$$
\begin{aligned}
& \beta_{3}\left(D_{2010} * D_{\text {Elegibilidade }}\right)+\beta_{3} D_{2010} * \text { Inclinacao+ } \\
& \beta_{4} \text { Sanitario }+\beta_{5} \text { Saneamento }+\sum_{j=1}^{J} \delta_{j} x_{j m t}+\eta_{m t}
\end{aligned}
$$




\section{Modelo Restrito:}

$$
\text { Lum._21_e_5 } 3_{m t}=\beta_{0}+\theta_{m}+\sum_{j=1}^{J} \delta_{j} x_{j m t}+\xi_{m t}
$$

Assim, o teste proposto por Arellano (1993) consiste em verificar o poder de explicação dos instrumentos utilizados. Os resultados podem ser verificador na tabela 3.1 a seguir:

\begin{tabular}{lrr}
\hline \hline Área com Luminosidade entre 21 e 53 DN & Estatística F & p-valor \\
\hline $\begin{array}{l}\text { Resultado } \\
\text { Modelo Irrestrito vs Modelo Restrito }\end{array}$ & 24.53 & 0.00 \\
\hline \hline
\end{tabular}

Tabela 3.1 - Teste de Wald para dados em painel

Como se pode notar, a hipótese de que o instrumento é fraco na regressão do primeiro estágio é rejeitada, de modo que a inclusão dos instrumentos explica a luminosidade em questão. É importante salientar que esse teste não sinaliza a presença de endogeneidade da variável $L u m$._21_e_5 $3_{m t}$, uma vez que tal hipótese não é testável. O que esse teste permite inferir é que, caso as relações sejam endógenas, a estimação do primeiro estágio com os instrumentos apresentados permite captar choques exógenos de luminosidade.

A segunda questão que se coloca é a possível existência de uma correlação espacial nas variáveis do modelo, o que pode causar inconsistência nos estimadores apresentados. Do ponto de vista empírico, nota-se que regiões com elevados índices de pobreza rural localizam-se próximas a outras regiões em situações semelhantes, o caso ao contrário também é verificado, regiões com baixos índices de pobreza rural estão próximas de regiões parecidas, isso pode ser observado na seção anterior de investigação da correlação espacial.

A fim de testar a hipótese de correlação espacial nos modelos sem a especificação das matrizes de vizinhança, Baltagi e Liu (2008) propôs um teste, sendo a hipótese nula de que os resíduos do modelo estimado não são espacialmente correlacionados. Para investigar no presente estudo, elaborou-se esse teste no modelo (1) de Efeitos Fixos, o qual pode ser observado na tabela 3.3, em sequência.

\begin{tabular}{lrr}
\hline \hline Variáveis & Estatística LM & p-valor \\
\hline Luminosidade Área & & \\
Pobreza Extrema (Rural) & 9.14 & 0.00 \\
Pobreza (Rural) & 10.46 & 0.00 \\
Vulnerável à Pobreza (Rural) & 7.64 & 0.00 \\
\hline \hline
\end{tabular}

Tabela 3.3 - Teste LM de Baltagi e Liu (2008) nas três variáveis de pobreza 


\begin{tabular}{|c|c|c|c|}
\hline & \multicolumn{3}{|c|}{ Pobreza rural extrema } \\
\hline & $\begin{array}{l}\mathrm{EF} \\
(1)\end{array}$ & $\begin{array}{l}\text { IV } \\
(2) \\
\end{array}$ & $\begin{array}{c}\text { SEM com IV } \\
\text { (3) }\end{array}$ \\
\hline Área com Luminosidade entre 21 e 53 DN & $\begin{array}{c}0.22 \\
(0.35)\end{array}$ & $\begin{array}{c}-9.84^{* * *} \\
(1.62)\end{array}$ & $\begin{array}{c}-9.76^{* * *} \\
(1.64)\end{array}$ \\
\hline Área com Luminosidade > 53 DN & $\begin{array}{c}0.81 \\
(0.54)\end{array}$ & $\begin{array}{c}3.34^{* * *} \\
(0.70)\end{array}$ & $\begin{array}{c}3.27^{* * * *} \\
(0.70)\end{array}$ \\
\hline Prop. de Fundamental Completo (Rural) & $\begin{array}{c}0.19 \\
(0.18)\end{array}$ & $\begin{array}{r}-0.56^{*} \\
(0.23)\end{array}$ & $\begin{array}{c}-0.57^{*} \\
(0.23)\end{array}$ \\
\hline Prop. de Ensino Médio Completo (Rural) & $\begin{array}{c}-1.09^{* * *} \\
(0.26)\end{array}$ & $\begin{array}{c}-1.73^{* * *} \\
(0.29)\end{array}$ & $\begin{array}{c}-1.72^{* * *} \\
(0.29)\end{array}$ \\
\hline Prop. de Ensino Superior Incompleto (Rural) & $\begin{array}{c}-2.94^{* * *} \\
(0.29)\end{array}$ & $\begin{array}{c}-3.06^{* * *} \\
(0.31)\end{array}$ & $\begin{array}{c}-3.05^{* * *} \\
(0.31)\end{array}$ \\
\hline Prop. de Ensino Superior Completo (Rural) & $\begin{array}{c}-4.96^{* * *} \\
(0.90)\end{array}$ & $\begin{array}{c}-4.75^{* * *} \\
(0.97)\end{array}$ & $\begin{array}{c}-4.77^{* * *} \\
(0.97)\end{array}$ \\
\hline Prop. com Carteira Assinada (Rural) & $\begin{array}{c}-4.82^{* * *} \\
(0.39)\end{array}$ & $\begin{array}{c}-3.34^{* * *} \\
(0.47)\end{array}$ & $\begin{array}{c}-3.36^{* * *} \\
(0.47)\end{array}$ \\
\hline Bolsa Familia (milhões de Reais) & $\begin{array}{c}-0.05^{*} \\
(0.02)\end{array}$ & $\begin{array}{c}0.13^{* * *} \\
(0.03)\end{array}$ & $\begin{array}{c}0.13^{* * *} \\
(0.04)\end{array}$ \\
\hline Prop. de Pretos e Pardos (Rural) & $\begin{array}{c}0.05 \\
(0.15)\end{array}$ & $\begin{array}{c}0.13 \\
(0.16)\end{array}$ & $\begin{array}{c}0.14 \\
(0.16)\end{array}$ \\
\hline Prop. que Sempre Morou (Rural) & $\begin{array}{c}0.18 \\
(0.20)\end{array}$ & $\begin{array}{l}-0.03 \\
(0.21)\end{array}$ & $\begin{array}{l}-0.03 \\
(0.21)\end{array}$ \\
\hline Prop. que Nasceu na UF (Rural) & $\begin{array}{c}0.23 \\
(0.38)\end{array}$ & $\begin{array}{c}0.66 \\
(0.41)\end{array}$ & $\begin{array}{c}0.66 \\
(0.41)\end{array}$ \\
\hline Razão de dependência (Rural) & $\begin{array}{c}-0.23^{* * *} \\
(0.04)\end{array}$ & $\begin{array}{c}-0.18^{* * *} \\
(0.04)\end{array}$ & $\begin{array}{c}-0.18^{* * *} \\
(0.04)\end{array}$ \\
\hline Fecundidade (Rural) & $\begin{array}{c}0.19 \\
(0.11)\end{array}$ & $\begin{array}{c}0.08 \\
(0.12)\end{array}$ & $\begin{array}{c}0.07 \\
(0.12)\end{array}$ \\
\hline Mãe Chefe de Família & $\begin{array}{c}0.25 \\
(0.18)\end{array}$ & $\begin{array}{l}-0.19 \\
(0.21)\end{array}$ & $\begin{array}{l}-0.18 \\
(0.21)\end{array}$ \\
\hline População Urbana & $\begin{array}{c}0.05 \\
(0.07)\end{array}$ & $\begin{array}{l}0.19^{*} \\
(0.08)\end{array}$ & $\begin{array}{l}0.18^{*} \\
(0.08)\end{array}$ \\
\hline Área de Agropecuária & $\begin{array}{c}0.13 \\
(0.07)\end{array}$ & $\begin{array}{l}0.19^{*} \\
(0.08)\end{array}$ & $\begin{array}{l}0.18^{*} \\
(0.08)\end{array}$ \\
\hline Área Vegetação Nativa & $\begin{array}{c}-0.42^{* * *} \\
(0.10)\end{array}$ & $\begin{array}{c}-0.28^{* *} \\
(0.11)\end{array}$ & $\begin{array}{c}-0.27^{*} \\
(0.11)\end{array}$ \\
\hline População Rural & $\begin{array}{c}1.12^{* * *} \\
(0.04)\end{array}$ & $\begin{array}{c}1.10^{* * *} \\
(0.04)\end{array}$ & $\begin{array}{c}1.10^{* * *} \\
(0.04)\end{array}$ \\
\hline $\begin{array}{l}\text { Observações } \\
\mathrm{R}^{2}\end{array}$ & $\begin{array}{c}10,900 \\
0.42\end{array}$ & $\begin{array}{c}10,900 \\
0.34\end{array}$ & $\begin{array}{c}10,900 \\
0.34\end{array}$ \\
\hline
\end{tabular}

Nota: ${ }^{*} \mathrm{p}<0.1 ;{ }^{* *} \mathrm{p}<0.05 ;{ }^{* * *} \mathrm{p}<0.01$. A situação de Pobreza Extrema é caracterizada por indivíduos com renda domiciliar per capita igual ou inferior a $R \$ 70,00$ mensais, em reais de agosto de 2010. Os dados de rendimento dos indivíduos em 2000 foram corrigidos para o mês de referência de 2010 a partir do IPCA acumulado entre os períodos. Os dados estão em estrutura de Painel balanceado de dois períodos (2000 e 2010) com 5.450 polígonos em cada ano correspondentes as AMCs do Brasil. O modelo (1), EF, corresponde ao de Efeito Fixo Clássico, o (2) corresponde ao modelo com Variáveis Instrumentais (IV), e, por fim, o (3) apresenta os resultados do modelo de Erros Espaciais (SEM) com Variáveis Instrumentais. 
O resultado do teste LM para o modelo (1) de Efeito Fixo está apresentado na linha da tabela, de Pobreza Extrema (Rural). As linha subsequentes, de Pobre (Rural) e Vulnerável à Pobreza (Rural) correspondem aos testes de LM para os modelos de Efeito Fixo nas outras duas linhas de pobreza. Nos três casos, hipótese nula de que não há correlação espacial nos resíduos, a partir da matriz de vizinhança utilizada, é rejeitada, o que sugere a utilização de um tratamento espacial dos modelos. Por isso, estimou-se os modelos de Erros Espacias com Variáveis Instrumentais, o que pode controlar tanto a questão da endogeneidade quanto a correlação espacial dos resíduos.

A utilização da variável de aclividade do terreno como uma função de custo exógena a pobreza segue um pressuposto importante de que a aclividade do terreno é não correlacionada com o total da população em situação de pobreza extrema. Deste modo, regrediu-se, para o ano de 2000, o total de habitantes em situação de pobreza extrema (rural) com as demais variáveis do modelo e com a variável de aclividade do terreno. Como se pode observar no apêndice $\mathrm{D}$, no primeiro período da análise, a variável de aclividade do terreno das AMCs em questão não são correlacionadas com a variável de pobreza extrema, o que contribui para a hipótese de que a aclividade interfere na composição total de pobreza do município apenas pelos choques exógenos de luminosidade.

No caso do modelo (2) da tabela 3.2, estimou-se o modelo com Variáveis Instrumentais, com a especificação apresentada na metodologia. Deste modo, no primeiro estágio, utilizouse os instrumentos para obter variações exógenas da variável "Área de Luminosidade entre 21 e 53 DN“ e assim, acrescentar como covariada os valores preditos para essa variável no primeiro estágio e no segundo estágio.

Os resultados apresentam uma mudança significante do efeito das variáveis de luminosidade, quando comparadas com o modelo (1) já discutido. No caso do modelo (2), o aumento de $1 \%$ da variável "Área de Luminosidade entre 21 e 53 DN“, diminui em 9,84\% o total da população em extrema pobreza que reside nas zonas rurais da AMCs, tudo mais constante.

No caso da variável "Área com Luminosidade > 53 DN", o efeito tem sinal oposto, de modo que o aumento de $1 \%$ da luminosidade aumenta em 3,34\% o número de habitantes em situação de pobreza extrema rural. Mantendo as ressalvas já mencionadas sobre essa variável, esse resultado levanta algumas reflexões sobre a diferença da atuação do crescimento de diferentes tipos de urbanização.

Um canal de atuação possível pode ser a mudança da composição dos habitantes do campo na AMC em análise, enquanto que o avanço da urbanização mais incipiente, marcado pelo crescimento da luminosidade entre 21 e $53 \mathrm{DN}$, pode corresponder a chegada da cidade nos ambientes rurais, uma vez que o Programa Luz para Todos pode ser o primeiro passo para o desenvolvimento local, que é o acesso a energia elétrica. O crescimento dos grandes 
centros urbanos pode afetar de maneira diferente as zonas rurais.

Do ponto de vista da migrações em busca de oportunidades de trabalho, o crescimento do centro urbano mais desenvolvido pode atrair habitantes de outros lugares para a região o que pode aumentar a população, inclusive as que se encontram em situação de extrema pobreza, aumentando a variável dependente. Outro canal pode ser a realocação interna dos habitantes, pois o crescimento da cidade pode afastar os mais pobres das zonas urbanas, por elevação de custos de vida, movendo-os para as zonas campestres, o que novamente aumenta o total de pessoas em situação de pobreza extrema.

Uma questão importante a ser ressaltada nesse modelo é o fato de todas as faixas de educação se apresentarem como redutoras da pobreza, apontando novamente a importância do investimento em capital humano para a redução da pobreza no campo.

Por fim, o modelo (3) corresponde ao principal resultado do presente estudo, por utilizar a técnica de Variáveis Instrumentais na variável de "Área com Luminosidade entre 21 e 53 DN“ e, além disso, utilizar a matriz de vizinhança de contiguidade do tipo Rainha nos termos de erro, para controlar a correlação espacial das variáveis, como apontou o teste LM proposto por Baltagi e Liu (2008). Como se pode observar os sinais dos parâmetros estimados seguem a mesma dinâmica do modelo (2), esse resultado é esperado, uma vez que a grande diferença entre um resultado e o outro é a correção dos erros-padrões dos estimadores, e o fato da estimação do modelo (3) ser feita a partir do método GMM, apresentado na seção 2.2 de metodologia.

Assim, o aumento de 1\% da variável "Área de Luminosidade entre 21 e 53 DN" no modelo (3), diminui em 9,76\% o total da população em extrema pobreza que reside nas zonas rurais da AMCs, tudo mais constante. No caso da variável "Área com Luminosidade > 53 DN“, o efeito novamente tem sinal oposto, de modo que o aumento de $1 \%$ da luminosidade aumenta em 3,27\% o número de habitantes em situação de pobreza extrema rural. Mantendo as ressalvas já mencionadas sobre essa variável.

Desta forma, destaca-se novamente os resultados contrários entre o crescimento da urbanização dos grandes centros, e o das regiões mais incipientes. A variável Área de Agropecuária, captada pelo Mapbiomas (SOUZA; AZEVEDO, 2017) como o total da área da AMC destinada a agricultura e pecuária, apresentou resultados positivos e significantes a $5 \%$ nos modelos (2) e (3) apresentados. Tal resultado promove uma reflexão da dinâmica entre o crescimento do agronegócio e possíveis impactos na população.

Uma afirmação mais contundente sobre a relação entre o avanço da agropecuária e a dinâmica das pessoas em situação de pobreza rural extrema nas AMCs necessitaria de pesquisas com enfoque nessa questão, mas a discussão pode ter inspiração no fato do crescimento das áreas de agropecuária entre 2000 e 2010 terem sido voltadas a monoculturas, como soja, cana de açúcar, entre outras, que, ao mesmo tempo que ampliaram suas áreas 
de atuação, aumentaram também a mecanização (WEINHOLD; KILLICK; REIS, 2013). Esse processo pode resultar em aumento da renda média da população, porém, pode também acarretar em aumento da desigualdade, pelo fato de não beneficiar os mais pobres da região.

Outro ponto importante de ser ressaltado é o fato da análise do total de habitantes em situação de pobreza nesse caso se limitar a duas fotografias dos municípios brasileiros, no caso em 2000 e 2010. Desta forma, não é possível analisar os possíveis efeitos da urbanização nos indivíduos residentes no campo, nota-se apenas os efeitos agregados nos pseudo-painéis compostos pelo total nas AMCs.

Essa ressalva é importante, pois, ao afirmar que, pelo modelo (3) o aumento da luminosidade acima de $53 \mathrm{DN}$ aumenta a pobreza no local, não implica, necessariamente, em uma piora das condições de vida da população local, isso pode ocorrer, por exemplo, em casos da cidade se apresentar como polo atrator de pessoas em busca de oportunidades de emprego, o que aumentaria o total de pessoas em situação de pobreza, mesmo mantendo os habitantes que já se situavam no local em condições inalteradas.

\subsection{Resultados dos modelos para as demais linhas de pobreza}

Haja vista os resultados encontrados para os dados da população em situação de extrema pobreza das zonas rurais na tabela 3.2 supracitada, as tabelas a seguir se colocam como extensões das análises dos efeitos do crescimento da Urbanização, captada pela variável proxy de Luminosidade entre 21 e $53 \mathrm{DN}$, agora às demais linhas de pobreza. Todas as tabelas apresentadas nessa seção possuem as mesmas covariadas apresentadas na seção anterior, neste caso, elas estão omitidas por fins de simplificação. Dessa forma, a tabela 3.4 apresenta os resultados para o total de habitantes em situação de pobreza nas zonas rurais brasileiras, a saber, para o conjunto de indivíduos com renda domiciliar per capita igual ou inferior a $\mathrm{R} \$$ 140,00 mensais, em reais de agosto de 2010.

Como se pode observar, os resultados se assemelham com os encontrados nos casos de pobreza extrema, com exceção do modelo de Efeitos Fixos (EF), no modelo (4), o qual apresenta um resultado negativo e significante para a luminosidade entre 21 e 53, de modo que o aumento de $1 \%$ da variável "Área de Luminosidade entre 21 e 53 DN", diminui em 1,04\% o total da população em extrema pobreza que reside nas zonas rurais da AMCs, tudo mais constante. No caso da variável "Área com Luminosidade > 53 DN“, o efeito não se mostrou estatisticamente significante sob um nível de 5\% de significância. Ademais, os resultados do crescimento da luminosidade entre 21 e 53 se mantém negativo e significante nos modelos com Variáveis Instrumentais, modelo (5), enquanto que a variável de luminosidade acima de 53 DN permanece com efeito positivo e significante, mantendo a mesma dinâmica no modelo (8), com Variáveis Instrumentais e Erros Espaciais. 


\begin{tabular}{lccc}
\hline \hline & \multicolumn{3}{c}{ Pobreza rural } \\
\cline { 2 - 4 } & $\mathrm{EF}$ & $\mathrm{IV}$ & SEM com IV \\
& $(4)$ & $(5)$ & $(6)$ \\
\hline Área com Luminosidade entre 21 e 53 DN & $-1.04^{* * *}$ & $-14.02^{* * *}$ & $\begin{array}{c}-13.85^{* * *} \\
(1.24)\end{array}$ \\
& $(0.22)$ & $(1.20)$ & $(1.24)$ \\
Área com Luminosidade $>53 \mathrm{DN}$ & -0.11 & $3.16^{* * *}$ & $3.10^{* * *}$ \\
& $(0.34)$ & $(0.52)$ & $(0.52)$ \\
Variáveis de Controle & Sim & Sim & Sim \\
\hline Observações & & & 10,900 \\
$\mathrm{R}^{2}$ & 10,900 & 10,900 & 0.53 \\
\hline \hline
\end{tabular}

Nota: ${ }^{*} \mathrm{p}<0.1 ;{ }^{* *} \mathrm{p}<0.05 ;{ }^{* * *} \mathrm{p}<0.01$. A situação de Pobreza é caracterizada por indivíduos com renda domiciliar per capita igual ou inferior a $\mathrm{R} \$ 140,00$ mensais, em reais de agosto de 2010. Os dados de rendimento dos indivíduos em 2000 foram corrigidos para o mês de referência de 2010 a partir do IPCA acumulado entre os períodos. Os dados estão em estrutura de Painel balanceado de dois períodos (2000 e 2010) com 5.450 polígonos em cada ano correspondentes as AMCs do Brasil. O modelo (1), EF, corresponde ao de Efeito Fixo Clássico, o (2) corresponde ao modelo com Variáveis Instrumentais (IV), e, por fim, o (3) apresenta os resultados do modelo de Erros Espaciais (SEM) com Variáveis Instrumentais.

Tabela 3.4 - Modelos para o total de habitantes em situação de pobreza no Brasil

A tabela 3.5, por sua vez, apresenta os resultados para o caso da população em situação de vulneráveis à pobreza, isto é, para o conjunto de indivíduos com renda domiciliar per capita igual ou inferior a $R \$ 255,00$ mensais, em reais de agosto de 2010 , o que equivalia a meio salário mínimo. No caso do modelo (7) de Efeitos Fixos, o resultado da variável "Área de Luminosidade entre 21 e 53 DN" se mostrou negativo e estatisticamente significante sob um nível de $1 \%$ de significância, de modo que o aumento de $1 \%$ da variável diminui em $0,73 \%$ o total da população em extrema pobreza que reside nas zonas rurais da AMCs, tudo mais constante. Uma ressalva aqui, ainda sobre o modelo (7) se refere ao resultado da variável "Área com Luminosidade > 53 DN", a qual se mostrou negativa estatisticamente significante sob um nível de $1 \%$ de significância, resultado esse que diverge de todos os demais encontrados para essa variável.

Entretanto, quando se analisa nos modelos com Instrumentos, modelos (8) e (9), encontra-se resultados semelhantes aos anteriores, com parâmetros estimados negativos e significantes para a variável "Área de Luminosidade entre 21 e 53 DN" e positivos e significantes para "Área com Luminosidade > 53 DN".

\subsection{Análise de Robustez e Sensibilidade}

Por mais que a classificação das faixas de luminosidade para a classificação do crescimento urbano tenham se embasado em pesquisas relacionadas, como a proposta de ÁlvarezBerríos, Parés-Ramos e Aide (2013), é necessário uma análise de sensibilidade da escolha 


\begin{tabular}{lccc}
\hline \hline & \multicolumn{3}{c}{ Vulneráveis à pobreza rural } \\
\cline { 2 - 4 } & EF & IV & SEM com IV \\
& $(7)$ & $(8)$ & $(9)$ \\
\hline Área com Luminosidade entre 21 e 53 DN & $-0.73^{* * *}$ & $-10.55^{* * *}$ & $-10.42^{* * *}$ \\
& $(0.14)$ & $(0.84)$ & $(0.88)$ \\
Área com Luminosidade $>53 \mathrm{DN}$ & $-0.79^{* * *}$ & $1.68^{* * *}$ & $1.62^{* * *}$ \\
& $(0.22)$ & $(0.36)$ & $(0.36)$ \\
Variáveis de Controle & Sim & Sim & Sim \\
\hline Observações & & & 10,900 \\
$\mathrm{R}^{2}$ & 10,900 & 10,900 & 0.33 \\
\hline \hline
\end{tabular}

Nota: ${ }^{*} \mathrm{p}<0.1 ;{ }^{* *} \mathrm{p}<0.05 ;{ }^{* * *} \mathrm{p}<0.01$. A situação de Vulneráveis à Pobreza é caracterizada por indivíduos com renda domiciliar per capita igual ou inferior a $\mathrm{R} \$ 255,00$ mensais, em reais de agosto de 2010, equivalente a $1 / 2$ salário mínimo nessa data, em reais de agosto de 2010. Os dados de rendimento dos indivíduos em 2000 foram corrigidos para o mês de referência de 2010 a partir do IPCA acumulado entre os períodos. Os dados estão em estrutura de Painel balanceado de dois períodos (2000 e 2010) com 5.450 polígonos em cada ano correspondentes as AMCs do Brasil. O modelo (1), EF, corresponde ao de Efeito Fixo Clássico, o (2) corresponde ao modelo com Variáveis Instrumentais (IV), e, por fim, o (3) apresenta os resultados do modelo de Erros Espaciais (SEM) com Variáveis Instrumentais.

Tabela 3.5 - Modelos para o total de habitantes em situação de vulneráveis à pobreza no Brasil

dessas classificações nos resultados encontrados. Esta seção se propõem a verificar o quão suscetíveis estão esses resultados sob diferentes classificações.

A tabela 3.6 a seguir apresenta os resultados dos modelos de Variáveis Instrumentais com Erros Espaciais (SEM com IV) para diferentes delimitações da variável de luminosidade. Os resultados do estudo apresentados até então utilizaram a delimitação de luminosidade entre 21 e 53 DN para a classificação da urbanização incipiente. A fim de verificar o quão sensível essa escolha pode ser, estimou-se o mesmo modelo, com diferentes classificações, indo de $5 \mathrm{DN}$ até $25 \mathrm{DN}$.

Como se pode observar, os resultados se mantém em questão de sinais e se diferenciam em termos de magnitude, com a mesma significância estatística em cada bloco de modelos. Em todos os casos, os modelos de Efeitos Fixo (EF) apresentam resultados não significante para os parâmetros estimados, tanto nas variáveis de luminosidade incipiente, quanto da luminosidade Core, acima de $53 \mathrm{DN}$.

No caso dos resultados para os modelos clássicos de Variáveis Instrumentais (IV), e dos Modelos de Variáveis Instrumentais com Erros Espaciais (SEM com IV) os resultados parecem consistentes para as escalas de luminosidade acima de $10 \mathrm{DN}$. Uma questão instigante é o fato do parâmetro estimado para a luminosidade acima de $53 \mathrm{DN}$ se mostrar negativa e significante em todos os modelos, com exceção do primeiro bloco, com luminosidade entre 5 e 53 DN, a princípio, não há uma explicação do porquê da inversão de sinal, quando comparado com as demais escalas de luminosidade.

Além da questão de sensibilidade apresentada, uma análise importante de ser ressal- 


\begin{tabular}{|c|c|c|c|}
\hline & \multicolumn{3}{|c|}{ Total de habitantes em situação de pobreza rural } \\
\hline & $\mathrm{EF}$ & IV & SEM com IV \\
\hline \multicolumn{4}{|l|}{ Luminosidade entre 06 e $53 \mathrm{DN}$} \\
\hline Área com Luminosidade entre 06 e 53 DN & $\begin{array}{l}-0.13 \\
(0.08)\end{array}$ & $\begin{array}{c}-4.31^{* * *} \\
(0.49)\end{array}$ & $\begin{array}{c}-4.37^{* * *} \\
(0.51)\end{array}$ \\
\hline Área com Luminosidade > $53 \mathrm{DN}$ & $\begin{array}{c}0.79 \\
(0.54)\end{array}$ & $\begin{array}{c}-1.65^{*} \\
(0.71)\end{array}$ & $\begin{array}{c}-1.79^{*} \\
(0.72)\end{array}$ \\
\hline \multicolumn{4}{|l|}{ Luminosidade entre 11 e 53 DN } \\
\hline Área com Luminosidade entre 11 e 53 DN & $\begin{array}{c}0.01 \\
(0.18)\end{array}$ & $\begin{array}{c}-7.18^{* * *} \\
(0.83)\end{array}$ & $\begin{array}{c}-7.17^{* * *} \\
(0.85)\end{array}$ \\
\hline Área com Luminosidade > 53 DN & $\begin{array}{c}0.86 \\
(0.54)\end{array}$ & $\begin{array}{c}3.06^{* * *} \\
(0.66)\end{array}$ & $\begin{array}{c}2.97^{* * * *} \\
(0.66)\end{array}$ \\
\hline \multicolumn{4}{|l|}{ Luminosidade entre 16 e 53 DN } \\
\hline Área com Luminosidade entre 16 e 53 DN & $\begin{array}{c}0.24 \\
(0.28)\end{array}$ & $\begin{array}{c}-9.06^{* * *} \\
(1.24)\end{array}$ & $\begin{array}{c}-9.01^{* * *} \\
(1.26)\end{array}$ \\
\hline Área com Luminosidade $>53 \mathrm{DN}$ & $\begin{array}{c}0.80 \\
(0.54)\end{array}$ & $\begin{array}{c}3.16^{* * *} \\
(0.67)\end{array}$ & $\begin{array}{c}3.08 * * * \\
(0.67)\end{array}$ \\
\hline \multicolumn{4}{|l|}{ Luminosidade entre 21 e $53 \mathrm{DN}$} \\
\hline Área com Luminosidade entre 21 e 53 DN & $\begin{array}{c}0.22 \\
(0.35)\end{array}$ & $\begin{array}{c}-9.84^{* * *} \\
(1.62)\end{array}$ & $\begin{array}{c}-9.76^{* * *} \\
(1.64)\end{array}$ \\
\hline Área com Luminosidade > 53 DN & $\begin{array}{c}0.81 \\
(0.54)\end{array}$ & $\begin{array}{c}3.34^{* * *} \\
(0.70)\end{array}$ & $\begin{array}{c}3.27^{* * *} \\
(0.70)\end{array}$ \\
\hline \multicolumn{4}{|l|}{ Luminosidade entre 26 e 53 DN } \\
\hline Área com Luminosidade entre 25 e 53 DN & $\begin{array}{c}0.11 \\
(0.44)\end{array}$ & $\begin{array}{c}-10.89^{* * *} \\
(2.11)\end{array}$ & $\begin{array}{c}-10.75^{* * *} \\
(2.14)\end{array}$ \\
\hline Área com Luminosidade > 53 DN & $\begin{array}{c}0.83 \\
(0.55)\end{array}$ & $\begin{array}{c}3.74^{* * *} \\
(0.79)\end{array}$ & $\begin{array}{c}3.66^{* * *} \\
(0.79)\end{array}$ \\
\hline
\end{tabular}

Nota: ${ }^{*} \mathrm{p}<0.1 ;{ }^{* *} \mathrm{p}<0.05 ;{ }^{* * *} \mathrm{p}<0.01$. A situação de Pobreza Extrema é caracterizada por indivíduos com renda domiciliar per capita igual ou inferior a $\mathrm{R} \$ 70,00$ mensais, em reais de agosto de 2010 . Os dados de rendimento dos indivíduos em 2000 foram corrigidos para o mês de referência de 2010 a partir do IPCA acumulado entre os períodos. Os dados estão em estrutura de Painel balanceado de dois períodos (2000 e 2010) com 5.450 polígonos em cada ano correspondentes as AMCs do Brasil. O modelo (1), EF, corresponde ao de Efeito Fixo Clássico, o (2) corresponde ao modelo com Variáveis Instrumentais (IV), e, por fim, o (3) apresenta os resultados do modelo de Erros Espaciais (SEM) com Variáveis Instrumentais.

Tabela 3.6 - Análise de sensibilidade na delimitação da luminosidade para urbanização incipiente nas AMCs 
tada é a de robustez no que tange a escolha das matrizes de vizinhança. Como os modelos são estimados a partir de uma matriz de vizinhança imposta, é importante verificar se diferentes especificações das matrizes de vizinhanças acarretam em diferentes resultados.

A partir disso estimou-se o modelo de Variáveis Instrumentais com outras três especificações de matrizes de vizinhança, são eles: o modelo (19), no qual cada AMC possui exatamente cinco vizinhos; o modelo (20), com exatamente 10 vizinhos; e o modelo (21), com uma matriz de inverso da distância para um raio de 283 quilômetros ${ }^{22}$.

Como se pode notar na tabela 3.7, os resultados mantém em termos de sinal, de modo que todos apresentam resultados negativos e significantes para a variável de luminosidade entre 21 e $53 \mathrm{DN}$, e positiva e significante para a área com luminosidade acima de $53 \mathrm{DN}$. Além disso, os parâmetros apresentam resultados próximos em termos de magnitude, o que sugere que a escolha das matrizes de vizinhança não afetam as interpretações realizadas anteriormente.

Uma breve contextualização dos resultados encontrados com a literatura sobre o tema, os efeitos da urbanização incipiente, com diminuição no total de habitantes em situação de pobreza, afirmação que se mantém nas três linhas de pobreza analisadas, também foi encontrado em outros países. No caso da Índia, por exemplo, Lanjouw e Murgai (2010) encontram uma diminuição nos indicadores de pobreza rural no país a partir do desenvolvimento urbano e apontam que um dos principais canais de atuação se deu via aumento da disponibilidade de trabalhos não-agrícolas para a população do campo.

Ainda no contexto indiano, Gibson et al. (2017) constroem as variáveis de crescimento urbano a partir dos mesmos dados de sensoriamento remoto utilizados no presente estudo. A partir de um modelo autorregressivo Durbin Espacial, comumente chamado de SDM na literatura de econometria espacial, os autores constatam que o crescimento das cidades secundárias, com urbanização incipiente, contribuem mais para a diminuição da pobreza rural via-à-vis o crescimento dos grandes centros urbanos. Novamente, o canal sob o qual os pesquisadores argumentam que o crescimento urbano corrobora na diminuição da pobreza rural por meio do mercado de trabalho.

Nos estudos voltados para o aumento da eletrificação nas zonas rurais, Dinkelman (2011) utilizam o programa de expansão das linhas de transmissão e a topografia da África do Sul para estimar um modelo de Variáveis Instrumentais e encontram um aumento de 9 a 9,5 pontos percentuais de incremento da mão de obra feminina, o que impulsionou a redução da pobreza rural nas regiões com maior probabilidade de ter recebido o programa.

No caso brasileiro, Brancher (2019) utilizam o programa Luz para Todos e os dados topográficos e encontram efeitos nas taxas de fertilidade, no peso médio dos bebês ao nascerem, nas taxas de mortalidade infantil e na cobertura de vacinação da população rural.

\footnotetext{
${ }^{22}$ Esse é o menor raio no qual as 5.450 AMCs da base de dados possuam ao menos um vizinho.
} 


\begin{tabular}{|c|c|c|c|c|}
\hline & \multicolumn{4}{|c|}{ Total de habitantes em situação de pobreza rural extrema } \\
\hline & $\begin{array}{c}\text { SEM com IV } \\
\text { (18) }\end{array}$ & $\begin{array}{l}k=5 \\
(19)\end{array}$ & $\begin{array}{l}\mathrm{k}=10 \\
(20)\end{array}$ & $\begin{array}{c}\text { dist }=283 \mathrm{~km} \\
(21)\end{array}$ \\
\hline Área com Luminosidade entre 21 e 53 DN & $\begin{array}{c}-9.76^{* * *} \\
(1.64)\end{array}$ & $\begin{array}{c}-9.72^{* * *} \\
(1.65)\end{array}$ & $\begin{array}{c}-9.58^{* * *} \\
(1.66)\end{array}$ & $\begin{array}{c}-8.67^{* * *} \\
(1.74)\end{array}$ \\
\hline Área com Luminosidade > 53 DN & $\begin{array}{c}3.27^{* * *} \\
(0.70)\end{array}$ & $\begin{array}{c}3.26^{* * *} \\
(0.70)\end{array}$ & $\begin{array}{c}3.22^{* * *} \\
(0.70)\end{array}$ & $\begin{array}{c}2.92^{* * *} \\
(0.69)\end{array}$ \\
\hline Prop. de Fundamental Completo (Rural) & $\begin{array}{c}-0.57^{*} \\
(0.23)\end{array}$ & $\begin{array}{c}-0.57^{*} \\
(0.23)\end{array}$ & $\begin{array}{c}-0.58^{*} \\
(0.23)\end{array}$ & $\begin{array}{c}-0.62^{* *} \\
(0.23)\end{array}$ \\
\hline Prop. de Ensino Médio Completo (Rural) & $\begin{array}{c}-1.72^{* * *} \\
(0.29)\end{array}$ & $\begin{array}{c}-1.72^{* * *} \\
(0.29)\end{array}$ & $\begin{array}{c}-1.73^{* * *} \\
(0.29)\end{array}$ & $\begin{array}{c}-1.71^{* * *} \\
(0.29)\end{array}$ \\
\hline Prop. de Ensino Superior Incompleto (Rural) & $\begin{array}{c}-3.05^{* * *} \\
(0.31)\end{array}$ & $\begin{array}{c}-3.05^{* * *} \\
(0.31)\end{array}$ & $\begin{array}{c}-3.04^{* * *} \\
(0.31)\end{array}$ & $\begin{array}{c}-2.95^{* * *} \\
(0.31)\end{array}$ \\
\hline Prop. de Ensino Superior Completo (Rural) & $\begin{array}{c}-4.77^{* * *} \\
(0.97)\end{array}$ & $\begin{array}{c}-4.73^{* * *} \\
(0.97)\end{array}$ & $\begin{array}{c}-4.68^{* * *} \\
(0.97)\end{array}$ & $\begin{array}{c}-4.49^{* * *} \\
(0.96)\end{array}$ \\
\hline Prop. com Carteira Assinada (Rural) & $\begin{array}{c}-3.36^{* * *} \\
(0.47)\end{array}$ & $\begin{array}{c}-3.37^{* * *} \\
(0.47)\end{array}$ & $\begin{array}{c}-3.41^{* * *} \\
(0.47)\end{array}$ & $\begin{array}{c}-3.43^{* * *} \\
(0.47)\end{array}$ \\
\hline Bolsa Familia (milhões de Reais) & $\begin{array}{c}0.13^{* * *} \\
(0.04)\end{array}$ & $\begin{array}{c}0.13^{* * *} \\
(0.04)\end{array}$ & $\begin{array}{c}0.12^{* * *} \\
(0.04)\end{array}$ & $\begin{array}{c}0.11^{* *} \\
(0.04)\end{array}$ \\
\hline Prop. de Pretos e Pardos (Rural) & $\begin{array}{c}0.14 \\
(0.16)\end{array}$ & $\begin{array}{c}0.14 \\
(0.16)\end{array}$ & $\begin{array}{c}0.15 \\
(0.16)\end{array}$ & $\begin{array}{c}0.21 \\
(0.16)\end{array}$ \\
\hline Prop. que Sempre Morou (Rural) & $\begin{array}{l}-0.03 \\
(0.21)\end{array}$ & $\begin{array}{l}-0.03 \\
(0.21)\end{array}$ & $\begin{array}{l}-0.02 \\
(0.21)\end{array}$ & $\begin{array}{l}-0.03 \\
(0.21)\end{array}$ \\
\hline Prop. que Nasceu na UF (Rural) & $\begin{array}{c}0.66 \\
(0.41)\end{array}$ & $\begin{array}{c}0.64 \\
(0.41)\end{array}$ & $\begin{array}{c}0.63 \\
(0.41)\end{array}$ & $\begin{array}{c}0.65 \\
(0.41)\end{array}$ \\
\hline Razão de dependência (Rural) & $\begin{array}{c}-0.18^{* * *} \\
(0.04)\end{array}$ & $\begin{array}{c}-0.18^{* * *} \\
(0.04)\end{array}$ & $\begin{array}{c}-0.18^{* * *} \\
(0.04)\end{array}$ & $\begin{array}{c}-0.19^{* * *} \\
(0.04)\end{array}$ \\
\hline Fecundidade (Rural) & $\begin{array}{c}0.07 \\
(0.12)\end{array}$ & $\begin{array}{c}0.07 \\
(0.11)\end{array}$ & $\begin{array}{c}0.07 \\
(0.12)\end{array}$ & $\begin{array}{c}0.08 \\
(0.11)\end{array}$ \\
\hline Mãe Chefe de Família & $\begin{array}{l}-0.18 \\
(0.21)\end{array}$ & $\begin{array}{l}-0.18 \\
(0.21)\end{array}$ & $\begin{array}{l}-0.17 \\
(0.21)\end{array}$ & $\begin{array}{l}-0.11 \\
(0.21)\end{array}$ \\
\hline População Urbana & $\begin{array}{l}0.18^{*} \\
(0.08)\end{array}$ & $\begin{array}{l}0.18^{*} \\
(0.08)\end{array}$ & $\begin{array}{l}0.18^{*} \\
(0.08)\end{array}$ & $\begin{array}{l}0.17^{*} \\
(0.08)\end{array}$ \\
\hline Área de Agropecuária & $\begin{array}{l}0.18^{*} \\
(0.08)\end{array}$ & $\begin{array}{l}0.18^{*} \\
(0.08)\end{array}$ & $\begin{array}{l}0.18^{*} \\
(0.08)\end{array}$ & $\begin{array}{l}0.15^{*} \\
(0.08)\end{array}$ \\
\hline Área Vegetação Nativa & $\begin{array}{c}-0.27^{*} \\
(0.11)\end{array}$ & $\begin{array}{c}-0.27^{*} \\
(0.11)\end{array}$ & $\begin{array}{c}-0.27^{*} \\
(0.11)\end{array}$ & $\begin{array}{c}-0.22^{*} \\
(0.10)\end{array}$ \\
\hline População Rural & $\begin{array}{c}1.10^{* * * *} \\
(0.04)\end{array}$ & $\begin{array}{c}1.10^{* * *} \\
(0.04)\end{array}$ & $\begin{array}{c}1.11^{* * *} \\
(0.04)\end{array}$ & $\begin{array}{c}1.09^{* * *} \\
(0.04)\end{array}$ \\
\hline $\begin{array}{l}\text { Observações } \\
R^{2}\end{array}$ & $\begin{array}{c}10,900 \\
034\end{array}$ & 10,900 & 10,900 & 035 \\
\hline
\end{tabular}

Nota: ${ }^{*} \mathrm{p}<0.1 ;{ }^{* *} \mathrm{p}<0.05 ;{ }^{* * *} \mathrm{p}<0.01$. O modelo (1) corresponde ao modelo base apresentado na tabela 3.2 com a matriz de vizinhança do tipo Rainha, o modelo (2), tem como matriz de vizinhança os 5 vizinhos mais próximos, enquanto que o modelo (3) foi estimado com a matriz dos 10 vizinhos mais próximos, o modelo (4) por sua vez foi estimado com uma matriz de distância, de modo que todos os municípios tenham ao menos um vizinho (distância mínima necessária foi de 283 km). 


\section{CONSIDERAÇÕES FINAIS}

Entre os anos 2000 e 2010 o Brasil vivenciou uma diminuição dos indivíduos em situação de pobreza extrema, pobreza e vulneráveis à pobreza com dinâmicas diferentes entre áreas urbanas e as zonas rurais. A pobreza rural responde a incentivos diferentes quando comparada com a mesma situação nas cidades, no caso dos habitantes do campo, com uma maior participação da agricultura na economia rural via-à-vis os demais setores. Deste modo, atividades relacionadas a atividades não agrícolas, muitas vezes com maior remuneração, são mais escassas nesses locais.

Um possível canal de atuação no combate a pobreza rural está relacionado ao crescimento urbano das cidades próximas, o processo de urbanização, que corresponde a ampliação das áreas urbanas, pode aumentar a conectividade entre as áreas rurais e urbanas, o que fomenta a demanda por produtos agrícolas locais e amplia a possibilidade de novos empregos não agrícolas, tanto no campo quanto em localidades próximas as zonas rurais, reduzindo então o número de indivíduos em situação de pobreza.

Nesse contexto, o crescimento urbano de cidades em direção as zonas rurais pode promover a redução da pobreza rural por meio da ampliação da demanda por trabalhos não-agrícolas os quais podem complementar a renda familiar no campo. Dentre os diferentes níveis de urbanização, o crescimento dos centros altamente urbanizados, tais como os das grandes metrópoles, parece afetar de maneira diferente o mercado de trabalho rural quando comparado com o avanço das áreas urbanas em estágios incipientes, como o observado nas cidades menores, mais próximas das zonas rurais.

O intuito do presente trabalho é avaliar o impacto do crescimento de diferentes níveis de urbanização das cidades brasileiras na redução da pobreza rural sob a ótica das três linhas de pobreza no campo: os que estão em situação de pobreza extrema, pobreza e vulneráveis à pobreza, com base nos informes de renda domiciliar per capita declarada. Nesse contexto, estimou-se os efeitos da urbanização dos grandes centros metropolitanos e das regiões incipientes, com menor nível de complexidade urbana, nos indicadores de pobreza rural, como o total de habitantes do campo com renda domiciliar per capita abaixo da linha de pobreza extrema a preços de 2010. Utilizou-se como proxy da urbanização imagens de sensoriamento remoto de luminosidade noturna, que somados com dados de uso da terra e informações dos Censos Demográficos de 2000 e 2010 compuseram a base de dados do estudo.

Assim, utilizou-se imagens de sensoriamento noturno como proxy do avanço urbano para as regiões no Brasil. Foram captados dois tipos de urbanização: a referente aos centros altamente urbanizados com alta luminosidade, e uma urbanização secundária, de regiões ainda incipientes. A introdução de ambas as variáveis nos modelos de Painel Espacial possibi- 
litou uma comparação dos impactos dos dois tipos de urbanização na redução da pobreza rural no país nas três linhas de pobreza supracitadas.

A base de dados utilizada contou com outras variáveis obtidas por imagem de satélite, tais como a área do município destinada a agricultura e a área de vegetação nativa, ambas obtidas pelo projeto MAPBIOMAS, e os dados de relevo e altimetria dos municípios brasileiros disponibilizados pela Embrapa. A unidade de análise territorial se deu no nível de Áreas Mínimas Comparáveis (AMCs) nos anos referência, as quais agregam municípios criados entre 2000 e 2010 no mesmo polígono, com base em 2000. Desta forma, tem-se um painel balanceado de AMCs para os dois períodos.

Tendo em vista o Programa Luz para Todos e as questões de aclividade do terreno, esta a estratégia de Variáveis Instrumentais com Erros Espaciais utilizada visou captar choques exógenos de luminosidade e assim, estimar os efeitos do crescimento da luminosidade nos indicadores de pobreza rural. No que tange a correção dos resíduos, espacialmente correlacionados, utilizou-se a especificação do modelo de Erros Espaciais no segundo estágio do modelo.

A estimação desses modelos se deu via Método dos Momentos Generalizados Factível com a matriz de vizinhança de contiguidade do tipo Rainha no termo de erro do segundo estágio. Os resultados gerais para os modelos relacionados a pobreza extrema apontam que o avanço da urbanização incipiente acompanha a diminuição da pobreza rural extrema, permanecendo negativo e significante em todas as estimações com Variáveis Instrumentais. Por outro lado, no tocante aos avanços dos centros altamente urbanizados o efeito se mostrou positivo e significante, no sentido de aumentar o total de habitantes em situação de pobreza extrema rural na região.

Ademais, os resultados para os modelos com as outras definições de linha de pobreza, sendo o total de pessoas em situação de pobreza e o total de indivíduos vulneráveis à pobreza apresentou a mesma dinâmica, no sentido do crescimento da luminosidade incipiente reduzir o total de pessoas nessas situações, e o sinal contrário para o avanço dos grandes centros. No que tange a análise de sensibilidade de diferentes especificações na escala de luminosidade, os resultados se mantiveram negativos e significantes com mudanças marginais nas classificações da luminosidade. E por fim, os resultados se mostraram robustos as escolhas das matrizes de vizinhança, o que indica que a determinação do critério de vizinhança utilizado não afeta a inferência dos efeitos encontrados.

Do ponto de vista de proposição para políticas públicas, o fomento das conexões entre as zonas rurais mais afastadas e as cidades menores pode promover uma ampliação dos empregos não-agrícolas no campo que, somados com os investimentos em capital humano, como educação, pode diminuir a pobreza rural, que apesar de apresentar-se em declínio, ainda se situa na casa dos milhões. 


\section{REFERÊNCIAS}

ALKIRE, S. et al. Multidimensional poverty measurement and analysis. [S.l.]: Oxford University Press, USA, 2015.

ÁLVAREZ-BERRÍOS, N. L.; PARÉS-RAMOS, I. K.; AIDE, T. M. Contrasting patterns of urban expansion in colombia, ecuador, peru, and bolivia between 1992 and 2009. Ambio, Springer, v. 42, n. 1, p. 29-40, 2013.

AMARAL, S.; DÓRIA, V. E. M.; DAL'ALASTA, A. P.; MONTEIRO, A. M. V. Luzes noturnas do sensor viirs para a identificação de atividades humanas na amazônia brasileira: observações de uma região na transamazônica (pa). 2015.

ANDRADE, T. A.; SERRA, R. V. O recente desempenho das cidades médias no crescimento populacional urbano brasileiro. Instituto de Pesquisa Econômica Aplicada (Ipea), 1998.

ANSELIN, L.; LE GALLO, J.; JAYET, H. Spatial panel econometrics. In: The econometrics of panel data. [S.l.]: Springer, 2008. p. 625-660.

ARAÚJO, J. de; TABOSA, F. J. S.; KHAN, A. S. Elasticidade-renda e elasticidade: desigualdade da probreza no nordeste brasileiro. Área de Informação da Sede-Artigo em periódico indexado (ALICE), Revista de Política Agrícola, Brasília, DF, ano 21, n. 1, p. 50-59, jan./mar. 2012., 2012.

ARBIA, G. A primer for spatial econometrics: with applications in R. [S.l.]: Springer, 2014.

ARELLANO, M. On the testing of correlated effects with panel data. Journal of econometrics, Elsevier, v. 59, n. 1-2, p. 87-97, 1993.

ASHLEY, C.; MAXWELL, S. Rethinking rural development. Development policy review, Wiley Online Library, v. 19, n. 4, p. 395-425, 2001.

BALTAGI, B. H.; LIU, L. Testing for random effects and spatial lag dependence in panel data models. Statistics \& Probability Letters, Elsevier, v. 78, n. 18, p. 3304-3306, 2008.

BANERJEE, A. et al. A multifaceted program causes lasting progress for the very poor: Evidence from six countries. Science, American Association for the Advancement of Science, v. 348, n. 6236, p. 1260799, 2015.

BARUFI, A. M.; HADDAD, E.; PAEZ, A. Infant mortality in brazil, 1980-2000: A spatial panel data analysis. BMC public health, BioMed Central, v. 12, n. 1, p. 181, 2012.

BERNARD, T. Impact analysis of rural electrification projects in sub-saharan africa. The World Bank Research Observer, Oxford University Press, v. 27, n. 1, p. 33-51, 2010.

BEZERRA, M. L.; BACELAR, T.; MIRANDA, C. O. d. S.; SILVA, H. O. d. S. Concepções da ruralidade contemporânea: as singularidades brasileiras. Instituto Interamericano de Cooperação para a Agricultura (IICA), 2013.

BRANCHER, M. C. Shedding light into rural electrification and health: evidence from Brazil. Tese (Doutorado), 2019.

CAMERON, A. C.; TRIVEDI, P. K. Microeconometrics: methods and applications. [S.1.]: Cambridge university press, 2005. 
CAMPELLO, T.; FALCÃO, T.; COSTA, P. V. da. O Brasil sem miséria. [S.l.]: Ministério do Desenvolvimento Social e Combate à Fome, 2014.

CHRISTIAENSEN, L.; KANBUR, R. Secondary towns, jobs and poverty reduction: Introduction to World Development Special Symposium. [S.l.]: Elsevier, 2018.

DINKELMAN, T. The effects of rural electrification on employment: New evidence from south africa. American Economic Review, v. 101, n. 7, p. 3078-3108, 2011.

DUFLO, E.; PANDE, R. Dams. The Quarterly Journal of Economics, MIT Press, v. 122, n. 2, p. 601-646, 2007.

EHRL, P. Minimum comparable areas for the period 1872-2010: an aggregation of brazilian municipalities. Estudos Econômicos (São Paulo), SciELO Brasil, v. 47, n. 1, p. 215-229, 2017.

ELHORST, J. P. Specification and estimation of spatial panel data models. International regional science review, Sage Publications, v. 26, n. 3, p. 244-268, 2003.

. Spatial econometrics: from cross-sectional data to spatial panels. [S.l.]: Springer, 2014. v. 479.

ELVIDGE, C. D. et al. The night light development index (nldi): a spatially explicit measure of human development from satellite data. Social Geography, Copernicus GmbH, v. 7, n. 1, p. 23-35, 2012.

FALCÃO, T.; COSTA, P. d. A linha de extrema pobreza e o público alvo do plano brasil sem miséria. Campello T, Falcão T, Costa PV, organizadores. O Brasil sem miséria. Brasília (DF): Ministério do Desenvolvimento Social e Combate à Fome, p. 67-94, 2014.

DE FERRANTI, D. et al. Beyond the city: the rural contribution to development. [S.l.]: The World Bank, 2005.

FERRÉ, C.; FERREIRA, F. H.; LANJOUW, P. Is there a metropolitan bias? the relationship between poverty and city size in a selection of developing countries. The World Bank Economic Review, v. 26, n. 3, p. 351-382, 2012. Disponível em: <http://dx.doi.org/10.1093/wber/lhs007>.

FREITAS, G. de; SILVEIRA, S. d. F. R. Programa luz para todos: uma representação da teoria do programa por meio do modelo lógico. Planejamento e Políticas Públicas, n. 45, 2015.

GIBSON, J.; DATT, G.; MURGAI, R.; RAVALLION, M. For india's rural poor, growing towns matter more than growing cities. World Development, Elsevier, v. 98, p. 413-429, 2017.

GLEWWE, P.; GAAG, J. Van der. Identifying the poor in developing countries: Do different definitions matter? World Development, Elsevier, v. 18, n. 6, p. 803-814, 1990.

HARRIS, J. R.; TODARO, M. P. Migration, unemployment and development: a two-sector analysis. The American economic review, JSTOR, v. 60, n. 1, p. 126-142, 1970.

HECKMAN, J. J. Heterogeneity and state dependence. In: Studies in labor markets. [S.1.]: University of Chicago Press, 1981. p. 91-140.

HENDERSON, M. et al. Validation of urban boundaries derived from global night-time satellite imagery. International Journal of Remote Sensing, Taylor \& Francis, v. 24, n. 3, p. 595-609, 2003. 
HENDERSON, V. The urbanization process and economic growth: The so-what question. Journal of Economic growth, Springer, v. 8, n. 1, p. 47-71, 2003.

HUANG, Q. et al. Detecting the 20 year city-size dynamics in china with a rank clock approach and dmsp/ols nighttime data. Landscape and Urban Planning, Elsevier, v. 137, p. 138-148, 2015.

IBGE, I. Censo demográfico 2000. IBGE: Insituto Brasileiro de Geografia e, 2000.

. Censo demográfico 2010. IBGE: Insituto Brasileiro de Geografia e, 2010.

JEAN, N. et al. Combining satellite imagery and machine learning to predict poverty. Science, American Association for the Advancement of Science, v. 353, n. 6301, p. 790-794, 2016.

KELEJIAN, H. H.; PRUCHA, I. R.; YUZEFOVICH, Y. Instrumental variable estimation of a spatial autoregressive model with autoregressive disturbances: Large and small sample results. In: Spatial and spatiotemporal econometrics. [S.l.]: Emerald Group Publishing Limited, 2004. p. 163-198.

LANJOUW, P.; MURGAI, R. Urban growth and rural poverty in India. [S.l.]: The World Bank draft, 2010.

LAURINI, M. P. Income estimation using night luminosity: a continuous spatial model. Spatial Demography, Springer, v. 4, n. 2, p. 83-115, 2016.

LESAGE, J.; PACE, R. K. Introduction to spatial econometrics. [S.l.]: Chapman and Hall/CRC, 2009.

LESAGE, J. P. What regional scientists need to know about spatial econometrics. Available at SSRN 2420725, 2014.

LEVIN, N.; DUKE, Y. High spatial resolution night-time light images for demographic and socio-economic studies. Remote Sensing of Environment, Elsevier, v. 119, p. 1-10, 2012.

LEWIS, W. A. Economic development with unlimited supplies of labour. The manchester school, Wiley Online Library, v. 22, n. 2, p. 139-191, 1954.

LIMA, A. R. d. Análise e gestão de riscos das ocupações de faixas de linhas de transmissão: estudo de caso da vila alta tensão. 2012.

LIPTON, M. Migration from rural areas of poor countries: the impact on rural productivity and income distribution. World development, Elsevier, v. 8, n. 1, p. 1-24, 1980.

LUCAS JR, R. E. Life earnings and rural-urban migration. Journal of Political Economy, The University of Chicago Press, v. 112, n. S1, p. S29-S59, 2004.

MA, T. et al. Quantitative estimation of urbanization dynamics using time series of $\mathrm{dmsp} / \mathrm{ols}$ nighttime light data: A comparative case study from china's cities. Remote Sensing of Environment, Elsevier, v. 124, p. 99-107, 2012.

MARTINE, G. R. Adaptação de migrantes ou sobrevivência dos mais fortes?. [S.l.]: Projeto de Planejamiento de Recursos HUmanos, Governo da República ..., 1976.

MATTOS, E. J. de; WAQUIL, P. D. Rural poverty in brazil: do different approaches produce different results? 2006. 
MILLO, G.; PIRAS, G. et al. splm: Spatial panel data models in r. Journal of Statistical Software, v. 47, n. 1, p. 1-38, 2012.

MME. Pesquisa quantitativa domiciliar de avaliação da satisfação e de impacto do programa luz para todos, 2009. Ministério de Minas e Energia do Governo Federal, v. 1, p. 17, 2009.

NATIONS, U. World population prospects: The 2015 revision. United Nations Econ Soc Aff, v. 33, n. 2, p. 1-66, 2015.

PAIVA, L. H.; FALCÃO, T.; BARTHOLO, L. From bolsa família to brasil sem miséria. Bolsa, 2013.

PAULA, J.; DALBERTO, C. R.; BOHN, L. Determinantes da pobreza rural no brasil: um enfoque espacial. In: $6^{a}$ Conferência Internacional sobre Estatísticas Agropecuárias. Rio de Janeiro. [S.l.: s.n.], 2013.

RANGEL, L. A.; ANDRADE, J.; DIVINO, J. A. Economic growth and income inequality in brazil: Analyzing the comparable minimum areas. Retrieved March, v. 21, p. 2009, 2008.

RAVALLION, M. Poverty comparisons. [S.l.]: Routledge, 2017.

RAVALLION, M.; CHEN, S.; SANGRAULA, P. New evidence on the urbanization of global poverty. Population and Development Review, Wiley Online Library, v. 33, n. 4, p. 667-701, 2007.

R CORE AND OTHERS. R: A language and environment for statistical computing. 2013.

REIS, E.; PIMENTEL, M.; ALVARENGA, A. I.; SANTOS, M. Áreas mínimas comparáveis para os períodos intercensitários de 1872 a 2000. Rio de Janeiro: Ipea/Dimac, p. 40, 2008.

SANTOS, M. A urbanização brasileira. [S.1.]: Edusp, 2005. v. 6.

SILVA, G. da; LOEBMANN, D. d. S.; VICTORIA, D. d. C.; VICENTE, L. Proposta metodológica de mapeamento do uso e cobertura da terra de extensas áreas por meio de multissensores. Embrapa Territorial-Documentos (INFOTECA-E), Campinas, SP: Embrapa Monitoramento por Satélite, 2013., 2013.

SILVA, J. F. G. da. O novo rural brasileiro. [S.l.]: Universidade Estadual de Campinas, Instituto de Economia, 1999.

DA SILVA, J. G. A nova dinâmica da agricultura brasileira. [S.1.]: Universidade Estadual de Campinas, Instituto de Economia, 1996.

SILVA, J. G. d. Velhos e novos mitos do rural brasileiro. Estudos avançados, SciELO Brasil, v. 15, n. 43 , p. 37-50, 2001.

SILVA, J. G. da. O novo rural brasileiro. Nova economia, v. 7, n. 1, 1997.

SOUSA, A.; DAL POZ, M. R.; BOSCHI-PINTO, C. Reducing inequities in neonatal mortality through adequate supply of health workers: evidence from newborn health in brazil. PLoS One, Public Library of Science, v. 8, n. 9, p. e74772, 2013.

SOUZA, C.; AZEVEDO, T. Mapbiomas general handbook. MapBiomas: São Paulo, Brazil, p. $1-23,2017$. 
SOUZA, H. G. de; TABOSA, F. J. S.; ARAUJO, J. A.; ALMEIDA, A. N. de. Analise espacial dos efeitos do crescimento econ ${ }^{\wedge}$ omico e da desigualdade de renda sobre a pobreza nos meios urbano e rural do brasil. 2018.

SQUIRE, L. Fighting poverty. The American Economic Review, JSTOR, v. 83, n. 2, p. 377-382, 1993.

TOBLER, W. R. A computer movie simulating urban growth in the detroit region. Economic geography, Taylor \& Francis, v. 46, n. sup1, p. 234-240, 1970.

TORRES, M. d. O. et al. Spatial patterns of rural poverty: an exploratory analysis in the são francisco river basin, brazil. Nova Economia, SciELO Brasil, v. 21, n. 1, p. 45-66, 2011.

VANDERCASTEELEN, J.; BEYENE, S. T.; MINTEN, B.; SWINNEN, J. Big cities, small towns, and poor farmers: Evidence from ethiopia. World Development, Elsevier, v. 106, p. 393-406, 2018.

VEGA, S. H.; ELHORST, J. P. On spatial econometric models, spillover effects, and w. In: 53rd ERSA Congress, Palermo, Italy. [S.l.: s.n.], 2013.

WEINHOLD, D.; KILLICK, E.; REIS, E. J. Soybeans, poverty and inequality in the brazilian amazon. World Development, Elsevier, v. 52, p. 132-143, 2013.

WORLD BANK. Poverty and shared prosperity 2016: taking on inequality. [S.l.]: World Bank Publications, 2016.

WWF. Unidades de conservção. Fundo Mundial para a Natureza, v. 1, p. 1, 2019.

ZHOU, Y. et al. A cluster-based method to map urban area from dmsp/ols nightlights. Remote Sensing of Environment, Elsevier, v. 147, p. 173-185, 2014. 

APPENDICES 



\section{APÊNDICE A - ÁREAS MÍNIMAS COMPARÁVEIS UTILIZADAS NO ESTUDO}

As Áreas Mínimas Comparáveis do Brasil nas pesquisas de economia começam a ganhar destaque com o avanço dos modelos econométricos com dados em painel. A partir dos dados de cartografia do IBGE, pesquisadores se empenharam na compatibilização dos dados desde o primeiro Censo Demográfico de 1872. Com bases nessas informações, pesquisas relacionadas as áreas de macroeconomia e desenvolvimento (RANGEL; ANDRADE; DIVINO, 2008), microeconomia aplicada (EHRL, 2017), inclusive com enfoque na saúde (BARUFI; HADDAD; PAEZ, 2012; SOUSA; POZ; BOSCHI-PINTO, 2013) se tornaram possíveis.

As unidades de análise utilizadas tiveram por base as fronteiras das AMCs entre $2000 \mathrm{e}$ 2010 no Brasil. Como mostra Reis et al. (2008), dada a evolução da divisão territorial do Brasil desde o primeiro Censo Demográfico de 1872, a agregação das informações dos microdados do Censo em AMCs deve ser estabelecida a partir da escolha dos períodos de análise. No caso do presente estudo, houve uma modificação marginal dos municípios entre os períodos com a criação de 58 municípios.

A primeira ressalva é o fato da área total do país não ter se alterado no período, portanto, a criação desse municípios se deu a partir do desmembramento de outros municípios já existentes. Deste modo, a compatibilização teve por base a divisão territorial municipal do Brasil em 2000, agregando-se, deste modo, os municípios criados nos seus antecessores.

Estabelecido os polígonos de AMCs das unidades de análise, o passo subsequente foi construir a base a partir de dois critérios importantes: i) ter ao menos um vizinho de contiguidade; ii) possuir uma população rural não nula. O primeiro critério é uma condição técnica para os modelos de Erros Espaciais em painel, isso exclui duas AMCs da base de dados, os municípios de Ilhabela/SP e Fernando de Noronha/PE.

O segundo critério, por sua vez, se baseia em uma estratégia empírica de análise, como as variáveis de interesse estão relacionadas aos indicadores de pobreza rural, sendo o total de pessoas em situação de pobreza rural extrema, pobreza rural, e vulneráveis à pobreza rural, os casos em que o município não possui população rural nos dados do Censo resultarão, por construção, em indicadores nulos de pobreza rural. Sob essa perspectiva, poderia-se atribuir o valor zero de pobreza rural para as AMCs que estão nesse caso, mas optou-se por não utilizar esses dados nos modelos. O resultado disso é uma base de AMCs de 5.450 unidades de observação em cada período do tempo que pode ser observada na figura A.1 a seguir. 


\section{Áreas Mínimas Comparáveis (AMCs)}

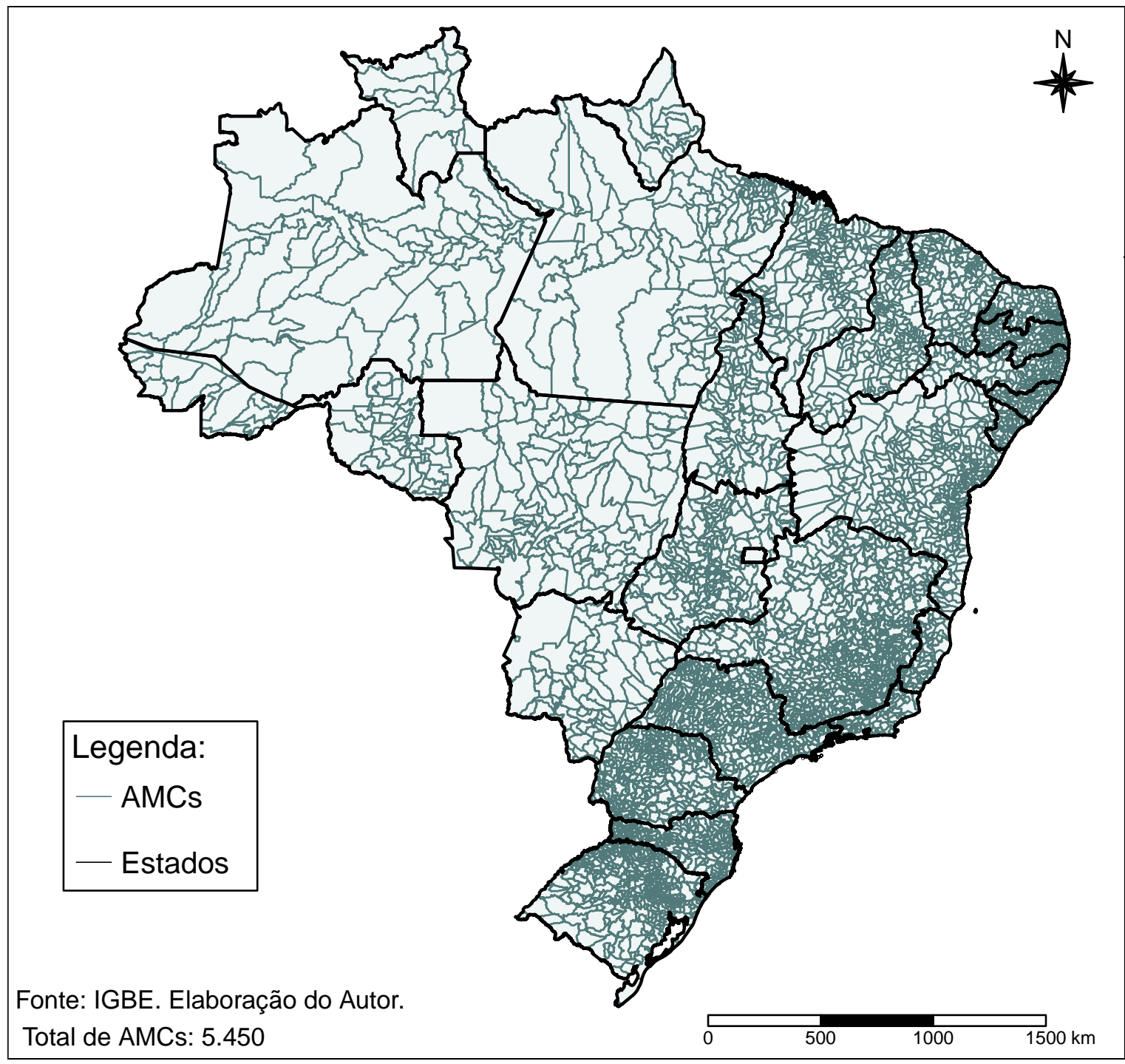

Figura A.1 - Áreas Mínimas Comparáveis (AMCs) no Brasil 


\section{APÊNDICE B - LINHAS DE TRANSMISSÃO NO BRASIL}

Linhas de Transmissão no Brasil

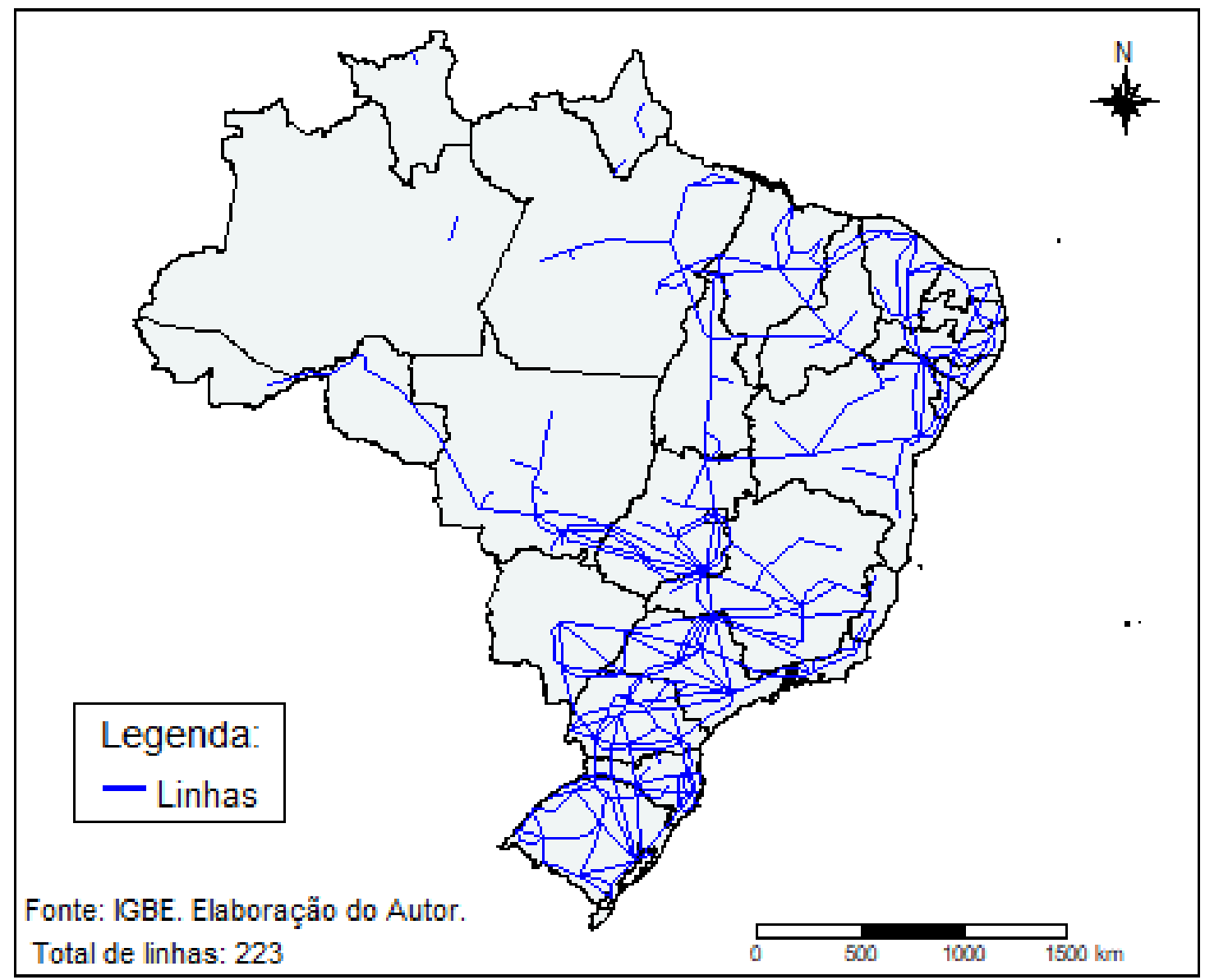

Figura B.1 - Linhas de Transmissão no Brasil 



\section{APÊNDICE C - MAPAS COM AS DEMAIS LINHAS DE POBREZA RURAL}

Figura C.1 - Distribuição espacial da Pobreza e de Vulneráveis à Pobreza Rural no Brasil

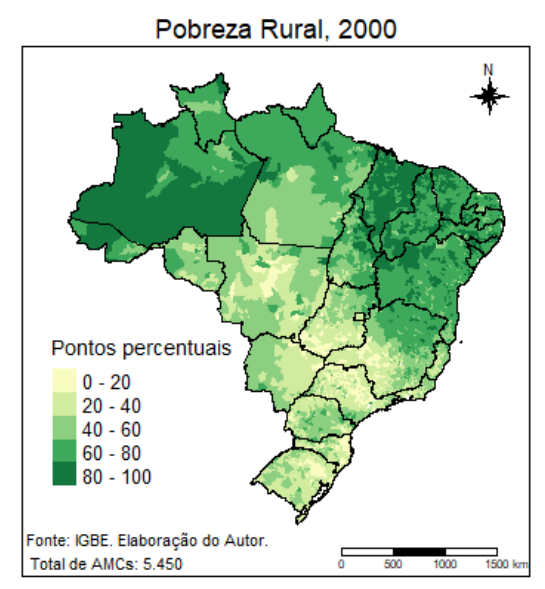

(a) Pobreza 2000

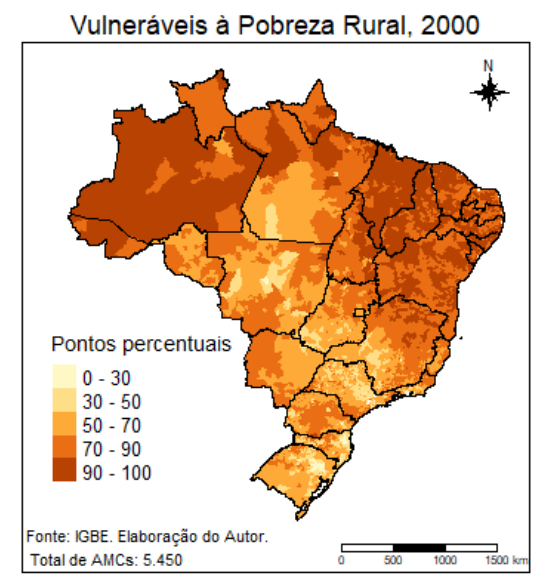

(c) Vulneráveis à Pobreza 2000

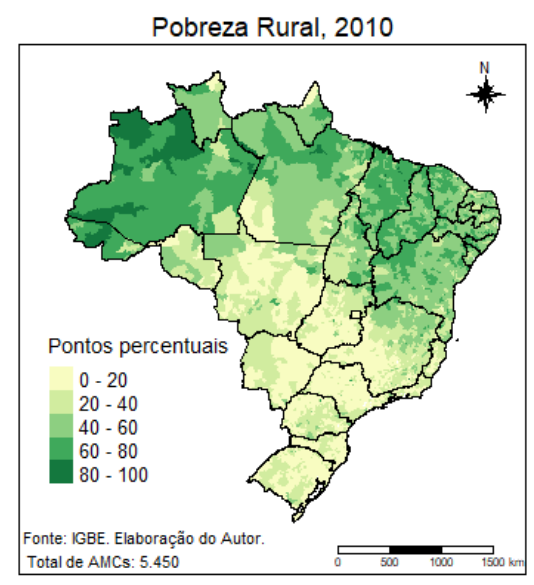

(b) Pobreza 2010

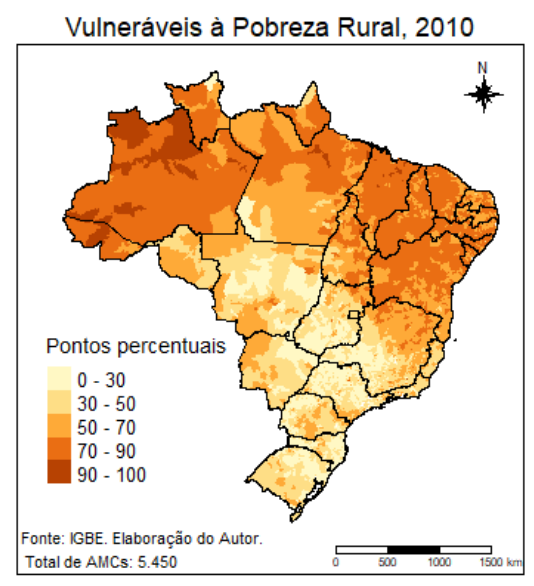

(d) Vulneráveis à Pobreza 2010 



\section{APÊNDICE D - INVESTIGAÇÃO DOS INSTRUMENTOS UTILIZADOS}

\begin{tabular}{lc}
\hline \hline & Variável Dependente: \\
\cline { 2 - 2 } & Total de habitantes em situação de pobreza extrema (rural) \\
\hline Oclividade do terreno & -0.02 \\
& $(0.03)$ \\
Área com Luminosidade entre 21 e 53 & $1.97^{* * *}$ \\
& $(0.30)$ \\
Área com Luminosidade $>53$ DN & 0.19 \\
& $(0.30)$ \\
Altimetria & $-0.0002^{* * *}$ \\
& $(0.0001)$ \\
Covariadas do segundo estágio & Sim \\
\hline Observações & \\
$\mathrm{R}^{2}$ & 5,450 \\
$\mathrm{R}^{2}$ Ajustado & 0.46 \\
\hline \hline
\end{tabular}

Nota: ${ }^{*} \mathrm{p}<0.1 ;{ }^{* *} \mathrm{p}<0.05 ;{ }^{* * *} \mathrm{p}<0.01$. A situação de Pobreza Extrema é caracterizada por indivíduos com renda domiciliar per capita igual ou inferior a $\mathrm{R} \$ 70,00$ mensais, em reais de agosto de 2010 . Os dados de rendimento dos indivíduos em 2000 foram corrigidos para o mês de referência de 2010 a partir do IPCA acumulado entre os períodos. Os dados estão em estrutura de Cross Section para o ano 2000 a nível de Áreas Mínimas Comparáveis. Foram incluídas todas as covariadas reportadas no segundo estágio, presentes na tabela 3.2 .

Tabela D.1 - Modelo OLS para a Aclividade média do terreno em 2000 



\section{APÊNDICE E - RESULTADOS DO PRIMEIRO ESTÁGIO DOS MODELOS COM VARIÁVEIS INSTRUMENTAIS}

\begin{tabular}{|c|c|}
\hline & Variável Dependente: \\
\hline & $\begin{array}{c}\text { Área com Luminosidade entre } 21 \text { e } 53 \\
\text { EF }\end{array}$ \\
\hline Dummy para o ano 2010 & $\begin{array}{c}0.01^{* * *} \\
(0.004)\end{array}$ \\
\hline Dummy Elegíveis ao LPT & $\begin{array}{c}0.01^{*} \\
(0.002)\end{array}$ \\
\hline Aclividade do terreno & $\begin{array}{c}0.004^{* * *} \\
(0.001)\end{array}$ \\
\hline Prop. Domicilios com Acesso a Sanitário & $\begin{array}{c}-0.04^{* * *} \\
(0.01)\end{array}$ \\
\hline Prop. Domicilios Instalação Sanitária & $\begin{array}{c}-0.01^{* * *} \\
(0.002)\end{array}$ \\
\hline Dummy para o ano 2010 x Dummy Elegíveis ao LPT & $\begin{array}{c}-0.04^{* * *} \\
(0.005)\end{array}$ \\
\hline Dummy para o ano $2010 \mathrm{x}$ Aclividade do terreno & $\begin{array}{l}-0.003 \\
(0.002)\end{array}$ \\
\hline Dummy para o ano 2010 x Dummy Elegíveis ao LPT x Aclividade do terreno & $\begin{array}{l}0.01^{*} \\
(0.003)\end{array}$ \\
\hline Covariadas do segundo estágio & Sim \\
\hline Observações & 10,900 \\
\hline $\mathrm{R}^{2}$ & 0.72 \\
\hline $\mathrm{R}^{2}$ Ajustado & 0.72 \\
\hline
\end{tabular}

Nota: ${ }^{*} \mathrm{p}<0.1 ;{ }^{* *} \mathrm{p}<0.05 ;{ }^{* * *} \mathrm{p}<0.01$. Os dados estão em estrutura de Painel balanceado de dois períodos (2000 e 2010) com 5.450 polígonos em cada ano correspondentes as AMCs do Brasil. Essa constitui a primeira etapa do processo de estimação em dois estágios tanto nos modelos clássicos de Variáveis Instrumentais, como nos modelos de Erros Espaciais, também Variáveis Instrumentais. Para os resultados apresentados com as diferentes luminosidades secundárias, entre 10 e 53, 15 e 53, e 25 e 53, utilizou-se o mesmo procedimento, substituindo apenas a variável dependente. Foram incluídas todas as covariadas reportadas no segundo estágio, presentes na tabela 3.2.

Tabela E.1 - Resultado do primeiro estágio das regressões com Variáveis Instrumentais 



\section{APÊNDICE F - MATRIZES DE VIZINHANÇA EM ECONOMETRIA ESPACIAL}

Na presença de autocorrelação espacial ou correlação espacial dos resíduos, os elementos fora da diagonal principal da matriz de variância-covariância podem não serem nulos, o que torna os estimadores de Mínimos Quadrados Ordinários ineficientes, e inclusive viesados em alguns casos. Nesse caso, se os parâmetros da correlação espacial forem conhecidos é possível obter estimadores mais eficientes via Mínimos Quadrados Generalizados.

Quando os dados estão sob estruturas espaciais, tais como países, municípios, pontos, e/ou qualquer forma poligonal geográfica, é possível especificar uma forma funcional da correlação espacial a partir das matrizes de vizinhança. Suponha um conjunto de dados transversais com $N$ observações, define-se uma matriz de vizinhança $w_{1}$, de dimensão $N \times N$, como:

$$
w_{1}=\left[\begin{array}{ccc}
w_{11} & \ldots & w_{1 n} \\
\vdots & \ddots & \vdots \\
w_{n 1} & \ldots & w_{n n}
\end{array}\right]
$$

Sendo que cada termo genérico é definido como:

$$
w_{m j}= \begin{cases}1 & j \in N(m) \\ 0 & \text { caso contrário }\end{cases}
$$

$N(m)$ é definido como o conjunto de vizinhos de um local $j$. É importante situar que, por definição, nenhum polígono é vizinho de si mesmo, a saber, a diagonal principal de $w_{1}$ conterá apenas zeros. A diferenças nas matrizes de vizinhança está no critério utilizado para classificar os polígonos como vizinho, para um dado $w_{m j}$, por exemplo, existem dois tipos de critérios de vizinhança por contiguidade, a saber, que dividem fronteiras geográficas entre si: os vizinhos do tipo Torre e do tipo Rainha. Arbia (2014) apresenta uma ilustração de ambos os casos da seguinte maneira: 


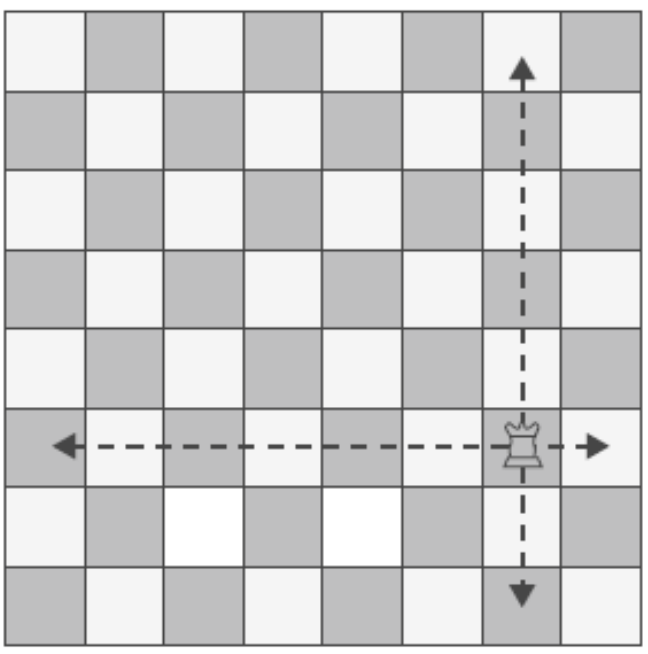

(a)

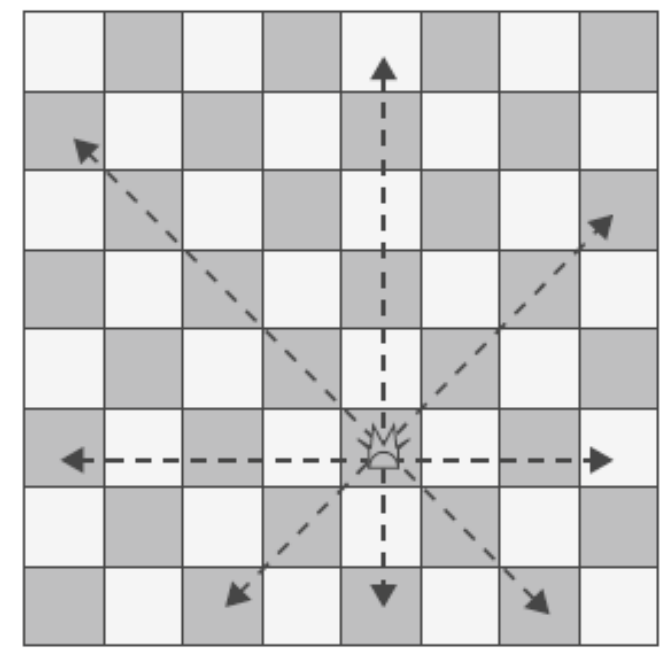

(b)

Figure 2.2 Contiguity criteria in a regular square lattice grid. (a) Rook's move and (b) Queen's move

Figura F.1 - Tipos de matrizes de vizinhança por contiguidade. Fonte: Arbia (2014)

Para o presente estudo, assume-se como critério de vizinhança do tipo Rainha, de modo que, todos os polígonos, no caso as AMCs, que dividem fronteira geográfica a $A M C_{m j}$ são consideradas vizinhas. Além desses casos existem outros tipos de vizinhança, tais como a de contiguidade do tipo Bispo, na qual são considerados vizinhos os polígonos contíguos que se encontram na diagonal de $m j$.

Construída a matriz $w_{1}$, uma das etapas necessárias à estimação dos modelos é a normalização da matriz de vizinhança a partir das linhas de suas linhas, definida como:

$$
w_{m j}^{*}=\frac{w_{m j}}{\sum_{j=1}^{N} w_{m j}} \quad \operatorname{sendo} w_{m j}^{*} \in w_{1}^{*}
$$

Deste modo, todas as linhas de $w_{1}^{*}$ devem somar um, por exemplo, se uma AMC tem apenas um vizinho, o mesmo terá um $w_{m j}^{*}=1$, mas se a AMC tiver dois vizinhos, então $w_{m j}=0,5$ para cada um dos vizinhos e assim sucessivamente. Estabelecido os critérios para as matrizes de vizinhança contemporâneas dos dados transversais, a extrapolação para os modelos em painel pode ser escrito da seguinte maneira:

$$
W^{*}=\left[\begin{array}{ccc}
w_{1}^{*} & \ldots & 0 \\
\vdots & \ddots & \vdots \\
0 & \ldots & w^{*}
\end{array}\right] \text { sendo } \quad w_{1}=\left[\begin{array}{ccc}
w_{11}^{*} & \ldots & w_{1 n}^{*} \\
\vdots & \ddots & \vdots \\
w_{n 1}^{*} & \ldots & w_{n n}^{*}
\end{array}\right]
$$


Portanto, a matriz de vizinhança para os dados em painel será uma matriz bloco diagonal com as matrizes $w_{1}^{*}$ que estabelecem as relações contemporâneas de vizinhança. Note que $W^{*}$ possui dimensão $N T \times N T$, sendo $N$ o total de AMCs da amostra e $T$ o número de períodos. Nos modelos de erros espaciais apresentados na seção 2.2 de metodologia, a matriz de vizinhança entra no termo de erro.

Como $w_{1}^{*}$ está normalizado na linha e $W^{*}$ é uma sequência bloco diagonal de $w_{1}^{*}$, então, $W^{*}$ também está normalizado na linha. Isso implica que não há correlação espacial entre as AMCs em períodos diferentes. É importante situar que há uma correlação temporal entre as observações, o que caracterizaria uma dependência de estado, como definido por Heckman (1981) e que será controlada nos modelos de efeitos fixos.

Uma hipótese relevante é que a matriz $w_{1}^{*}$ que estabelece o padrão de vizinhança entre as unidades de análise contemporâneas, será tida como constante ao longo dos períodos neste modelo. Isso implica que as interações entre as regiões vizinhas são as mesmas ao longo do tempo, o que parece fazer sentido, pois as grandes cidades permaneceram como metrópoles no período de análise (2000-2010). Para esses casos de modelos, é muito importante que o painel seja balanceado para que a matriz de pesos espaciais não mude a sua dimensão. 



\section{AnEXos}





\section{ANEXO A - CLASSIFICAÇÃO DAS CIDADES A PARTIR DA LUMINOSIDADE}

A figura foi proposta por Álvarez-Berríos, Parés-Ramos e Aide (2013) com base nos dados de luminosidade noturna nos países da América do Sul

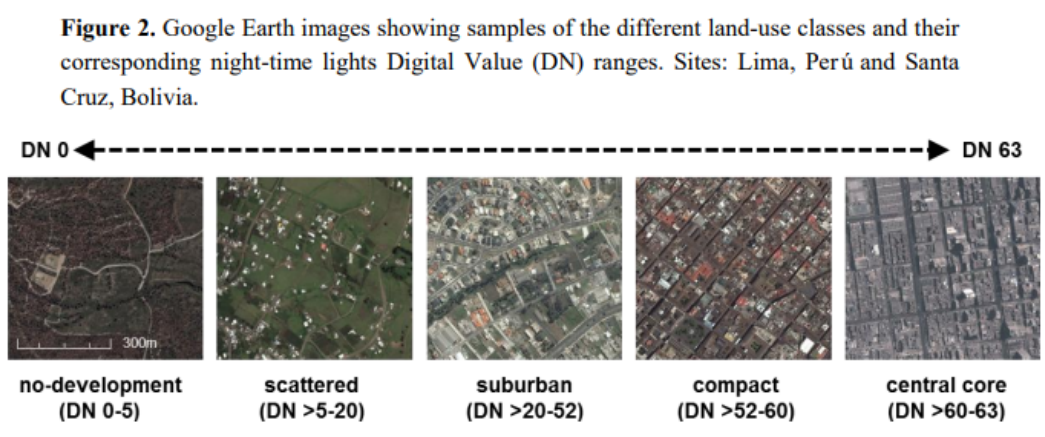

Figura A.1 - Classificação dos níveis de Urbanização a partir de imagens de satélite. Fonte: Álvarez-Berríos, Parés-Ramos e Aide (2013) 